\title{
Demand Shifting with Thermal Mass in Large Commercial Buildings in a California Hot Climate Zone
}

Peng Xu \& Rongxin Yin, Lawrence Berkeley National Laboratory Carrie Brown \& DongEun Kim, University of California, Berkeley

June 2009 


\section{Disclaimer}

This document was prepared as an account of work sponsored by the United States Government. While this document is believed to contain correct information, neither the United States Government nor any agency thereof, nor The Regents of the University of California, nor any of their employees, makes any warranty, express or implied, or assumes any legal responsibility for the accuracy, completeness, or usefulness of any information, apparatus, product, or process disclosed, or represents that its use would not infringe privately owned rights. Reference herein to any specific commercial product, process, or service by its trade name, trademark, manufacturer, or otherwise, does not necessarily constitute or imply its endorsement, recommendation, or favoring by the United States Government or any agency thereof, or The Regents of the University of California. The views and opinions of authors expressed herein do not necessarily state or reflect those of the United States Government or any agency thereof or The Regents of the University of California. 


\section{Acknowledgments}

The work described in this report was coordinated by the Demand Response Research Center and funded by the California Energy Commission (Energy Commission), Public Interest Energy Research (PIER) Program, under Work for Others Contract No. 500-03-026 and by the U.S. Department of Energy under Contract No. DE-AC02-05CH11231.

The authors wish to thank the Cigna Health Insurance and Joe Perine from Northrop Grumman Space \& Mission Systems Corporation for providing access to the test buildings and the Pacific Energy Center for the loan of instrumentation. The authors also thank the following individuals and organizations for their support of this research project: Martha Brook (Energy Commission) and Mary Ann Piette (Lawrence Berkeley National Laboratory/Energy Commission PIER Demand Response Research Center).

The authors would also like to thank the members of this study's Technical Advisory Committee: Robert Young (California Environmental Protection Agency Headquarters), Barbara Blair (Washington Mutual), Gene Ameduri (Energy Connect), Alan Gartner (Energy Connect), David Reed (Southern California Edison), Lawrence Oliva (Consultant), Lance DeLaura (Sempra), Bruce Vincent (SMUD), Mark Levi (GSA), and Mark Martinez (Southern California Edison) for their input, suggestions and comments. The authors appreciate the helpful comments provided by the peer reviewers of this report: Mary Ann Piette (Lawrence Berkeley National Laboratory / Energy Commission PIER Demand Response Research Center), Chris Scruton (Energy Commission), Steve Galanter (Southern California Edison), Phil Haves (Lawrence Berkeley National Laboratory), and Nance Matson (Lawrence Berkeley National Laboratory).

Please cite this report as follows:

Xu, P., R. Yin, C. Brown, and D. E. Kim. 2009. Demand Shifting with Thermal Mass in Large Commercial Buildings in a California Hot Climate Zone. California Energy Commission, PIER Energy-Related Environmental Research Program. 


\section{Table of Contents}

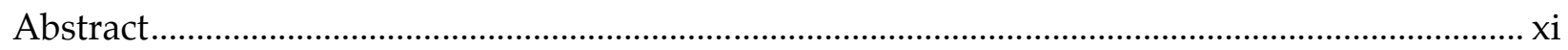

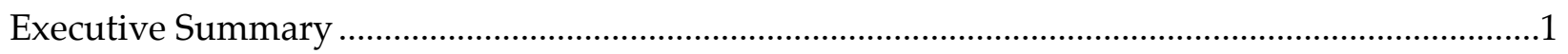

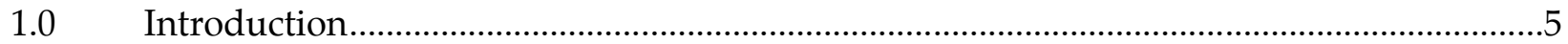

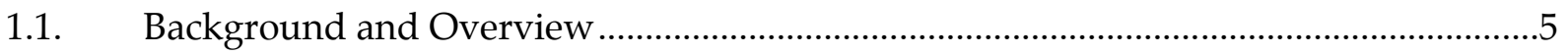

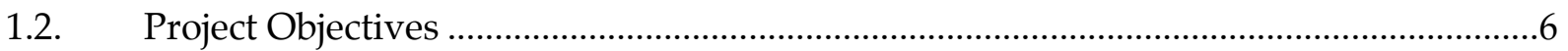

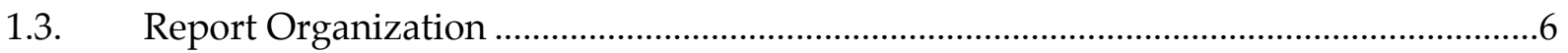

2.0 Pre-Cooling Field Studies: Project Approach and Results ..............................................9

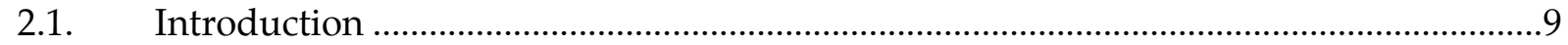

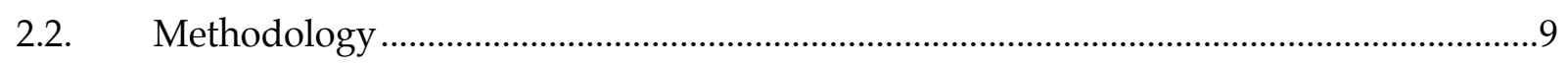

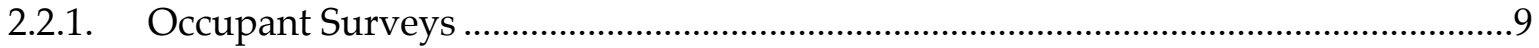

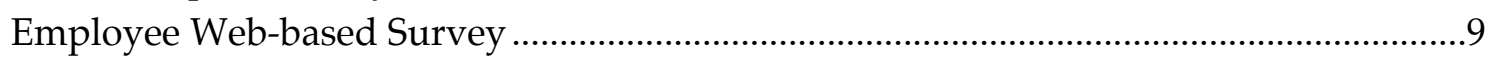

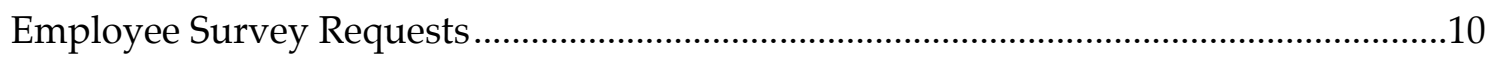

2.2.2. Thermal Conditions Monitoring..........................................................................11

2.2.3. Weather and Test Conditions ..............................................................................11

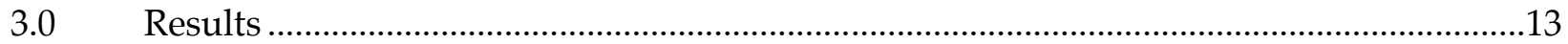

3.1. Test Site I - Office Building in Visalia, CHCCC …....................................................13

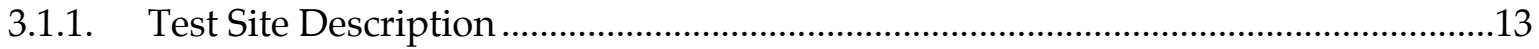

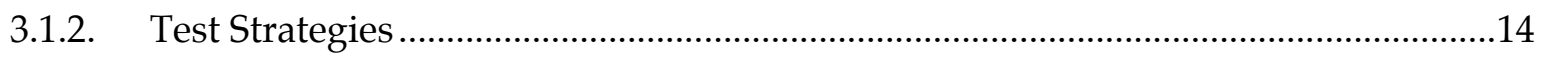

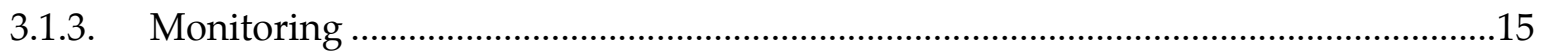

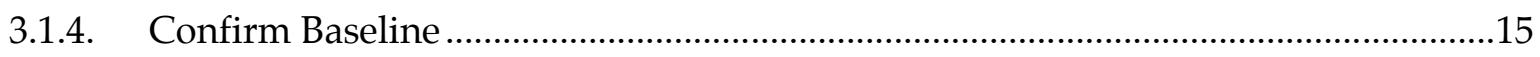

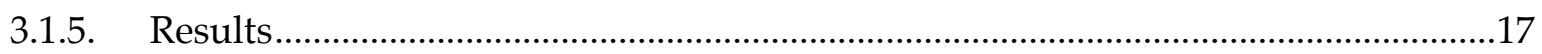

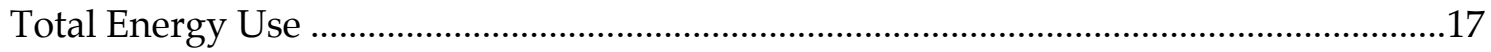

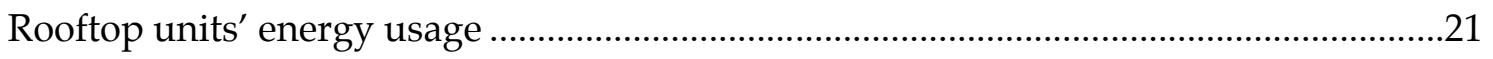

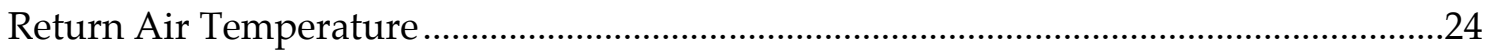

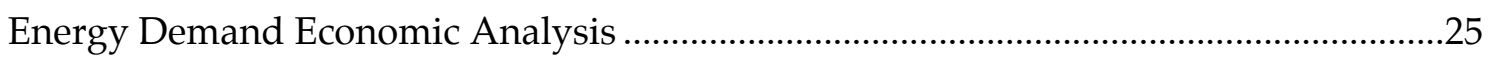

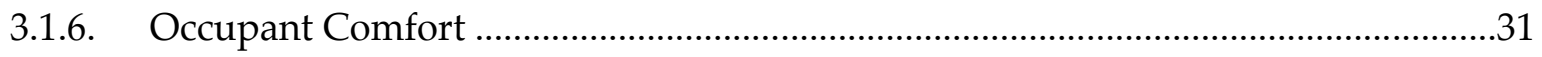

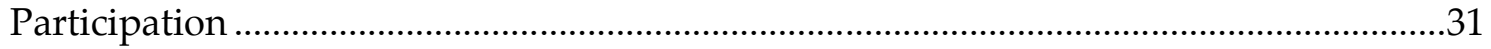

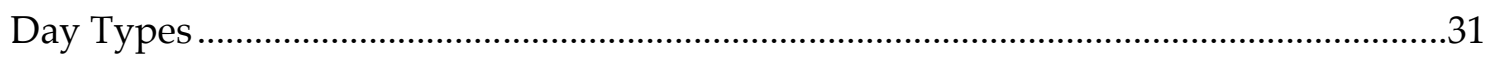

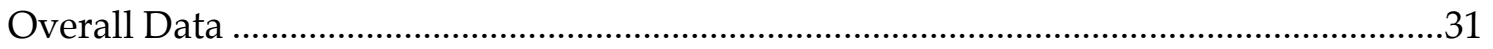

No Pre-cooling / Afternoon Setup …..................................................................................

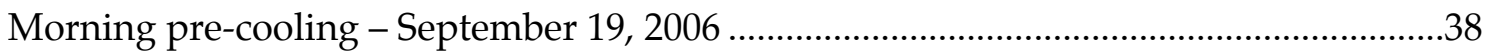

Morning pre-cooling - September 27, 2009 ......................................................................40

3.2. Test Site II - Typical Office Building in San Bernardino, TCCSB..................................41

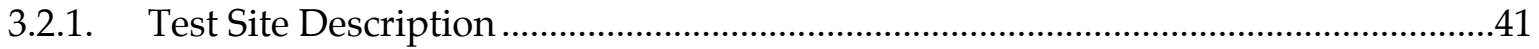

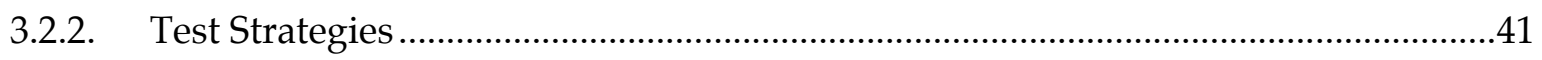

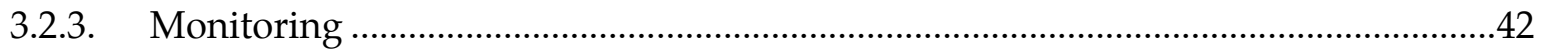

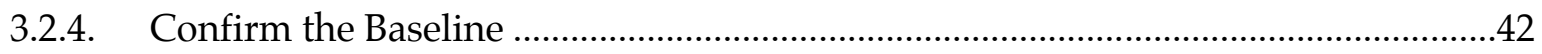




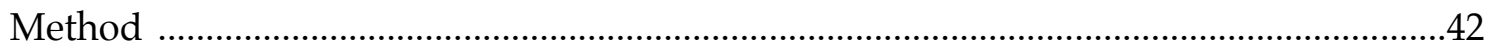

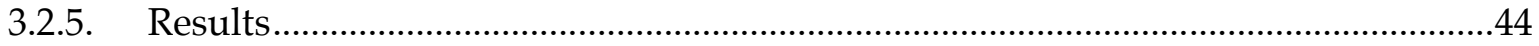

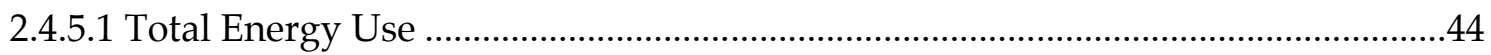

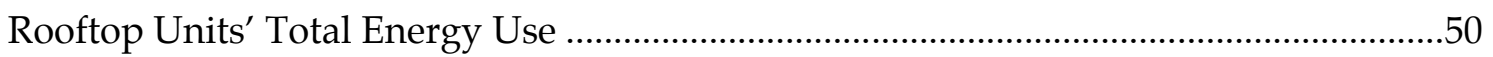

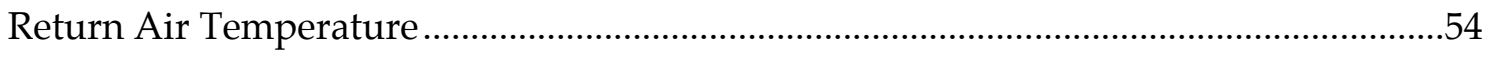

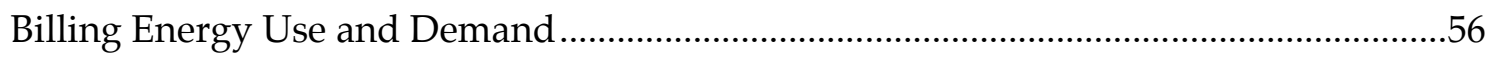

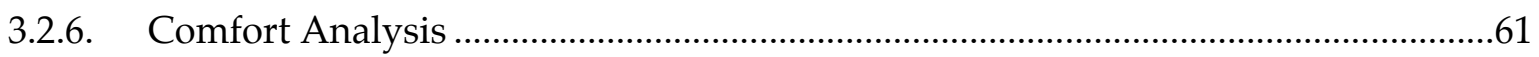

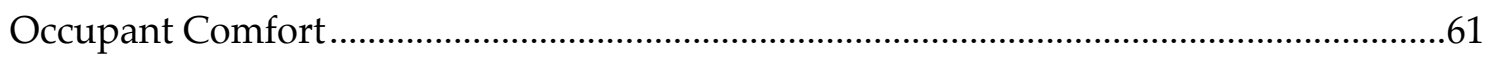

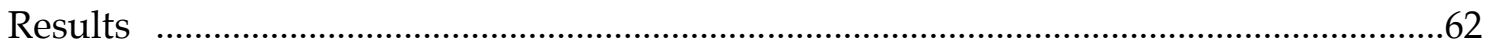

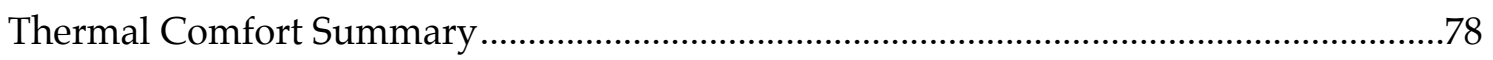

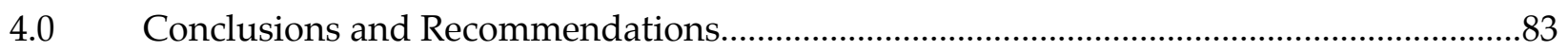

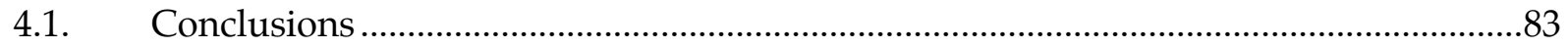

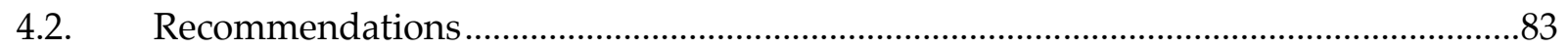

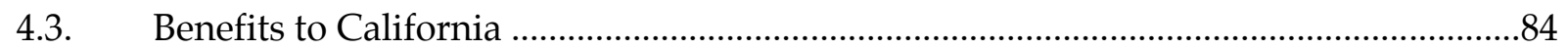

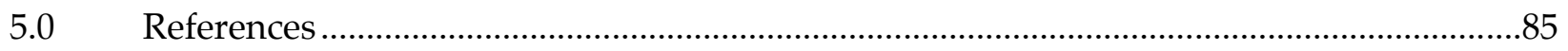

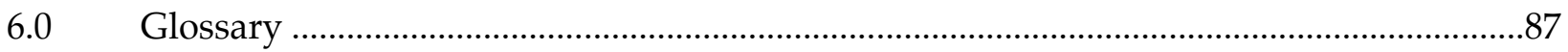

Appendix A: Request for Participation Summer 2006 Demand Shifting with Thermal Mass

Appendix B: Demand Shedding with Building Thermal Mass for Large Commercial Facilities Test Plan

Appendix C: Web-based survey instrument for employees

Appendix D: Employee web-based survey invitations 


\section{List of Figures}

Figure 1. Web-based Polling station for surveying visitors ............................................................10

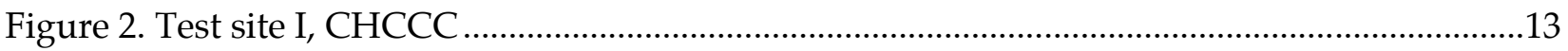

Figure 3. Pre-cooling strategies tested .............................................................................................

Figure 4. Night and morning pre-cooling with linear temperature reset in peak hours, CHCCC

Figure 5. Effects of night pre-cooling on second day cooling load - warm days, CHCCC exponential temperature reset.

Figure 6. Effects of night pre-cooling on upcoming day cooling load - moderately warm days, CHCCC.

Figure 7. Rooftoop units total demand $(\mathrm{kW})$ - Morning pre-cooling with linear temperature reset, $\mathrm{CHCCC}$.

Figure 8. Rooftop units - demand $(\mathrm{kW})$ - Morning pre-cooling with exponential temperature reset, $\mathrm{CHCCC}$.

Figure 9. Rooftops units - Total Demand $(\mathrm{kW})$ - Night and morning pre-cooling with exponential temperature reset, $\mathrm{CHCCC}$.

Figure 10. Rooftops units - Total Demand (kW) - Morning pre-cooling versus no precooling, CHCCC

Figure 11. Return air temperature on one typical pre-cooling test days, CHCCC Expanded temperature reset

Figure 12. Morning pre-cooling with linear temperature reset, $\mathrm{CHCCC}$ - Energy usage $(\mathrm{kWh})$

Figure 13. Morning pre-cooling with linear temperature reset, $\mathrm{CHCCC}$ - Energy cost (\$).

Figure 14. Morning pre-cooling with exponential temperature reset, CHCCC - Energy usage $(\mathrm{kWh})$

Figure 15. Morning pre-cooling with exponential temperature reset, CHCCC - Energy cost $(\$)$.

Figure 16. Night and morning pre-cooling with exponential temperature reset, CHCCC Energy usages $(\mathrm{kWh})$

Figure 17. Night and morning pre-cooling with exponential temperture reset, CHCCC Energy cost (\$)

Figure 18. Outside temperature profiles through the surveyed period .32 
Figure 19. Temperature votes per day...... .32

Figure 20. Correlation between temperature sensation and perceived productivity 33

Figure 21. Thermal sensation vs. indoor temperature .34

Figure 22. Daily outdoor temperature and sensation votes for 9/22/2006 baseline and 9/20/2006 test day. .35

Figure 23. Breakdown of sensation votes for $9 / 22 / 2006$ baseline and 9/20/2006 test .36

Figure 24. Breakdown of productivity votes for 9/22/2006 baseline and 9/20/2006 test. .36

Figure 25. Daily outdoor temperature and sensation votes for 9/19/2006 baseline and 9/26/2006 test day. .37

Figure 26. Breakdown of sensation votes for 9/19/2006 baseline and 9/60/2006 test .37

Figure 27. Breakdown of productivity votes for 9/19/2006 baseline and 9/26/2006 test. 38

Figure 28. Daily outdoor temperature and sensation votes for 9/19/2006 baseline and 9/14/2006 test day. 38

Figure 29. Breakdown of sensation votes for 9/19/2006 baseline and 9/14/2006 test 39

Figure 30. Breakdown of productivity votes for 9/19/2006 baseline and 9/14/2006 test.

Figure 31. Daily outdoor temperature and sensation votes for 9/27/2006 baseline and $9 / 22 / 2006$ test day.... 40

Figure 32. Breakdown of sensation votes for $9 / 27 / 2006$ baseline and 9/22/ 2006 test .40

Figure 33. Breakdown of productivity votes for 9/27/2006 baseline and 9/22/2006 test..... .41

Figure 34. No pre-cooling with zonal reset in peak hours, TCCSB. .45

Figure 35. Pre-cooling with linear temperature reset in peak hours, TCCSB. . .46

Figure 36. Pre-cooling with exponential temperature reset in peak hours, TCCSB . .47

Table 17. Demand shed - Pre-cooling with exponential temperature reset (hot days) . .47

Figure 37. Outside air temperature - Hot Days .48

Figure 38. Pre-cooling with exponential temperature reset in peak hours - Ext. Hot Days . .48

Figure 39. Outside air temperature - Cool weather conditions, TCCSB... .49

Figure 40. Pre-cooling with exponential temperature reset in peak hours - Cool Days, TCCSB .50

Figure 41. No pre-cooling with zonal reset in peak hours, TCCSB. . .51

Figure 42. Pre-cooling with linear temperature reset in peak hours, TCCSB. 52

Figure 43. Pre-cooling with exponential temperature reset in peak hours, TCCSB . .52 
Figure 44. Pre-cooling with exponential temperature reset in peak hours, TCCSB ........................53

Figure 45. Pre-cooling with exponential temperature reset in peak hours, TCCSB ........................54

Figure 46. Return air temperature under three strategies on test days - Hot Days, TCCSB...........55

Figure 47. Return air temperature on test days - Extreme Hot Day, TCCSB …...............................55

Figure 48. Return air temperature on test days - Cool Day, TCCSB ...............................................56

Figure 49. Energy usages $(\mathrm{kWh})$ on test days - Hot Days, TCCSB .................................................57

Figure 50. Energy cost on test days - Hot Days, TCCSB ...................................................................57

Figure 51. Energy use (kWh) on test day - Extreme Hot Day, TCCSB.............................................58

Figure 52. Energy cost (\$) on test days - Extreme Hot Day, TCCSB …..............................................59

Figure 53. Energy use (kWh) on test days - Cool Day, TCCSB .....................................................60

Figure 54. Energy cost $(\$)$ on test days - Cool Day, TCCSB ..............................................................60

Figure 56. Temperature votes per day (orange = too warm; yellow = just right; blue = too

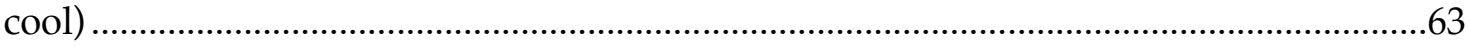

Figure 57. Correlation between thermal sensation and perceived productivity.............................64

Figure 58. Thermal sensations vs. indoor temperature ….................................................................65

Figure 59. Daily outdoor temperature and sensation votes in the five zones for the $8 / 28 / 2007$ baseline and the $8 / 14 / 2007$ test day

Figure 60. Average indoor air temperatures in the five zones for the $8 / 28 / 2007$ baseline and the $8 / 14 / 2007$ test day

Figure 61. Breakdown of sensation votes for the 8/28 / 2007 baseline and the 8/14 / 2007 test

Figure 62. Breakdown of productivity votes for the $8 / 28 / 2007$ baseline and the $8 / 14 / 2007$ test.

Figure 63. Daily outdoor temperature and sensation votes for the $8 / 28 / 2007$ baseline and combined votes from the $8 / 15 / 2007$ and $8 / 16 / 2007$ test days.

Figure 64. Average indoor air temperatures in the five zones for the $8 / 28 / 2007$ baseline day and combined temperatures from the $8 / 15 / 2007$ and $8 / 16 / 2007$ test days

Figure 65. Breakdown of sensation votes for the $8 / 28 / 2007$ baseline day and combined votes from the $8 / 15 / 2007$ and $8 / 16 / 2007$ test days

Figure 66. Breakdown of productivity votes for the $8 / 28 / 2007$ baseline and combined votes from the $8 / 15 / 2007$ and $8 / 16 / 2007$ test days

Figure 67. Daily outdoor temperature and sensation votes for the $8 / 28 / 2007$ baseline and the $8 / 29 / 2007$ test day 
Figure 68. Average indoor air temperatures in the five zones for the $8 / 28 / 2007$ baseline and the $8 / 29 / 2007$ test day

Figure 69 . Breakdown of sensation votes for the $8 / 28 / 2007$ baseline and the $8 / 29 / 2007$ test day

Figure 70. Breakdown of productivity votes for the $8 / 28 / 2007$ baseline and the $8 / 29 / 2007$ test..

Figure 71. Daily outdoor temperature and sensation votes for the $8 / 28 / 2007$ baseline and the $9 / 18 / 2007$ test days.......

Figure 72. Average indoor air temperatures in the five zones for the $8 / 28 / 2007$ baseline and the $9 / 18 / 2007$ test days.....

Figure 73. Breakdown of sensation votes for the $8 / 28 / 2007$ baseline and the $9 / 18$ /2007 tests.....

Figure 74. Breakdown of productivity votes for the $8 / 28 / 2007$ baseline and the $9 / 18$ / 2007 test

Figure 75. Plot of survey responses to thermal comfort using data from all days. $7=$ "Too Cool" and 1 = “Too Warm." $\mathrm{N}=287$.

Figure 76. Cumulative Distribution Function (CDF) plot of binned "too hot" and "too cold" votes.

Figure 77. Plot of binned "too warm" and "too cool" votes with logit curves fitted to the binned sensation responses. "Too cool" = votes 6 and 7, $\mathrm{N}=17$ (descending curve), and "Too Warm" = votes 1 and 2, $\mathrm{N}=78$ (ascending curve). The dotted lines provide a visual approximation of the variability of the data 


\section{List of Tables}

Table 1. Proposed test scenarios—zone temperature setpoint schedules....................................... 15

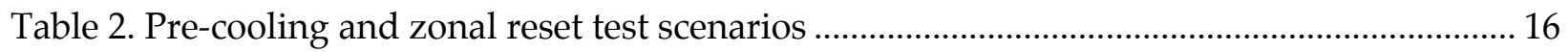

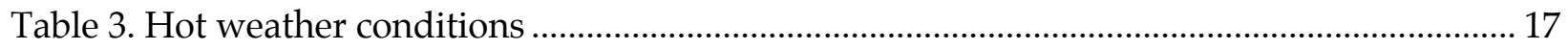

Table 4. Demand shed - Morning pre-cooling with linear temperature reset.............................. 18

Table 5. Demand shed - Morning pre-cooling with exponential temperture reset ....................... 19

Table 6. Demand shed - Night and morning pre-cooling with exponential temperature reset .. 21

Table 7. Time of Use time period-General service rate schedules .................................................. 25

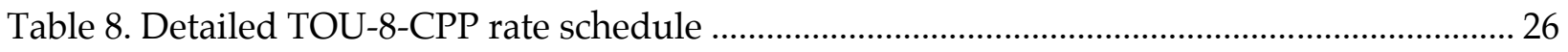

Table 9. Test days and their corresponding baseline days........................................................ 31

Table 10. Demand response temperature setpoint offset $\left({ }^{\circ} \mathrm{F}\right)$......................................................... 42

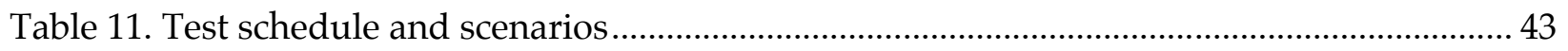

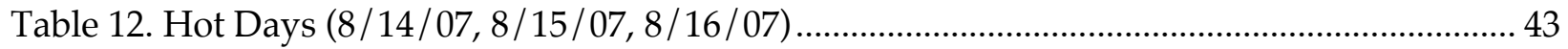

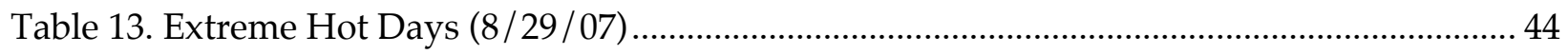

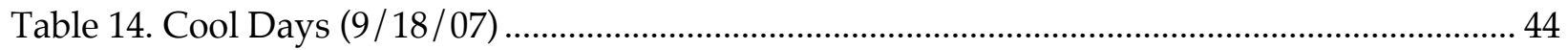

Table 15. Demand shed - No pre-cooling with zonal temperature reset ..................................... 45

Table 16. Demand shed - pre-cooling with linear temperature reset ............................................. 46

Table 18. Demand shed - Pre-cooling with exponential temperature reset (Ext. Hot days) ......... 49

Table 19. Demand shed - Pre-cooling with exponential temperature reset (cool days) ............... 50

Table 20. Number of responses on test days and their corresponding baseline days .................. 61 


\begin{abstract}
The potential for using building thermal mass for load shifting and peak energy demand reduction has been demonstrated in a number of simulation, laboratory, and field studies. Previous Lawrence Berkeley National Laboratory research has demonstrated that the approach is very effective in cool and moderately warm climate conditions (California Climate Zones 2-4). However, this method had not been tested in hotter climate zones.

This project studied the potential of pre-cooling the building early in the morning and increasing temperature setpoints during peak hours to reduce cooling-related demand in two typical office buildings in hotter California climates - one in Visalia (CEC Climate Zone 13) and the other in San Bernardino (CEC Climate Zone 10). The conclusion of the work to date is that pre-cooling in hotter climates has similar potential to that seen previously in cool and moderate climates. All other factors being equal, results to date indicate that pre-cooling increases the depth $(\mathrm{kW})$ and duration $(\mathrm{kWh})$ of the possible demand shed of a given building. The effectiveness of night pre-cooling in typical office building under hot weather conditions is very limited. However, night pre-cooling is helpful for office buildings with an undersized HVAC system. Further work is required to duplicate the tests in other typical buildings and in other hot climate zones and prove that pre-cooling is truly effective.
\end{abstract}

Keywords: Pre-cooling, demand response, thermal mass, hot climates, office buildings 


\section{Executive Summary}

\section{Introduction}

The principle of pre-cooling with setpoint adjustment to shift energy demand is to pre-cool buildings during off-peak hours at night or in the morning, cooling the building thermal mass, and adjusting zone temperature setpoint during on-peak hours, to reduce cooling loads during the peak hours. Cost savings are achieved by reducing on-peak energy and demand charges. A great potential for using building thermal mass for load shifting and peak demand reduction has been demonstrated in a number of simulation, laboratory, and field studies.

This research study was preceded by three other studies conducted by Lawrence Berkeley National Laboratory on the potential for pre-cooling and demand limiting in large commercial buildings. The first of these studies was a 2003 pre-cooling case study at the Santa Rosa Federal Building. The second was a 2004 pre-cooling study along with occupant comfort surveys in two office buildings (Santa Rosa and Rancho Cordova). The third was a 2005 pre-cooling study in one heavy mass and one light mass commercial building in the San Francisco Bay Area.

\section{Purpose}

The purpose of this research project was to study the potential of pre-cooling and demand limiting in typical office buildings in extreme hot climate areas, such as Southern California and California's Central Valley.

\section{Project Objectives}

In previous studies, significant demand reductions have been achieved in field tests of both large and small commercial buildings-all with relatively small impacts on occupant comfort. However, none of these buildings were in extreme hot climates. To test pre-cooling strategies fully, there is a need to demonstrate demand reduction and evaluate occupant comfort under the more extreme conditions during which utility-based demand control requests would typically be issued. Furthermore, there is a need to develop a better fundamental understanding of the impact of short-term zone temperature variations on occupant comfort to determine the extent to which temperature setpoints could be raised during demand-limiting periods.

To address these questions, Lawrence Berkeley National Laboratory and the University of California at Berkeley's Center for the Built Environment performed field tests in two mediumsized office buildings - one in Visalia and another in San Bernardino. For confidentiality purposes, the buildings are referenced as CHCCC and TCCSB. Another key feature of the 2006 study was the intensive temperature monitoring through the two buildings. We installed more than 100 temperature sensors in the occupied space to correlate the comfort reaction with temperature measured in the space. To supplement the field tests of 2005, the team tested different reset strategies in the afternoon in both buildings and assessed the impact of these strategies and methods to avoid rebounds and maximize load reduction.

Different demand response strategies were tested under extreme hot weather conditions. Occupant comfort surveys were conducted on each test day. Based on demand reduction and occupant comfort survey results, the research team found that pre-cooling strategies in hot 
weather $\left(95-102^{\circ} \mathrm{F}\right)$ could reduce the whole building peak load with minimal impact on thermal comfort.

\section{Project Outcomes}

The pre-cooling and demand shifting strategies were equally effective in the hot- and coolclimate buildings tested in the studies to date. The team was able to reduce the peak electricity demand of the whole building by 15 to 30 percent on days when peak outside-air temperatures were over $100^{\circ} \mathrm{F}$. The comfort survey results indicate that occupant comfort was generally maintained during the pre-cooling tests. There were some occupant complaints of feeling cold in the morning, but occupants were generally happy in the afternoon when setpoints were ramped up. As observed in the 2005 tests, it was important to manage the afternoon load shedding by ramping up the zone temperature setpoints exponentially rather than stepping them up or ramping them up linearly. This strategy could be particularly important on hot days or in buildings with smaller thermal time constants, where air conditioning-related electrical power could rebound (sharp increase in electricity load) and exceed the peak demand typically seen under normal operation. If the heating, ventilation and air-conditioning system is oversized, the minimum air supply through variable air volume boxes may use more cooling capacity than necessary and can complicate the demand response tests. This did not happen with the built up system previously tested, but this could be a problem with buildings with rooftop units.

\section{Conclusions}

The team found that pre-cooling has the potential to improve the demand responsiveness of commercial buildings while maintaining acceptable comfort conditions in extreme hot weather conditions. Results to date indicate that pre-cooling increases the depth (kilowatts) and duration (kilowatt-hours) of the shed capacity of a given building, all other factors being equal. Precooling reduced peak loads by 15-30 percent for six hours in these two office buildings, both of which had typical levels of thermal mass. The team did not find that night pre-cooling under hot weather conditions was any better than in cool weather conditions and thus does not play a significant role. Further work is needed to duplicate the tests in other office buildings in hot climate zones to identify the most appropriate pre-cooling strategies for buildings with rooftop units, to estimate the broader benefits to the customer and the utility.

\section{Recommendations}

Although this study has established the potential for pre-cooling and demand shifting strategies, it has identified several issues that should be resolved before pre-cooling can be reliably implemented in large commercial buildings. The following activities are recommended for future work:

Develop guidelines for appropriate control strategies according to building characteristics. Different buildings with different mechanical systems and different levels of control may require different pre-cooling strategies. For example, the zone temperature setpoint strategies studied in the work reported here are only practical if the zone temperatures are controlled by networked digital controllers. A detailed guide to selecting, implementing, and testing demandshifting control strategies by building mechanical system and control type is needed to support their routine use. 
Develop test methods and performance metrics to characterize building internal mass.

Internal mass plays an important role in peak load reduction and demand shifting. Field tests and simulation studies have proved that the internal thermal mass is more important than the building envelope in demand response effectiveness. However, it is difficult to characterize the internal mass such as furniture, books and internal walls. A detailed guide on how to test and quantify internal mass is needed.

\section{Benefits to California}

Reducing electrical peak loads has a huge economic and environmental benefit to California. This approach is cost-effective and can be easily implemented, without the added long-term capital investment associated with active thermal mass storage systems. This study expanded the previous pre-cooling study in cool buildings and has demonstrated that passive demand shedding can be as useful in hot climate areas as in cool climate areas. Under extreme weather conditions when demand reduction requests are typically issued, commercial office buildings in California can use pre-cooling strategies to reduce the peak load by $15-30 \%$ on average with minimal impact on perceived thermal comfort. 


\subsection{Introduction}

\subsection{Background and Overview}

The structural mass within existing commercial buildings can be effectively used to reduce operating costs through simple adjustments of zone temperature setpoints within a range that does not compromise thermal comfort. Generally, the building is pre-cooled at night or in the early morning at moderately low cooling setpoint temperatures (for example, $68^{\circ} \mathrm{F}-70^{\circ} \mathrm{F}$ ) and then the cooling setpoints are raised within the comfort zone (below $78^{\circ} \mathrm{F}$ ) during peak electricity demand periods. Heating setpoints must be left unchanged or lowered to avoid unwanted increases in heating system energy. The cooled mass and higher on-peak zone setpoint temperatures lead to reduced on-peak cooling loads seen by the heating, ventilating, and air-conditioning (HVAC) systems, resulting in lower on-peak energy consumption and related demand charges. The potential for using building thermal mass for load shifting and peak demand reduction has been demonstrated in a number of simulation, laboratory, and field studies (Braun 1990; Ruud et al. 1990; Conniff 1991; Andresen and Brandemuehl 1992; Mahajan et al. 1993; Morris et al. 1994; Keeney and Braun 1997; Becker and Paciuk 2002; Xu et al. 2004; Xu et al. 2005; Lee K.H. and Braun, 2008a, Lee, K.H. and Braun, 2008b. This strategy appears to have significant potential for demand reduction if applied within an overall demand response program.

Over the past several years, Lawrence Berkeley National Laboratory (LBNL), the Center for the Built Environment (CBE) at the University of California, Berkeley, and Purdue University (West Lafayette, Indiana), in cooperation with three California utilities (Pacific Gas and Electric [PG\&E], Southern California Edison [SCE], and the Sacramento Municipal Utility District [SMUD]) have conducted research to investigate strategies for using building thermal mass to shift building cooling loads in Northern California buildings.

In the summer of 2003, LBNL conducted a pre-cooling case study at the Santa Rosa Federal Building. The research team found that a simple demand-limiting strategy performed well in this building. This strategy involved maintaining zone temperatures at the lower end of the comfort range $\left(70^{\circ} \mathrm{F}\right)$ during the occupied hours before the peak period (usually occurring between 12 noon and 6 p.m) and floating the zone temperatures up to the high end of the comfort range $\left(78^{\circ} \mathrm{F}\right)$ during the peak period. With this strategy, the chiller power was reduced by $80 \%$ to $100 \%$ (1 to 2.3 watts per square foot $\left[\mathrm{W} / \mathrm{ft}^{2}\right]$ ) during peak hours without having any thermal comfort complaints submitted to the facility operations staff (Xu et al. 2004).

In the summer of 2004, LBNL conducted pre-cooling tests along with online real-time comfort surveys to determine occupant reactions to the thermal conditions in the Santa Rosa Federal building and in a Sacramento office building. The results of these buildings' comfort surveys indicate that occupant comfort was maintained during the pre-cooling tests as long as the zone temperatures were between $70^{\circ} \mathrm{F}$ and $76^{\circ} \mathrm{F}(\mathrm{Xu} 2006)$.

In Summer 2005, the team conducted additional tests to determine how thermal mass may be discharged more efficiently and more smoothly with no electrical load rebound. The team also started to determine building thermal mass metrics and estimate the load reduction potential. Two building sites were studied - a lightweight office building with $100 \%$ window-to-wall ratio and a heavy mass museum with modest direct solar heat gain. The team found that pre-cooling 
and demand shift strategies worked well with no reductions in comfort levels in the lightweight office building and was able to reduce cool loads significantly ( 35\% on cool days, $\sim 25 \%$ on hot days). The well-controlled exponential temperature setup (Lee and Braun 2006) test in those buildings used during the shed period discharged thermal mass smoothly and with no rebound. The study also indicated that night pre-cooling had noticeable effects on the second day's cooling load in heavy mass buildings.

\subsection{Project Objectives}

In previous studies, significant demand reduction has been demonstrated through testing of large and small commercial buildings, all with relatively small impacts on occupant comfort. However, in the previous phases of this overall effort, data were not obtained at very hot conditions. There is a need to demonstrate demand reduction and evaluate occupant comfort under more extreme conditions - conditions which could trigger a utility demand response program event, such as a Critical Peak Pricing (CPP) event. Furthermore, there is a need to develop a better fundamental understanding of the impact of short-term zone temperature variations on occupant comfort to determine the extent to which setpoints should be raised during demand-limiting periods (12 p.m.-6 p.m.).

Demand limiting refers to shedding loads when predetermined peak demand limits are about to be exceeded. Demand limits can be placed on equipment (such as a chiller or fan), systems (such as a cooling system), or a whole building. This is typically done to flatten the load shape when the pre-determined peak is the monthly peak demand. Demand shifting is achieved by changing the time that electricity is used. Thermal energy storage is an example of a demandshifting technology. Thermal storage can be achieved with active systems such as chilled water or ice storage, or with passive systems such as building mass.

The tests in 2003, 2004, and 2005 were blind tests where the occupants were not informed in advance. In 2005, the team considered informing occupants before the tests so they could change their clothing level accordingly. Akin to commuting by carpool or bicycle on a regional air quality "spare the air day," occupants may be willing to adjust to temporarily inconvenient or uncomfortable conditions that they know have long-term benefits. Since advance notice was thought to bias the tests, the 2005 tests were conducted without notifying the occupants. Since testing in 2006 and 2007 was conducted during extreme hot outside conditions, the indoor air temperatures were significantly lower than the outdoor temperature in the early morning. For those tests, occupants were informed prior to test end to see what the occupants' reaction could be if pre-cooling persisted for a longer period and they had opportunities to adjust to the new thermal environment.

\subsection{Report Organization}

Chapter 1 provided an introduction with descriptions of previous studies, the theory and the objectives of this research. Chapter 2 gives field test results, covering load-shedding and thermal comfort surveys in two medium sized office buildings. Chapter 3 provides conclusions and recommendations for future work. Appendix A, Request for Participation, provides an example of the document sent to facility owners and operators to recruit sites. Appendix $B$ includes the test plan for the study. Appendix $C$ includes the web-based survey instrument that 
was used to obtain comfort observations from building occupants, while Appendix D includes a copy of the e-mail sent out to recruit occupant participation in the comfort surveys. 


\subsection{Pre-Cooling Field Studies: Project Approach and Results}

\subsection{Introduction}

With the help of Southern California Edison, the research team selected two typical office buildings to demonstrate the capability of automated demand shed in buildings on critical peak pricing (CPP) days - an office building in Visalia and the other one in San Bernardino. The selection was based on location, technical feasibility, and owner participation. A strategy similar to the demand-shifting strategy implemented in the 2004 study, based on zone temperature reset, was used in these two office buildings.

There were several reasons for selecting these two office buildings, which for the purpose of confidentiality are labeled CHCCC and TCCSB. Both were medium-sized buildings with full digital direct controls (DDC) that allow for zone temperature setpoint adjustments. CHCCC is a typical office building with open space cubicles and a large portion of the floor area covered with the carpets. It has a large glazing area on the west and east façades. TCCSB is also a typical three-story office building with carpeted floor. The windows are tinted single panes. Studying buildings with a typical design and layout gave researchers the opportunity to test and verify the thermal mass metrics models and applicability of the methods to other office buildings. In addition, both of these buildings are occupied by a single tenant. The building property management teams were innovative and interested in trying new ideas and methods to reduce their utility costs.

\subsection{Methodology}

\subsubsection{Occupant Surveys}

Demand shifting and load-shedding strategies should be acceptable from the perspective of the building users so that employee productivity and customer satisfaction are not hampered. CBE surveyed building occupants to access their comfort levels during the tests. Occupants were surveyed in the morning, early afternoon, and late afternoon to assess the effects of the precooling period, the moderate shed period, and the high shed period.

\section{Employee Web-based Survey}

The Center for the Built Environment had developed a web-based occupant indoor environmental quality survey that had been conducted in more than 230 office buildings in North America and Europe. For the 2004 tests, CBE developed a customized comfort survey instrument to assess employees' thermal sensation, comfort and productivity ratings. The same comfort survey instrument was employed during the 2006 tests.

The web-based comfort survey had three pages, preceded by a welcome page. The welcome page informed the users of the survey's purposes; its voluntary, confidential, and anonymous nature; and the expected time to complete it. On the first survey page, users were asked to fill in their office or cubicle number to identify their location in the building for later analysis with temperature logs. The second survey page contained questions about the occupants' current clothing and activity. This allowed CBE to calculate their clo value (the insulation value of clothes; 1 clo a person wearing a typical business suit) and metabolic rate, and to evaluate 
whether people take off / put on clothing as the temperature shifts to keep themselves comfortable. On the third page, as shown in Figure 1, two questions were asked. One was designed to assess sensation and comfort, and the other polled the respondents for their opinion of the effect of the temperature on their productivity. It should be noted that both questions are self-assessment questions rather than objective questions based on physical measurements. Both questions use seven-point scales for the users' responses. The information collected in the survey, along with the detailed thermal measurements recorded in proximity to the occupants, also enabled CBE to calculate the Predicted Mean Vote (PMV) $)^{1}$ for comparison with the actual comfort vote. The entire survey instrument is included in Appendix C.

\section{Please answer the following questions based on your experience right now:}

How would you rate the current temperature in your workspace?

Much too warm

Too warm

Comfortably warm

$\bigcirc$ Comfortable (and neither cool nor warm)

Comfortably cool

Too cool

Much too cool

Does the current temperature in your workspace enhance or interfere with your ability to get your job done?

Enhances at 0000000 na interferes

Any additional comments or recommendations about the current temperature?

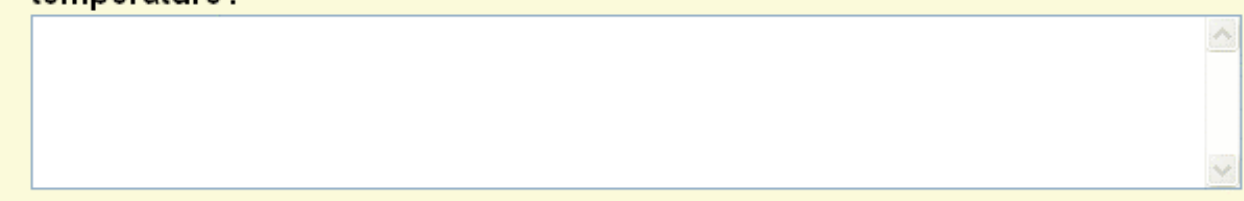

Figure 1. Web-based Polling station for surveying visitors

Source: Center for the Built Environment, UC Berkeley

\section{Employee Survey Requests}

Employees were asked by e-mail to take the survey at least twice per day (once in the morning and once in the afternoon) and more often if possible. The survey was brief and took two to three minutes to complete on the first viewing and about one minute thereafter. Although it

\footnotetext{
${ }^{1}$ PMV is predicated mean vote, the average comfort vote predicted by a theoretical index (generally that of Fanger) for a group of subjects when subjected to a particular set of environmental conditions.
} 
would have been ideal to have all employees take the survey at frequent, specified times throughout the day, the reality of the typical office schedule made the success of this approach unlikely. Further, the research team was wary of demanding too much of the occupants. During the 2004 tests, the team had notified the occupants each time they wanted them to take the survey and learned that some of the employees had found the multiple e-mails intrusive. During the 2005 tests, the team attempted to minimize the communication impact. This strategy was apparently successful at an Oakland, California, site, but there was low participation from the employees at the Chabot Space and Science Center. During the 2006 tests, to increase the participation rate, $\mathrm{CBE}$ used in-kind support to offer three Apple iPods as the rewards to the occupants. The strategy worked well and spurred a higher participation rate from this building than from among all the buildings tested previously.

As a first step, an e-mail was sent to all building occupants to explain the purpose of the survey and to ask the recipient to fill out the survey on the days before the pre-cooling tests, to construct a baseline. Then a brief e-mail was sent the day before a test or baseline day to remind people to participate. See Appendix D for employee survey informational e-mails.

CBE sent the e-mail directly to the property manager, and the manger forwarded the e-mail to the occupants. In general, it has been preferable to have the occupants receive the survey request from a known, respected person in the building, such as a supervisor or facilities manager. This can foster good response rates because it conveys a sense of importance and sanctions taking the survey during working hours.

\subsubsection{Thermal Conditions Monitoring}

During the study period, LBNL monitored the study sites via the emergency management and control system (EMCS), and CBE logged thermal measurements in the spaces every five minutes using $100 \mathrm{HOBO}^{\circledR}$ loggers. The new Onset Technology HOBO loggers allowed continuous logging through the test without reading and restarting. Three different types were used: 50 U-10 temperature loggers, 25 U-12 loggers with internal temperature and relative humidity sensors, and 25 U-12 loggers equipped with external temperature sensors in addition to the internal ones. The loggers were placed in a regular grid pattern throughout the building. In previous years, Indoor Climate Monitors (ICMs) were also used. The ICMs log ambient temperature, radiant temperature, and air speed. However, these devices are more difficult to transport and would have required multiple trips to download data. In the 2007 test, there were generally very low air speeds and little variation between the ambient and radiant temperatures. Therefore, it was decided that the ICMs would not be used and the density of HOBOs would be increased.

\subsubsection{Weather and Test Conditions}

The 2006 tests in Visalia began in late summer and weather conditions were slightly cooler than desired, although tests were conducted on several extremely hot days. During the 2005 tests, the weather was not as hot as hoped for at the test sites, so the majority of those tests were conducted in moderately warm weather. All of the surveys in 2006 were conducted between September and October. Most tests were conducted on days with $95^{\circ} \mathrm{F}$-plus peak outside air temperatures. A few were conducted when outside air temperature reached above $100^{\circ} \mathrm{F}$. 
The 2007 tests in San Bernardino were conducted on extremely hot days, hot days, and cool days. The outside air temperature on the extremely hot day reached above $110^{\circ} \mathrm{F}$. The peak outside air temperatures on the hot and cool days, respectively, was $104^{\circ} \mathrm{F}$ and $85^{\circ} \mathrm{F}$. 


\subsection{Results}

\subsection{Test Site I - Office Building in Visalia, CHCCC}

\subsubsection{Test Site Description}

The test site designated as CHCCC is an 87,000-square-foot typical office building in the city of Visalia, California (see Figure 2). The building is a medium mass rectangular building with most floors carpeted. The walls are well insulated, but the plenum space is not insulated. The window to wall ratio on the longer west and east sides was about $30 \%$.

There are eight 50-ton air-handling rooftop units that chill water to condition outside air and provide air circulation throughout the entire facility. All of them are single-duct variable air volume (VAV) air handling units (AHUs). An AutomatedLogic Supervision DDC control system provides indoor comfort control.
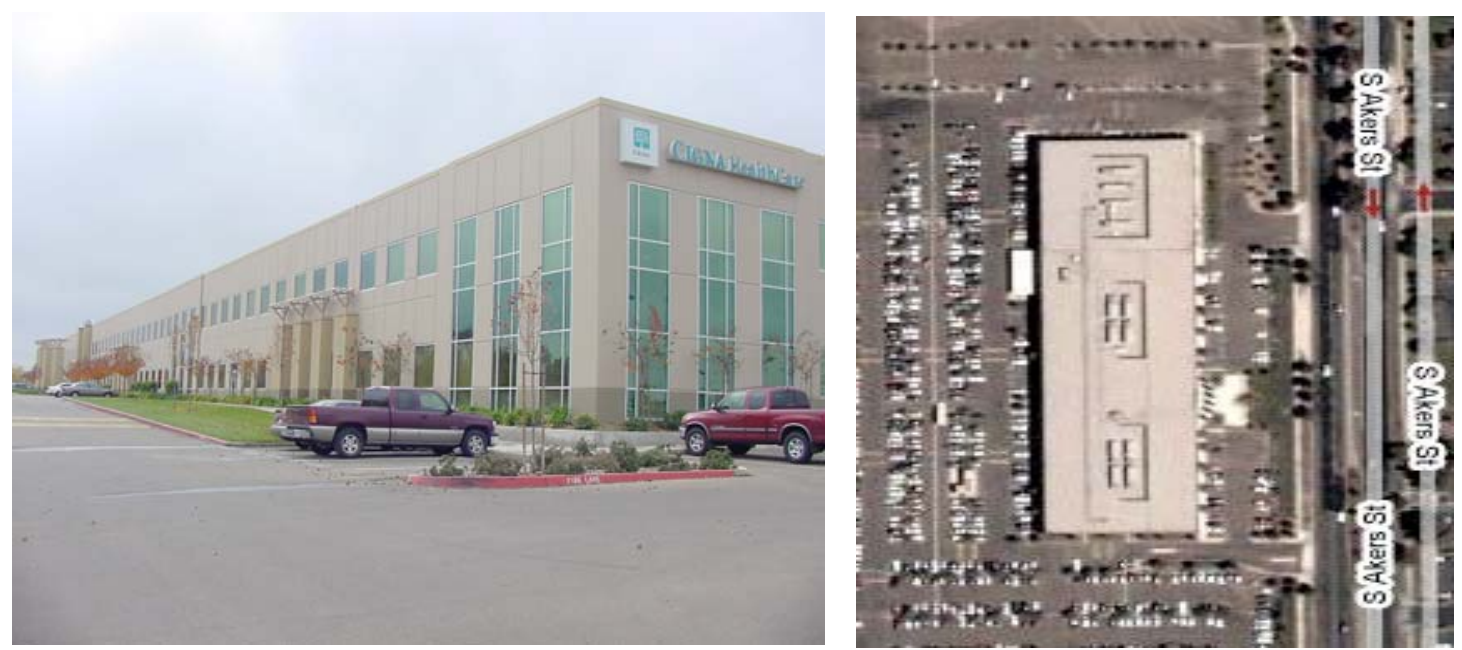

Figure 2. Test site I, CHCCC

The building has a separate rooftop unit serving the north side of the building. Those units were off during the tests. In summer, the outside air ventilation rate is constant to keep the zonal $\mathrm{CO}_{2}$ levels within the desired range. The supply and return fans for the larger dual duct system are equipped with variable frequency drives (VFD). There are about 40 zones in the building. Although the building is fully equipped with DDC, it had no global zone temperature adjustment capability before the study. This function was added to the DDC system's program as part of this study.

The building's operation is typical of that of many offices, except the early start in the morning as a call center. The building is open to workers from as early as 4 a.m. However, the majority of employees come to work after 8 a.m. In normal operation, the HVAC system starts at 2 a.m. and pre-heats or pre-cools the building until 8 a.m., depending on the outside weather conditions. Before the tests, no major faults in the mechanical system were apparent in this building; however, some controllers had not been tuned properly and certain valves and dampers were oscillating during operation. Because of broken VAV dampers, there were a few comfort 
complaints in the corresponding offices. The building operators had worked at the building for a while and were quite confident and familiar with its mechanical system.

\subsubsection{Test Strategies}

Figure 3 shows the pre-cooling and zone temperature reset strategies that were tested. The building was normally operated at a constant setpoint of $74^{\circ} \mathrm{F}$ throughout the startup and occupied hours. After 6 p.m., the system was shut off and zone temperatures were allowed to float. Under normal operation (5 a.m. to 6 p.m.), the setpoints in individual zones ranged from $72^{\circ} \mathrm{F}$ to $76^{\circ} \mathrm{F}$, with an average value of about $74^{\circ} \mathrm{F}$.

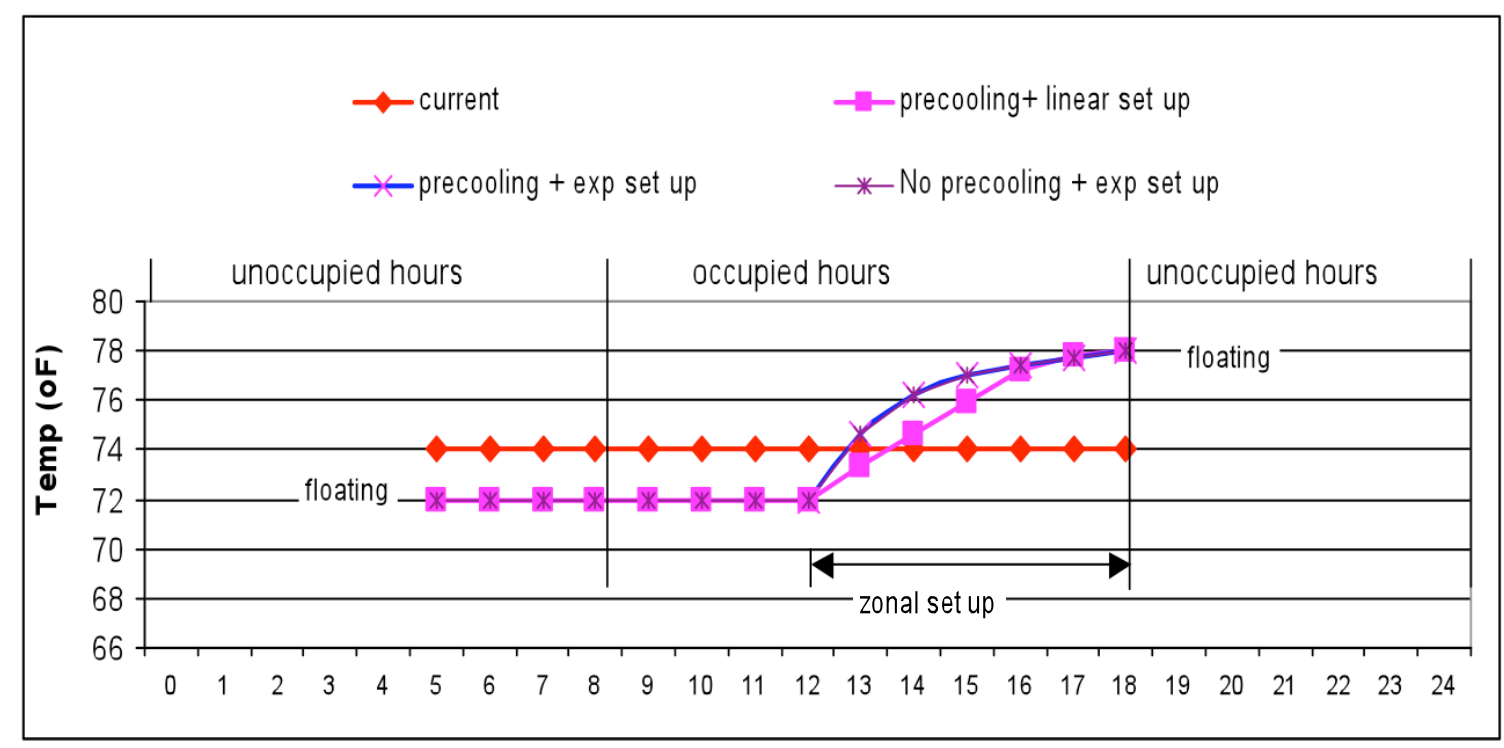

Figure 3. Pre-cooling strategies tested

The first strategy tested was termed pre-cooling + linear zonal reset. The HVAC system was turned on earlier in the morning than in normal operation to pre-cool the building to $70^{\circ} \mathrm{F}$ from 3 a.m. to 7 a.m. From 7 a.m. to 12 p.m., mostly occupied hours, all the zone temperature setpoints were changed to $72^{\circ} \mathrm{F}$. From 12 p.m. to 6 p.m., the CPP moderate and high price periods, the setpoints were raised linearly to $78^{\circ} \mathrm{F}$. After 6 p.m., before the system was shut off, the setpoints were kept at $74^{\circ} \mathrm{F}$.

The second strategy was termed pre-cooling + exponential reset. The temperatures were raised exponentially rather than linearly in the afternoon period. This increases the setpoint temperatures faster and is expected to reduce rebound effects as the system is not trying to maintain the lower temperatures longer.

The third strategy was called no pre-cooling + exponential reset. The zone temperatures were raised exponentially in the afternoon in the same way as in the second strategy, but there was no pre-cooling from 3 a.m. to 7 a.m. One aim of the tests was to determine the effect of the extended pre-cooling on the upcoming peak demand shedding period. 
Table 1 shows the setpoints for the existing (baseline) operation and the test schedules that were proposed to be programmed into the control system. In the first week, different strategies were tested to collect information for analyzing the effect of pre-cooling strategies.

\section{Table 1. Proposed test scenarios-zone temperature setpoint schedules}

\subsubsection{Monitoring}

The building has a whole building power meter and no other sub-meters. There is no weather station measuring outside air temperature and humidity. The control system has a dedicated outside air temperature sensor. In addition to that, one HOBO sensor was installed on the rooftop to collect outside air temperature. The HVAC performance data were recorded using the building control system. Roughly 50 data points were collected at 15-minute intervals. Eight power meters were installed on the rooftop units to determine the impact of control strategies on the cooling load and cooling power. Temperatures in the zones were recorded through the building control system. These temperature data were compared with indoor air temperature measurements from devices installed by CBE in both the office and exhibition areas.

\subsubsection{Confirm Baseline}

In the 2003 and 2004 studies, the expected strong correlation between peak outside temperature and whole building power was observed in all tested buildings (Xu et al. 2004). For this study, in order to decrease the difference of the outside temperature profile between baseline and test days, baseline days for each test day were selected based on similarity of peak outside air temperature and outside temperature profiles.

First, according to similarity of peak outside air temperature, there were few days that could be selected as baseline days. The average variance of hourly outside air temperature (AVHOAT) between the baseline days and test days were calculated as:

$$
A V H O A T=\frac{1}{24} \sum_{i=1}^{24}\left(B_{i}-T_{i}\right)^{2}
$$

$\mathrm{Bi}=$ the hourly outside air temperature of baseline days

$\mathrm{Ti}=$ the hourly outside air temperature of test days

The tests were conducted on hot days from September 11 through September 25, 2006. The daily peak outside air temperatures were between $90^{\circ} \mathrm{F}$ and $100^{\circ} \mathrm{F}$. The forecasted outdoor temperature was about three degrees higher than the real temperature measured from a HOBO sensor installed on the roof. The hottest temperature observed by the HOBO sensor during the summer 2006 was $102^{\circ} \mathrm{F}$.

In total, the research team conducted nine tests (see Table 2). Each test lasted for one day. There were nine pre-cooling and zonal reset tests including no pre-cooling with zonal reset, seven of them were on cool days and two of them were on warm days. There were two pre-cooling + 
linear reset tests, two pre-cooling + aggressive linear reset tests, one pre-cooling + exponential reset test, and two non-pre-cooling + zonal reset tests. All tests were duplicated except for the precooling + exponential reset test, which was not duplicated because of time constraints. The remaining two days were baseline survey days on which no intervention occurred. Table 2 shows the dates, strategies, and weather conditions for the tests.

Table 2. Pre-cooling and zonal reset test scenarios

\begin{tabular}{l|llc}
\hline Number & Date & Strategies & $\begin{array}{c}\text { Peak Outside Air } \\
\text { Temp }\end{array}$ \\
\hline 1 & $9 / 11 / 2006$ & Baseline, no comfort survey & $99^{\circ} \mathrm{F}$ \\
2 & $9 / 12 / 2006$ & Morning pre-cooling + linear set up & $99^{\circ} \mathrm{F}$ \\
3 & $9 / 13 / 2006$ & Night/morning pre-cooling + exp set up & $102^{\circ} \mathrm{F}$ \\
4 & $9 / 14 / 2006$ & Morning pre-cooling + exp set up & $102^{\circ} \mathrm{F}$ \\
5 & $9 / 19 / 2006$ & Baseline, comfort survey & $95^{\circ} \mathrm{F}$ \\
6 & $9 / 20 / 2006$ & No pre-cooling + exp set up & $95^{\circ} \mathrm{F}$ \\
7 & $9 / 21 / 2006$ & Morning pre-cooling + zonal set up & $95^{\circ} \mathrm{F}$ \\
8 & $9 / 25 / 2006$ & Baseline & $95^{\circ} \mathrm{F}$ \\
9 & $9 / 26 / 2006$ & No pre-cooling + zonal set up & $99^{\circ} \mathrm{F}$ \\
\hline
\end{tabular}

Table 3 presents the comparisons of hourly outside air temperature between the pre-cooling test days and baseline days. The 9/7/06 baseline was confirmed to be the best baseline and that day was used as the baseline for all of the "Hot" weather test days. 
Table 3. Hot weather conditions

\begin{tabular}{ccccccc}
\hline & \multicolumn{5}{c}{ Test day } & \multicolumn{5}{c}{ Baseline days } \\
\cline { 2 - 7 } Date & $9 / 12 / 06$ & $9 / 4 / 06$ & $9 / 6 / 06$ & $9 / 7 / 06$ & $9 / 8 / 06$ & $9 / 19 / 06$ \\
\hline $\begin{array}{c}\text { Peak Outside Air } \\
\left.\text { Temperature ( }{ }^{\circ} \mathrm{F}\right)\end{array}$ & 99.0 & 93.2 & 98.6 & 98.6 & 91.4 & 93 \\
\hline AVHOAT & - & 22.67 & 12.22 & 4.36 & 4.36 & 13.14 \\
\hline & & \multicolumn{5}{c}{ Baseline days } \\
\hline Date & Test day & \multicolumn{5}{c}{9} \\
\cline { 2 - 7 } & $9 / 13 / 06$ & $9 / 4 / 06$ & $9 / 6 / 06$ & $9 / 7 / 06$ & $9 / 8 / 06$ & $9 / 19 / 06$ \\
\hline $\begin{array}{c}\text { Peak Outside Air } \\
\text { Temperature ( }{ }^{\circ} \text { F) }\end{array}$ & 102 & 93.2 & 98.6 & 98.6 & 91.4 & 93 \\
\hline AVHOAT & - & 39.77 & 7.17 & 7.05 & 51.01 & 67.07 \\
\hline
\end{tabular}

The building property manger sent the web-based survey e-mail to the employees. All of the resulting data could be correlated with air temperature measurements made near the survey respondent.

\subsubsection{Results}

\section{Total Energy Use}

The test data showed significant peak demand savings for all the pre-cooling strategies in both cool and warm/hot conditions.

Morning pre-cooling with linear temperature reset. Figure 4 shows whole building power measurement for the "baseline" and "morning pre-cooling + linear temperature reset" on the hot days. The baseline day electricity usage for cooling was slightly lower than that on test days. At 12 p.m., when the zone temperature setpoints started to rise, the demand power was reduced with the linear temperature reset on the pre-cooling test days. An equal amount of the load was shifted from the afternoon on-peak period to the morning off-peak period. The afternoon cooling load was reduced by as much as $25 \%$ during the high price period from 3 p.m. to 6 p.m.

Table 4 presents the demand shed in the moderate and high price period. The high price period difference in maximum demand was 166 kilowatts $(\mathrm{kW})$. During the test, the research team observed no rebound of package unit power before 6 p.m., which indicated that the temperature had not yet reached to the $78^{\circ} \mathrm{F}$ setpoint at the end of the test and some thermal mass had not been fully discharged in this building. 


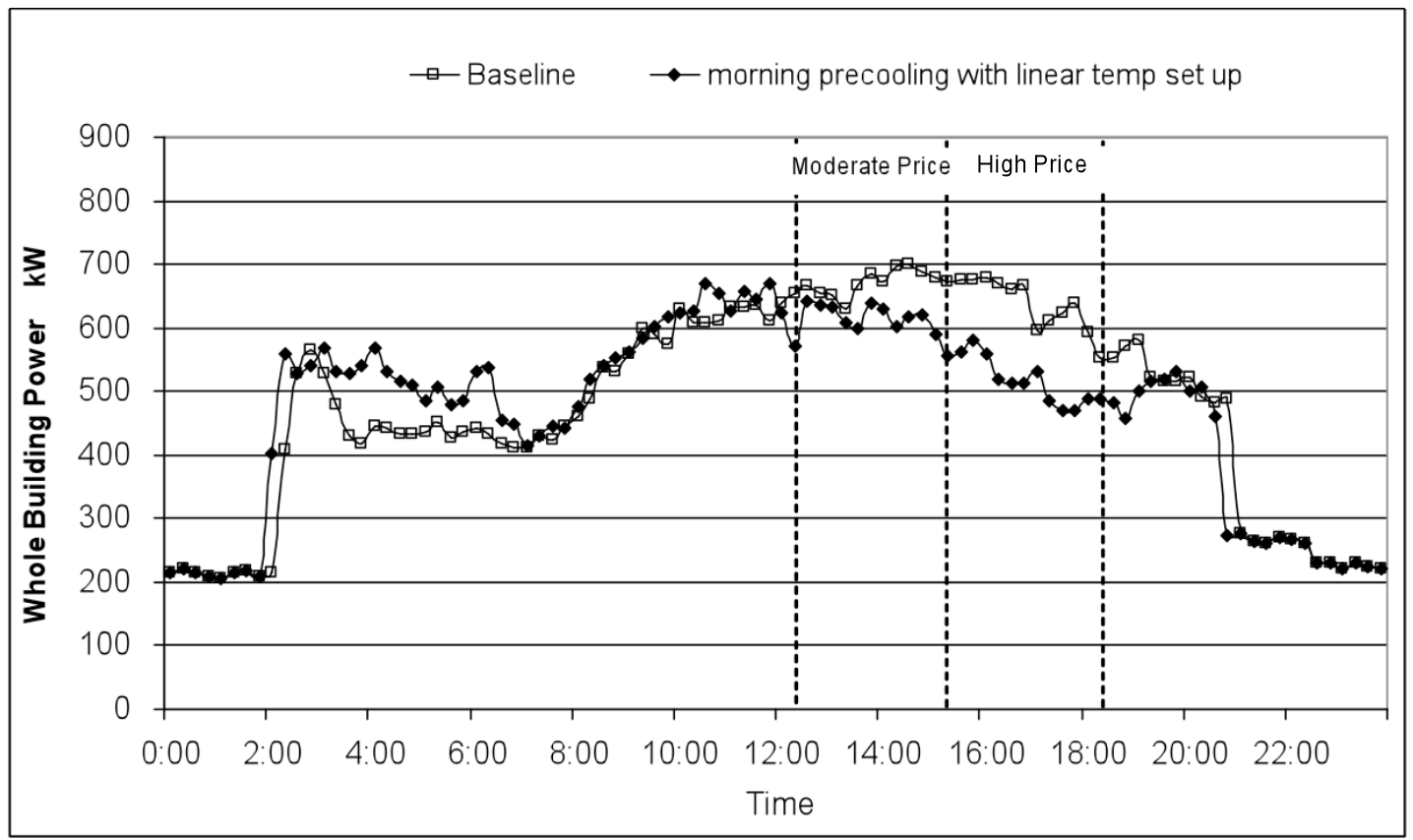

Figure 4. Night and morning pre-cooling with linear temperature reset in peak hours, CHCCC

Table 4. Demand shed - Morning pre-cooling with linear temperature reset

\begin{tabular}{c|cccccc}
\hline Price Level & \multicolumn{2}{|c}{$\boldsymbol{k} W$} & \multicolumn{2}{c}{$\boldsymbol{W} / \mathbf{s q} \boldsymbol{f t}$} & \multicolumn{2}{c}{$\boldsymbol{W B P} \%$} \\
\cline { 2 - 7 } & Max & Ave & Max & Ave & Max & Ave \\
$\begin{array}{c}\text { Moderate } \\
\text { Price }\end{array}$ & 94 & 49 & 1.08 & 0.56 & $13 \%$ & $7 \%$ \\
$\begin{array}{c}\text { High Price } \\
\text { Mighy }\end{array}$ & 166 & 124 & 1.91 & 1.42 & $25 \%$ & $19 \%$ \\
\hline
\end{tabular}

Note: WBP\% is the percent of whole building peak demand.

Morning pre-cooling with exponential temperature reset. Figure 5 shows the effects of exponential temperature reset in the afternoon. The demand reductions during the moderate price period were much more obvious than those during the linear temperature reset test, because the temperature setpoints were raised much faster during the exponential temperature reset test. 


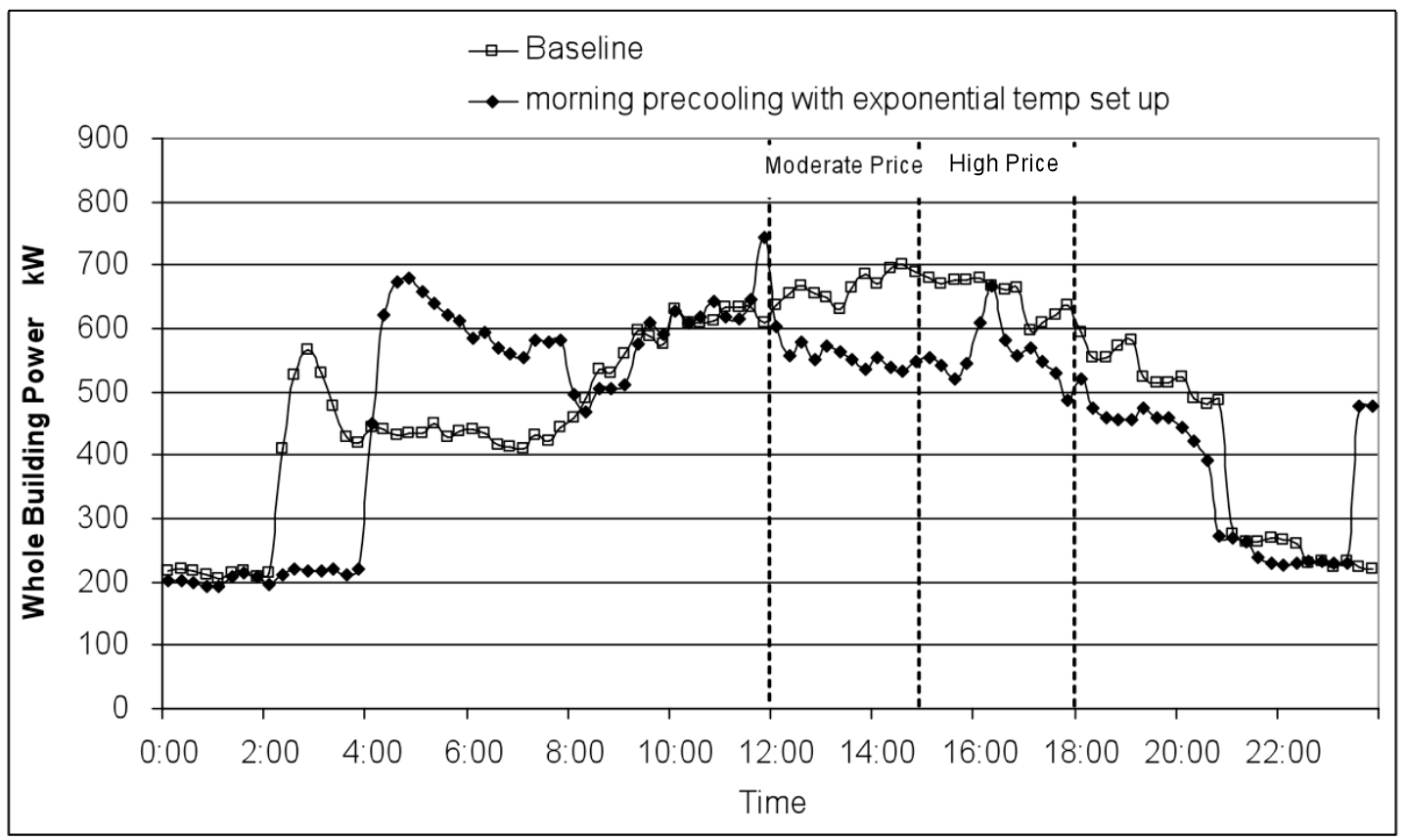

Figure 5. Effects of night pre-cooling on second day cooling load - warm days, CHCCC - exponential temperature reset.

Table 5 shows the demand shed for morning pre-cooling with exponential temperature reset. It was obvious that the pre-cooling with exponential strategy reduce the demand throughout the CPP period. The cumulative demand shed was $170 \mathrm{~kW}$ before 4 p.m.; however, the maximum demand was not reduced as much as expected during the high price period.

\begin{tabular}{|c|c|c|c|c|c|c|}
\hline \multirow[t]{2}{*}{ Price Level } & \multicolumn{2}{|c|}{$k W$} & \multicolumn{2}{|c|}{$W / s q f t$} & \multicolumn{2}{|c|}{ WBP\% } \\
\hline & Max & Ave & Max & Ave & Max & Ave \\
\hline $\begin{array}{l}\text { Moderate } \\
\text { Price }\end{array}$ & 170 & 110 & 1.96 & 1.26 & $24 \%$ & $16 \%$ \\
\hline High Price & 154 & 94 & 1.77 & 1.08 & $23 \%$ & $14 \%$ \\
\hline
\end{tabular}

Similar to the linear temperature reset test, the reduction in demand did last until the unoccupied hours, but the cooling energy demand rebounded in the afternoon by the end of the test. The exponential temperature rise was a little bit too aggressive and a smaller building time constant should be used to calculate the optimal exponential trajectory. The thermal mass of this building is much heavier than that of the value calculated. The approaches and assumptions made in the model need to be evaluated. That said, the rebound demand was still smaller than the original peak demand and the overall demand savings are still very substantial. 
Morning pre-cooling versus night pre-cooling. The effects of night pre-cooling on the upcoming day load were minimal. Figure 6 shows two tests that used the same exponential reset strategy in the afternoon. One test used night and morning pre-cooling and the other used morning precooling only. On both test days, the demand reduction in the afternoon was substantial. However, compared to morning pre-cooling, only the night and morning pre-cooling scenarios had no strong effect on the morning and afternoon load reduction. The load reduction in the afternoon period for morning pre-cooling test was slightly lower than that of night and morning pre-cooling. Comparing the results in Table 5 (morning pre-cooling) and Table 6, (night and morning pre-cooling) the night pre-cooling did not take much advantage of cooling stored in the night period. On the night pre-cooling days, the rooftop units started about three hours earlier than that of the baseline. The effect of night pre-cooling seems to be very weak, and there was no substantial reduction in the morning load. It was mostly because of the relative light mass of the building. Night pre-cooling did not reduce the cooling load in the morning, while the afternoon temperature reset shifted the cooling load from peak hours to non-peak hours. In heavy mass buildings that the team had tested before, it was shown that night pre-cooling could reduce load in the morning.

These test results are helpful in addressing questions from tests performed in 2003, 2004, and 2005. The results from both 2003 and 2004 tests in lighter thermal mass building indicated that night pre-cooling had very limited effects on afternoon electrical demand, especially on relatively cool days. The results from 2005 tests indicated that, for heavy mass buildings, the effect of night pre-cooling could be very significant. This study indicated that, regardless of mass, level night pre-cooling had very little effect.

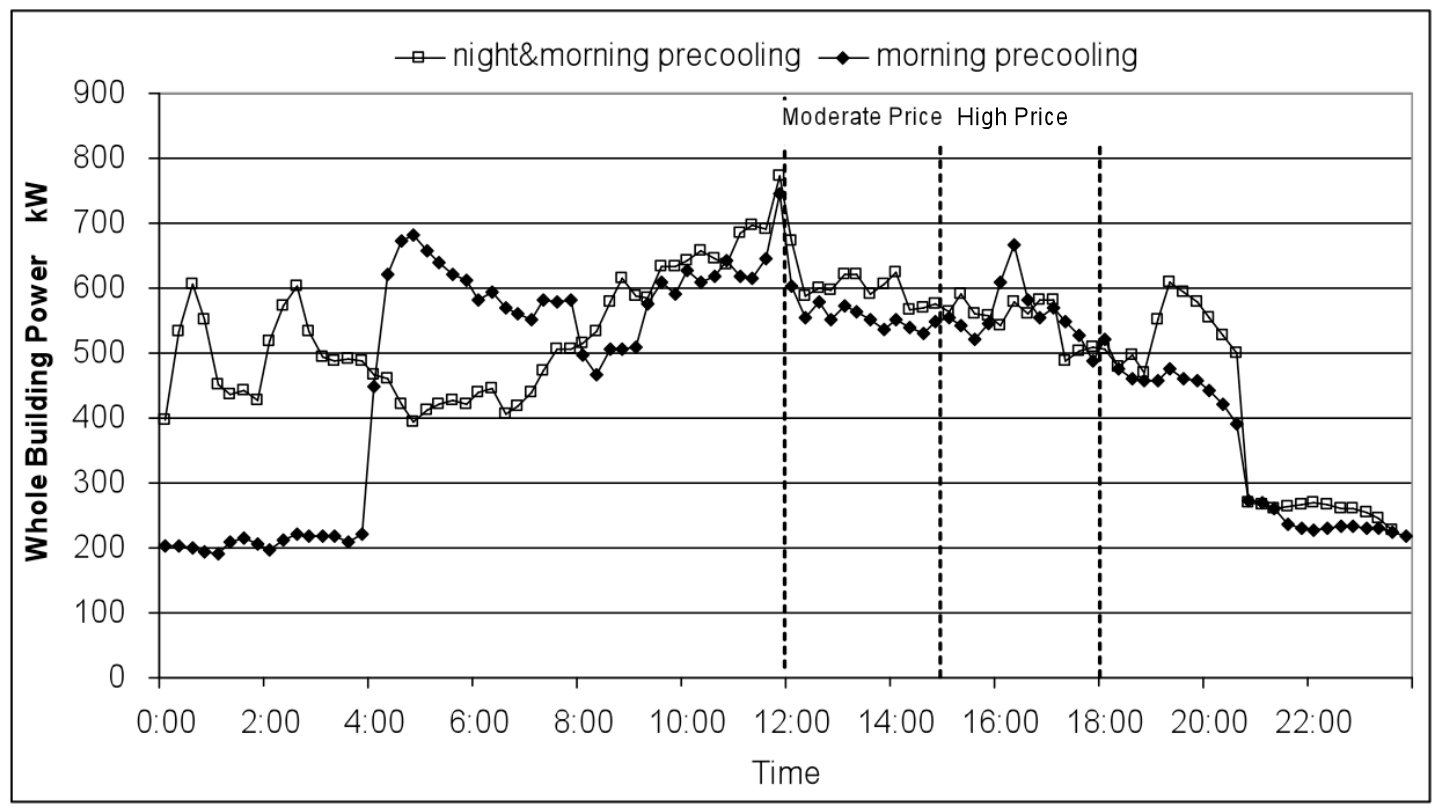

Figure 6. Effects of night pre-cooling on upcoming day cooling load moderately warm days, CHCCC 
Table 6. Demand shed - Night and morning pre-cooling with exponential
temperature reset

\begin{tabular}{c|cccccc}
\hline Price Level & \multicolumn{2}{|c}{$\boldsymbol{k} W$} & \multicolumn{2}{c}{$\boldsymbol{W} / \mathbf{s q} \boldsymbol{f t}$} & \multicolumn{2}{c}{$\boldsymbol{W B P} \%$} \\
\hline & Max & Ave & Max & Ave & Max & Ave \\
$\begin{array}{c}\text { Moderate } \\
\text { Price }\end{array}$ & 131 & 64 & 1.51 & 0.73 & $19 \%$ & $10 \%$ \\
$\begin{array}{c}\text { High Price } \\
136\end{array}$ & 101 & 1.56 & 1.17 & $20 \%$ & $16 \%$ \\
\hline
\end{tabular}

\section{Rooftop units' energy usage}

Morning pre-cooling with linear temperature reset. Figure 7 shows the comparison of the electrical demand of the rooftop units between the baseline and the test day with "morning pre-cooling with linear temperature reset." During the morning pre-cooling period, the demand was almost two times the baseline. After 12 p.m., the rooftop units' demand began to decrease, and it reduced further during the high price period. However, the results indicated that the demand profile of the rooftop units was not flat under pre-cooling with linear temperature reset.

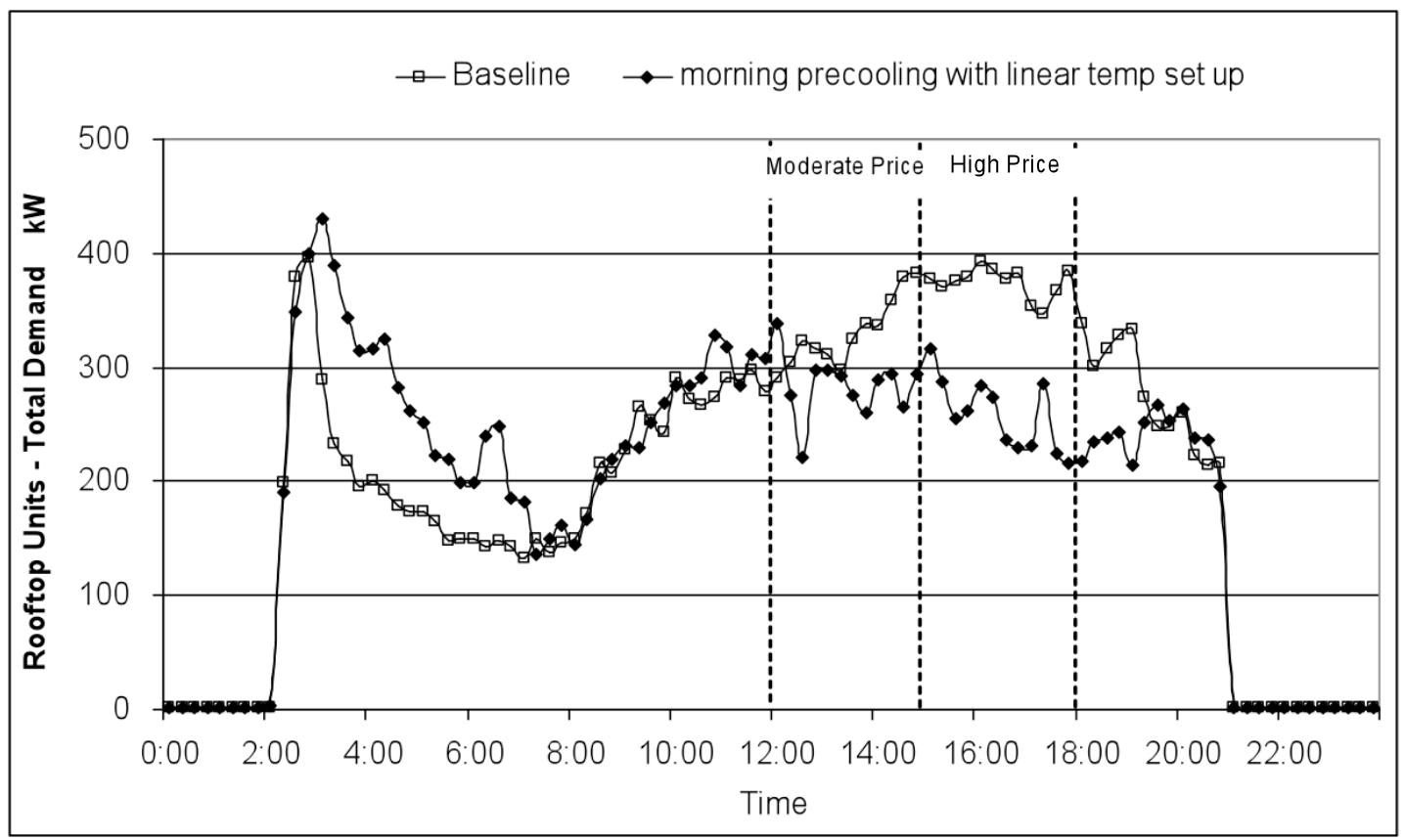

Figure 7. Rooftop units total demand (kW) - Morning pre-cooling with linear temperature reset, CHCCC

Morning pre-cooling with exponential temperature reset. As shown in Figure 8, pre-cooling with exponential temperature reset was able to reduce demand throughout the CPP period, but there was a rebound during the high price period. Around 3 p.m., the demand of the rooftop units decreased rapidly by as much as $50 \%$. As discussed before, the exponential temperature reset strategy setpoints resulted in peak demand savings. 


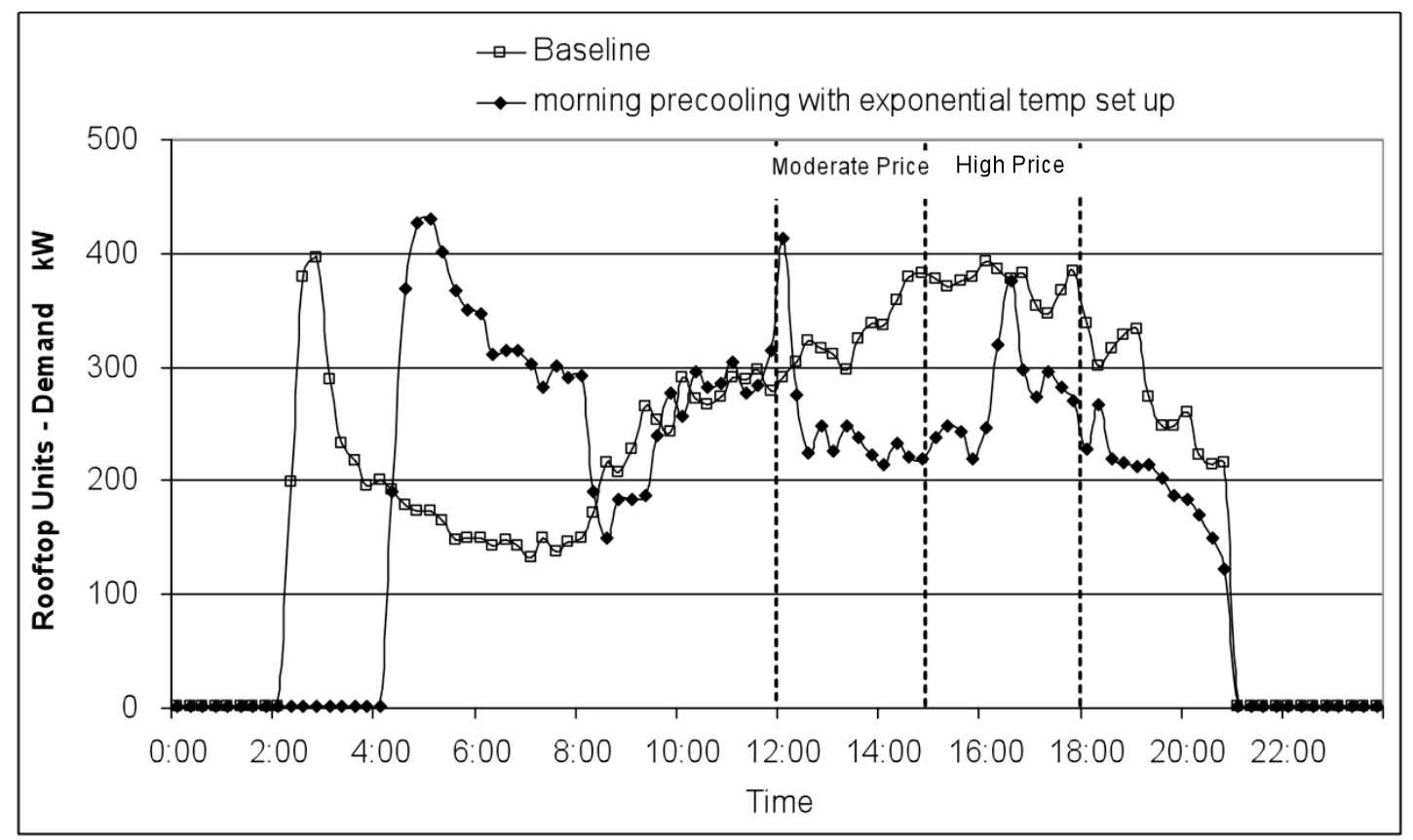

Figure 8. Rooftop units - demand (kW) - Morning pre-cooling with exponential temperature reset, CHCCC

Night and morning pre-cooling with exponential temperature reset. Figure 9 shows the effect of "night \& morning pre-cooling with exponential temperature reset." The demand profile during the "exponential temperature reset" period was flat, as shown in Figure 9. Compared to the effect of "morning pre-cooling with exponential temperature reset," it did not reduce the demand that much during the morning and moderate price periods, and there was a slight rebound in the high price period. The max/min demand power was reduced by $100 \mathrm{~kW}$ over the high price period. 


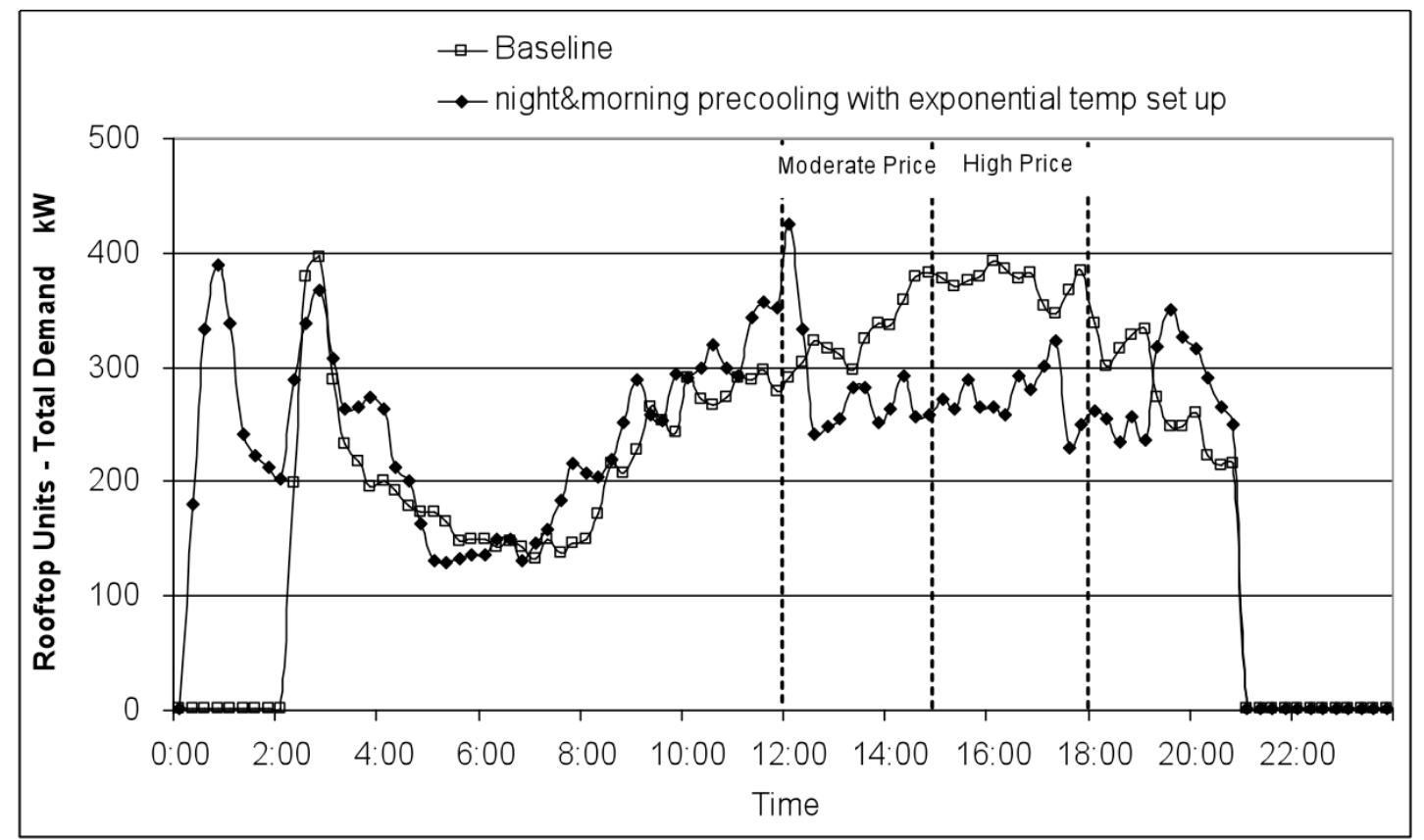

Figure 9. Rooftops units - Total Demand (kW) - Night and morning precooling with exponential temperature reset, CHCCC

Morning pre-cooling versus no pre-cooling. Figure 10 shows the impact of the morning pre-cooling temperature reset strategies. Temperature resetting in the afternoon alone (no pre-cooling) can result in peak demand reductions. However, morning pre-cooling shifts loads from the peak hours to off peak hours, resulting in a $50 \mathrm{~kW}$ higher than the demand savings without precooling.

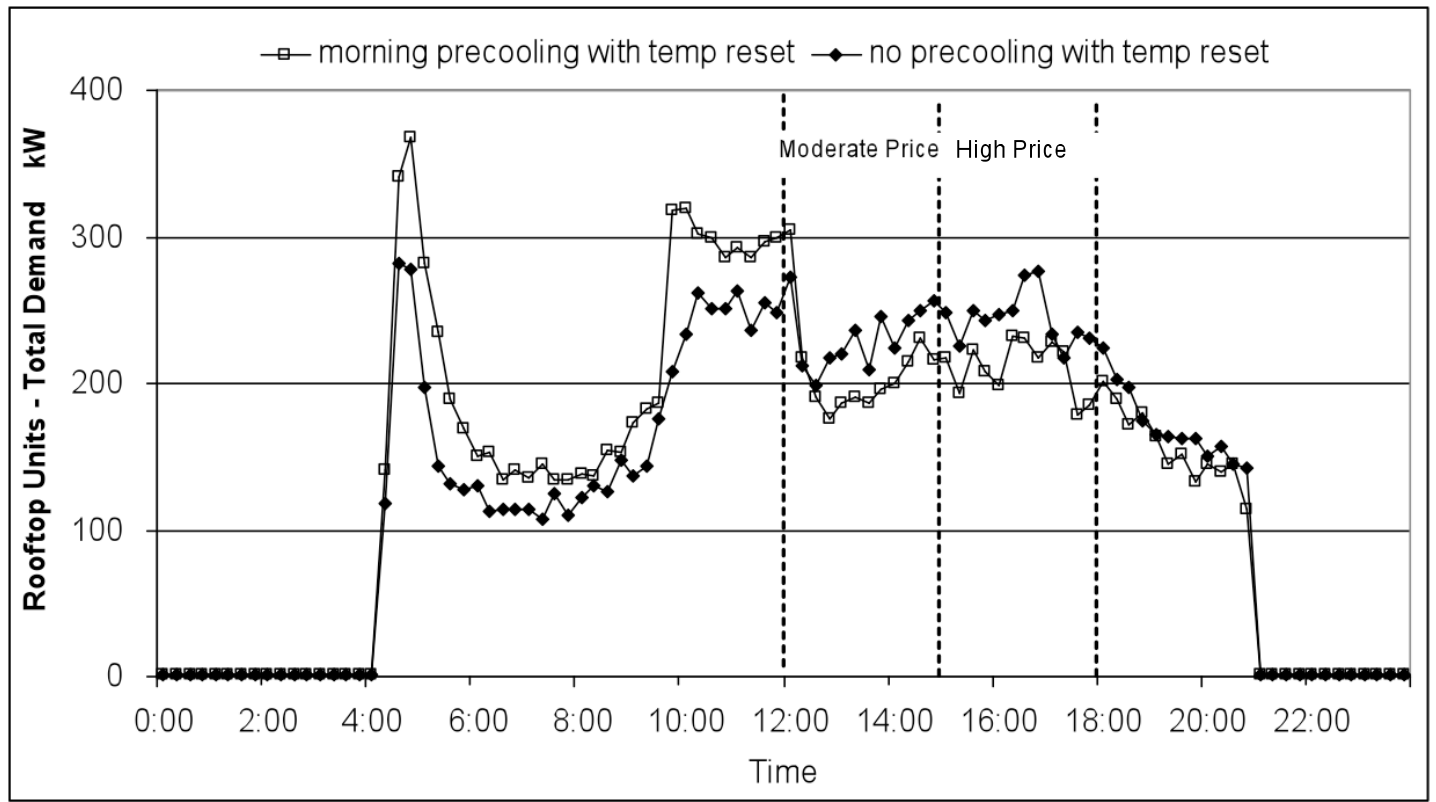

Figure 10. Rooftops units - Total Demand (kW) - Morning pre-cooling versus no pre-cooling, CHCCC 


\section{Return Air Temperature}

Return air temperature. As shown in Figure 11, the return air temperature on a typical exponential temperature reset test day was never higher than $75^{\circ} \mathrm{F}$, although the building setpoints were at $78^{\circ} \mathrm{F}$ by the end of the peak hour. In the night pre-cooling and morning precooling period, the temperature followed the setpoints in the morning. In the afternoon period, the setpoints were reset higher, but the zone temperatures remained lower than the setpoints. This is one reason why no complaints were registered in the afternoon.

This could be due to the high minimum air flow rate - the VAV minimum air flow rate may have been set too high or the system supply air temperature may have been set too low. Although the VAV box dampers were pushed to their minimum positions, the cooling delivered through the minimum air flow rate was sufficient to keep the building at $75^{\circ} \mathrm{F}$. To fully take advantage of the building thermal mass, the supply air temperature should be reset to a higher value than before the peak period. That test was not done in this study because the supply temperature reset function was not built in to the EMCS.

In summary, these tests underestimate both potential peak energy savings and impact on occupant comfort.

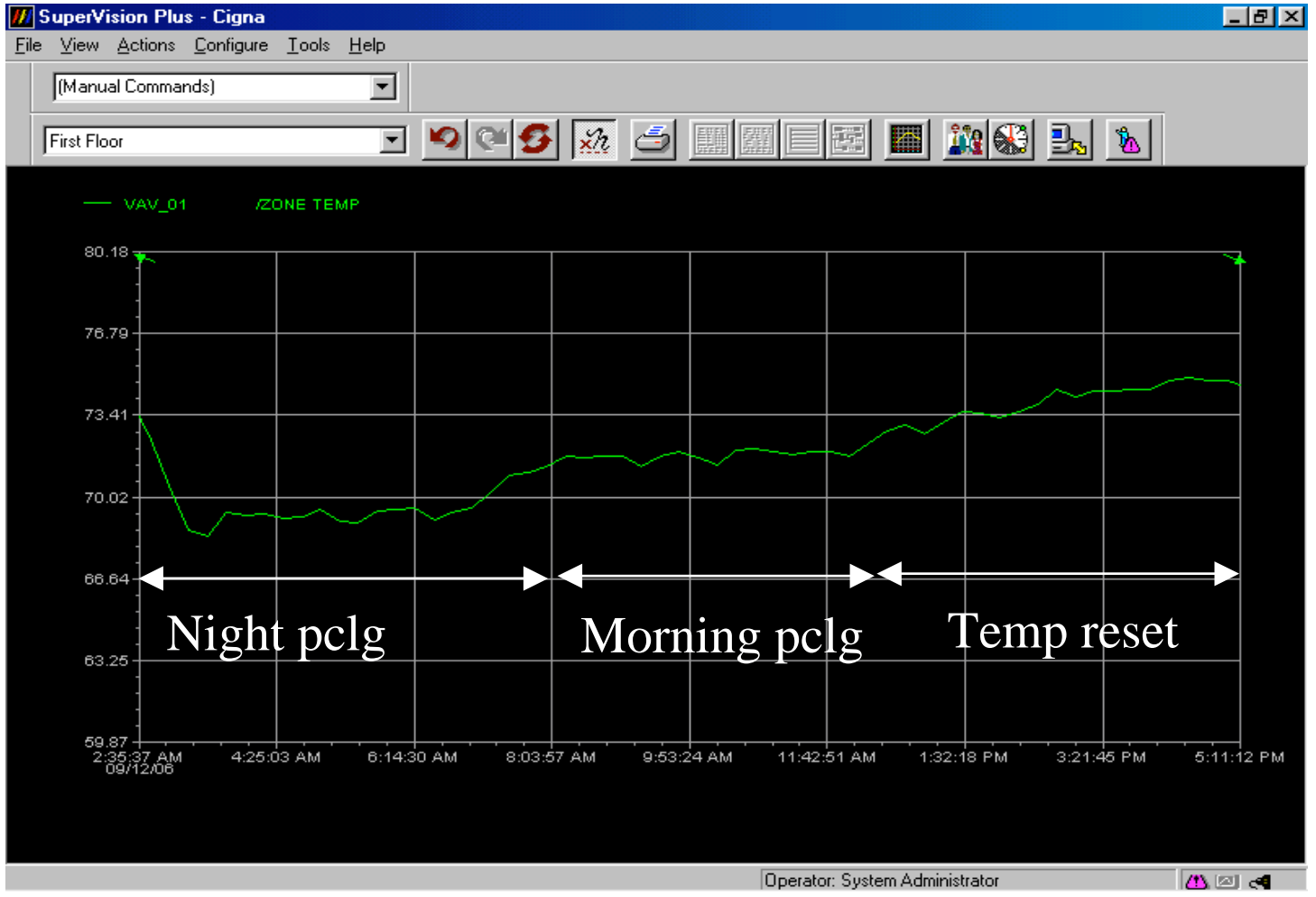

Figure 11. Return air temperature on one typical pre-cooling test days, CHCCC - Expanded temperature reset 


\section{Energy Demand Economic Analysis}

Southern California Edison (SCE) is the utility provider for these two office building. Table 7 shows the Time of Use time period-General service rate schedules. Table 8 includes Schedule TOU-8-CPP details - the schedule on which the building is billed when participating in the Critical Peak Pricing program.

The total energy cost includes customer charge, energy charge, and demand charge. For the energy charge and demand charge, these charges are calculated according to time of use rates and time-related demand charge rates. Especially during CPP period, the effect of these precooling strategies is obvious on energy cost saving. The energy charges during high price period ( 3 p.m. to 6 p.m.) are approximately nine times the standard rate schedule. The field test data indicate that the maximum demand shed always appears during the high price period, therefore, pre-cooling and demand shed strategies can reduce energy usage and energy cost.

\section{Table 7. Time of Use time period-General service rate schedules}

\section{TOU-8 Summer Season}

First Sunday in June to the first Sunday in October

\begin{tabular}{|c|c|c|c|c|c|c|c|}
\hline & Monday & Tuesday & Wednesday & Thursday & Friday & Saturday & Sunday \\
\hline \multicolumn{8}{|l|}{8 a.m. } \\
\hline & & & & & & & \\
\hline \multicolumn{8}{|l|}{ Noon } \\
\hline & & & & & & & \\
\hline & & & & & & & \\
\hline \multicolumn{8}{|l|}{6 p.m. } \\
\hline & & & & & & & \\
\hline \multicolumn{8}{|c|}{11 p.m. } \\
\hline 8 a.m. & & & & & & & \\
\hline
\end{tabular}

TOU-8 Winter Season

First Sunday in October to the first Sunday in June

\begin{tabular}{|c|c|c|c|c|c|c|c|}
\hline & Monday & Tuesday & Wednesday & Thursday & Friday & Saturday & Sunday \\
\hline \multicolumn{8}{|l|}{8 a.m. } \\
\hline \multicolumn{8}{|l|}{10 a.m. } \\
\hline & & & & & & & \\
\hline & & & & & & & \\
\hline \multicolumn{8}{|l|}{9 p.m. } \\
\hline & & & & & & & \\
\hline 8 a.m. & & & & & & & \\
\hline
\end{tabular}

Source: Southern California Edison (2008) 
Table 8. Detailed TOU-8-CPP rate schedule

\begin{tabular}{|c|c|c|c|c|}
\hline $\begin{array}{c}\text { Rate } \\
\text { Schedule }\end{array}$ & $\begin{array}{c}\text { Rate } \\
\text { Structure }\end{array}$ & $\begin{array}{c}\text { Customer } \\
\text { Charge }\end{array}$ & $\begin{array}{c}\text { Demand (kW) } \\
\text { Charge }\end{array}$ & $\begin{array}{l}\text { Energy Charge } \\
\text { (per kWh) }\end{array}$ \\
\hline $\begin{array}{l}\text { TOU-8-CPP } \\
\text { (Below } 2 \text { kV) }\end{array}$ & $\begin{array}{l}\text { - Time-of-Use rates } \\
\text { - Facilities- and } \\
\text { Time-related } \\
\text { demand charges } \\
\text { - Seasonal structure } \\
\text { - Benefits customers } \\
\text { who can } \\
\text { significantly } \\
\text { reduce usage } \\
\text { during an } \\
\text { activated Critical } \\
\text { Peak Pricing (CPP) } \\
\text { period }\end{array}$ & $\begin{array}{l}\$ 414.98 \\
\text { per month } \\
\text { per meter }\end{array}$ & $\begin{array}{l}\text { Facilities-related demand } \\
\text { charge per monthly } \\
\text { maximum kW per meter } \\
\text { Delivery: } \$ 9.71 \\
\text { Generation: } \$ 0.00 \\
\text { Time-related demand } \\
\text { charge per monthly } \\
\text { maximum kW per meter } \\
\text { in the summer season only } \\
\text { Delivery: } \\
\$ 0.00 / \text { on-peak } \\
\text { (Including CPP High-Price) } \\
\$ 0.00 / \text { mid-peak } \\
\text { Generation: } \\
\$ 15.37 / \text { on-peak } \\
\text { (Including CPP High-Price) } \\
\$ 5.19 / \text { mid-peak }\end{array}$ & $\begin{array}{l}\text { Delivery: } \\
\$ .01390 \\
\text { DWR Generation: } \\
\text { \$.09490 } \\
\text { SCE Generation: } \\
\text { Summer Season - } \\
\$ .33377 \text { (CPP } \\
\text { Mod. Price Period } \\
\text { Noon - 3:00 p.m.) } \\
\text { High Price Period } \\
3: 00 \text { p.m. - 6:00 p.m.) } \\
\$ .73249 \\
\text { Non CPP Event Time } \\
\text { Periods } \\
\text { Summer Season - } \\
\$ .08840 / \text { on-peak } \\
\$ .06291 / \text { mid-peak } \\
\$ .03637 / \text { off-peak } \\
\text { Winter Season - } \\
\$ .06547 / \text { mid-peak } \\
\$ .04014 / \text { off-peak }\end{array}$ \\
\hline
\end{tabular}

Morning pre-cooling with linear temperature reset. The energy cost was calculated based on the rate schedule and energy usages. Figure 12 shows the energy usages in different rate periods and total energy consumption. Figure 13 shows the corresponding energy costs. It shows that an almost equal amount of the energy was shifted from CPP period to the non-CPP period. The energy charge on pre-cooling test day was reduced by $\$ 278$ because of the rate difference between the CPP period and the other period. The energy cost saving for the demand charge will be around $\$ 1380$ per month if the building runs this strategy in these hot weather conditions. 


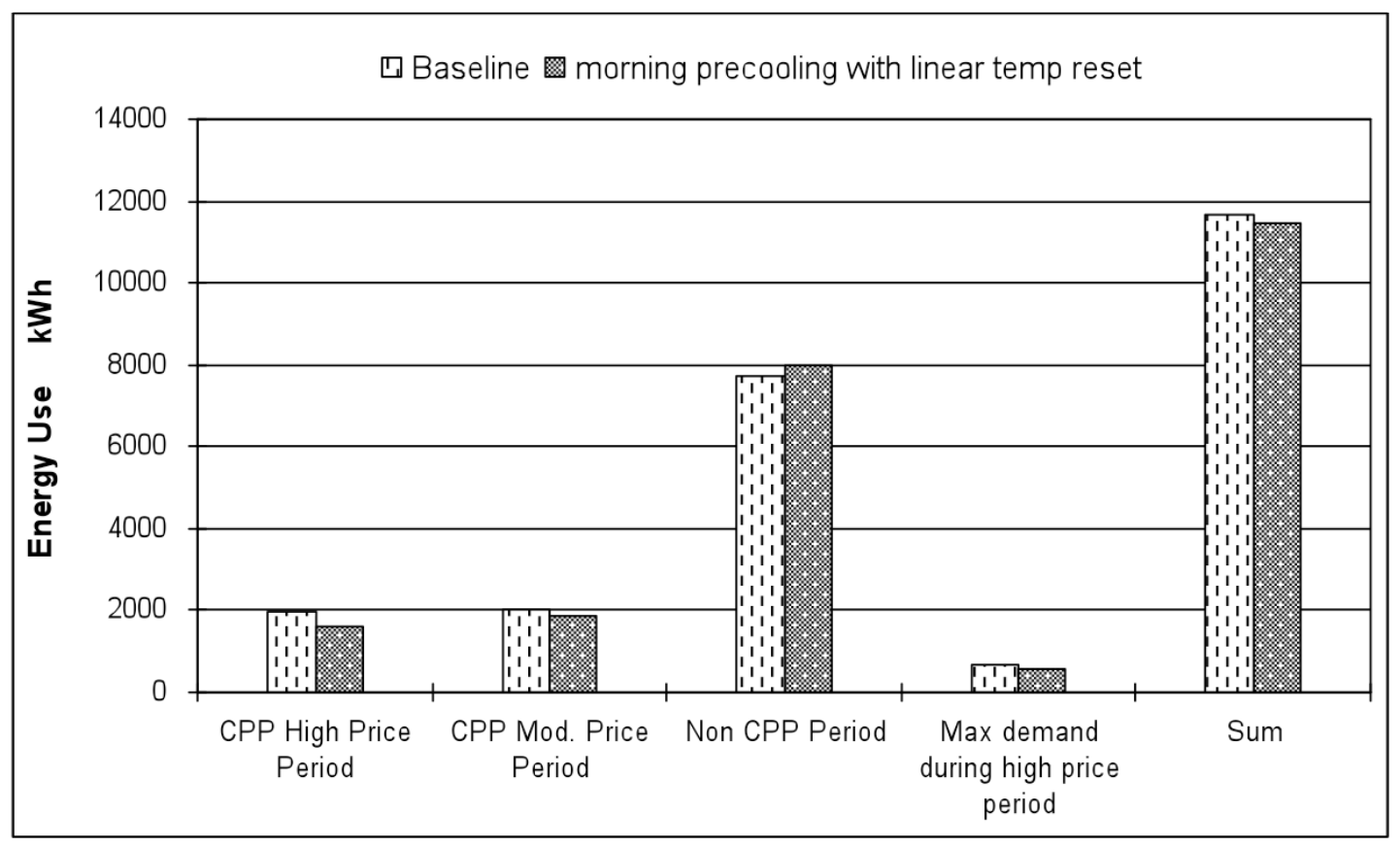

Figure 12. Morning pre-cooling with linear temperature reset, $\mathrm{CHCCC}-$ Energy usage (kWh)

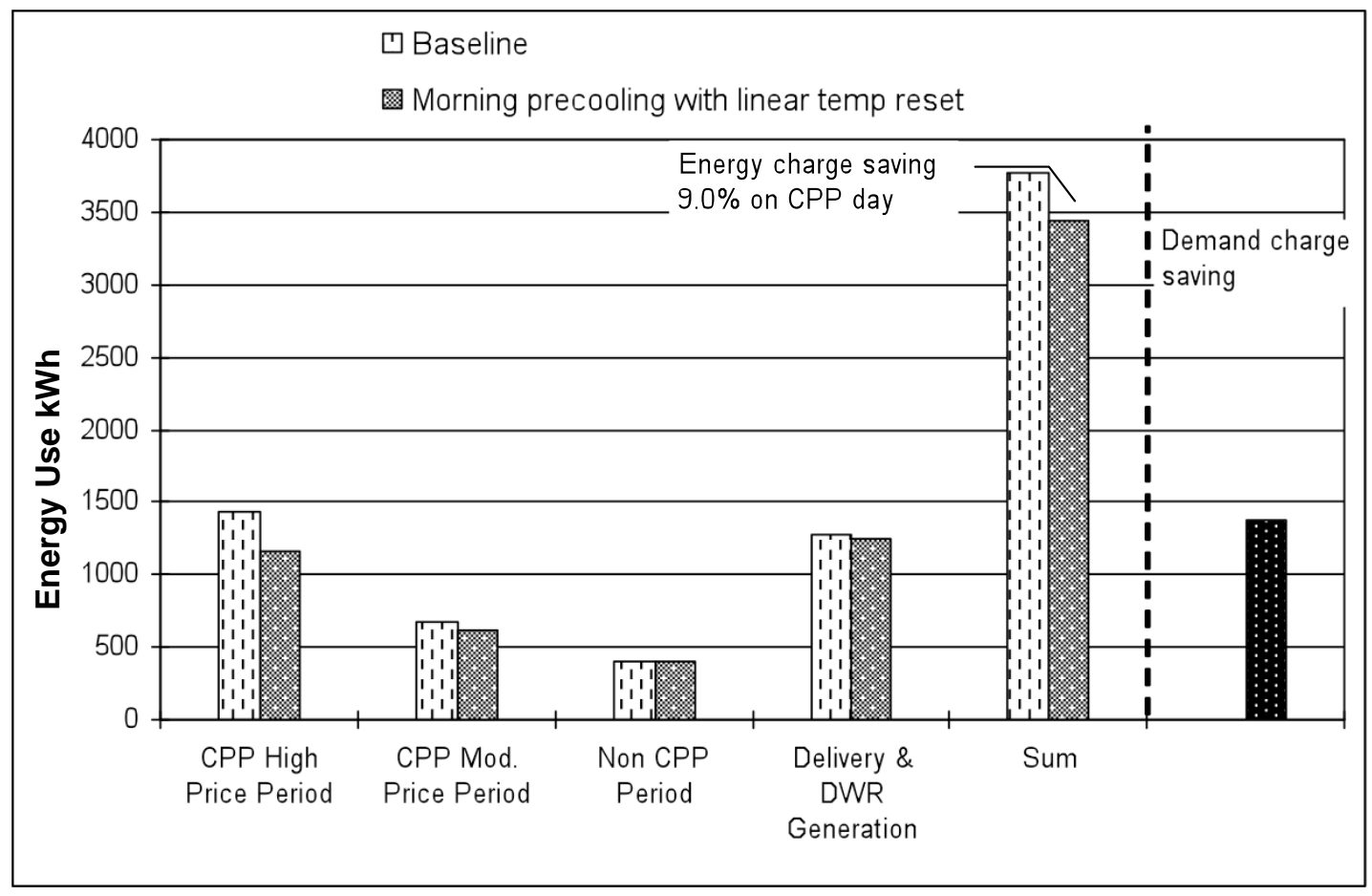

Figure 13. Morning pre-cooling with linear temperature reset, CHCCC Energy cost (\$) 
Morning pre-cooling with exponential temperature reset. Figure 14 and Figure 15 show the comparison of energy usages and cost between the baseline day and pre-cooling test day. It could be seen that "morning pre-cooling with exponential temperature reset" decreased the total energy usage more than "morning pre-cooling with linear temperature reset." However, the demand charge saving was much smaller because of the demand rebound in the high price period. It indicates that it is very important to prevent the demand rebounding in the high price period, or the effect of this pre-cooling strategy would be eliminated for decreasing peak demand.

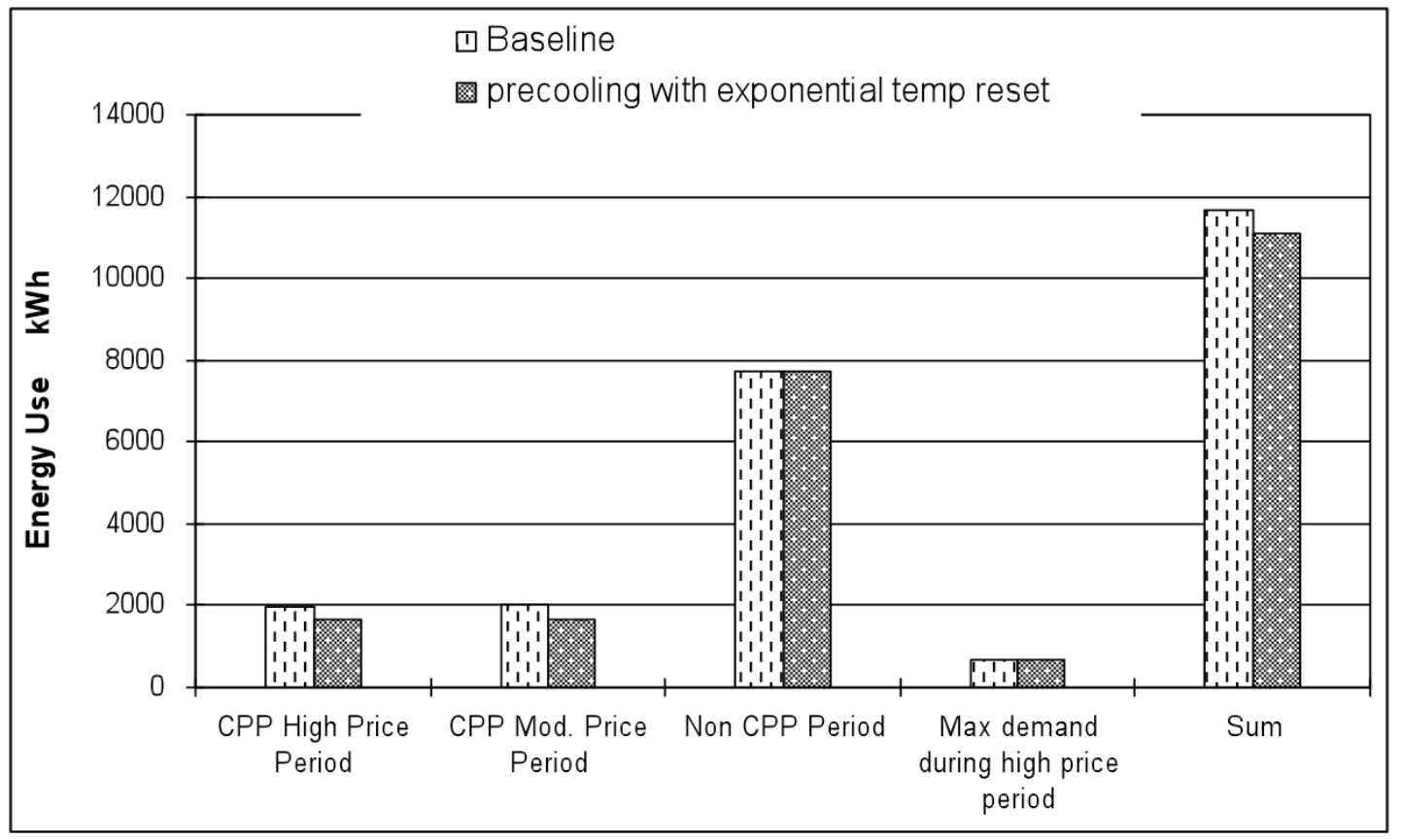

Figure 14. Morning pre-cooling with exponential temperature reset, $\mathrm{CHCCC}$ Energy usage (kWh) 


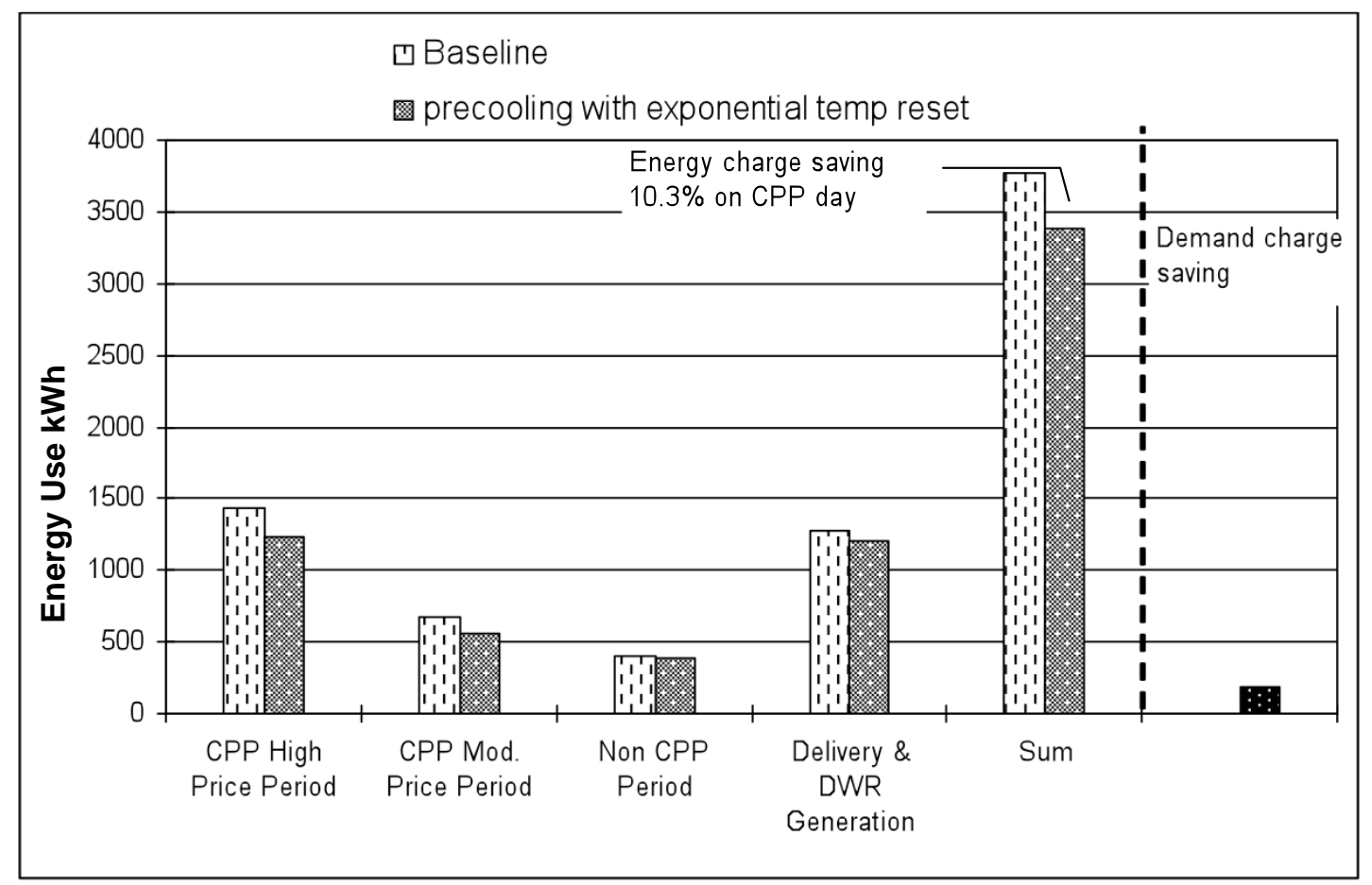

Figure 15. Morning pre-cooling with exponential temperature reset, CHCCC -
Energy cost (\$)

Night and morning pre-cooling with exponential temperature reset. Figure 16 shows the comparison of energy usage while Figure 17 shows the corresponding costs. "Night \& morning pre-cooling with exponential temperature reset" did not reduce much demand in morning and moderate price period; at the same time, this strategy increased the energy consumption at night. The total energy consumption on pre-cooling test day was higher than the baseline day by $400 \mathrm{kWh}$. However, there was slight rebound in high price period for this strategy, therefore, the demand charge saving was around $\$ 1358$, which was much higher than "Morning pre-cooling with exponential temperature reset." 


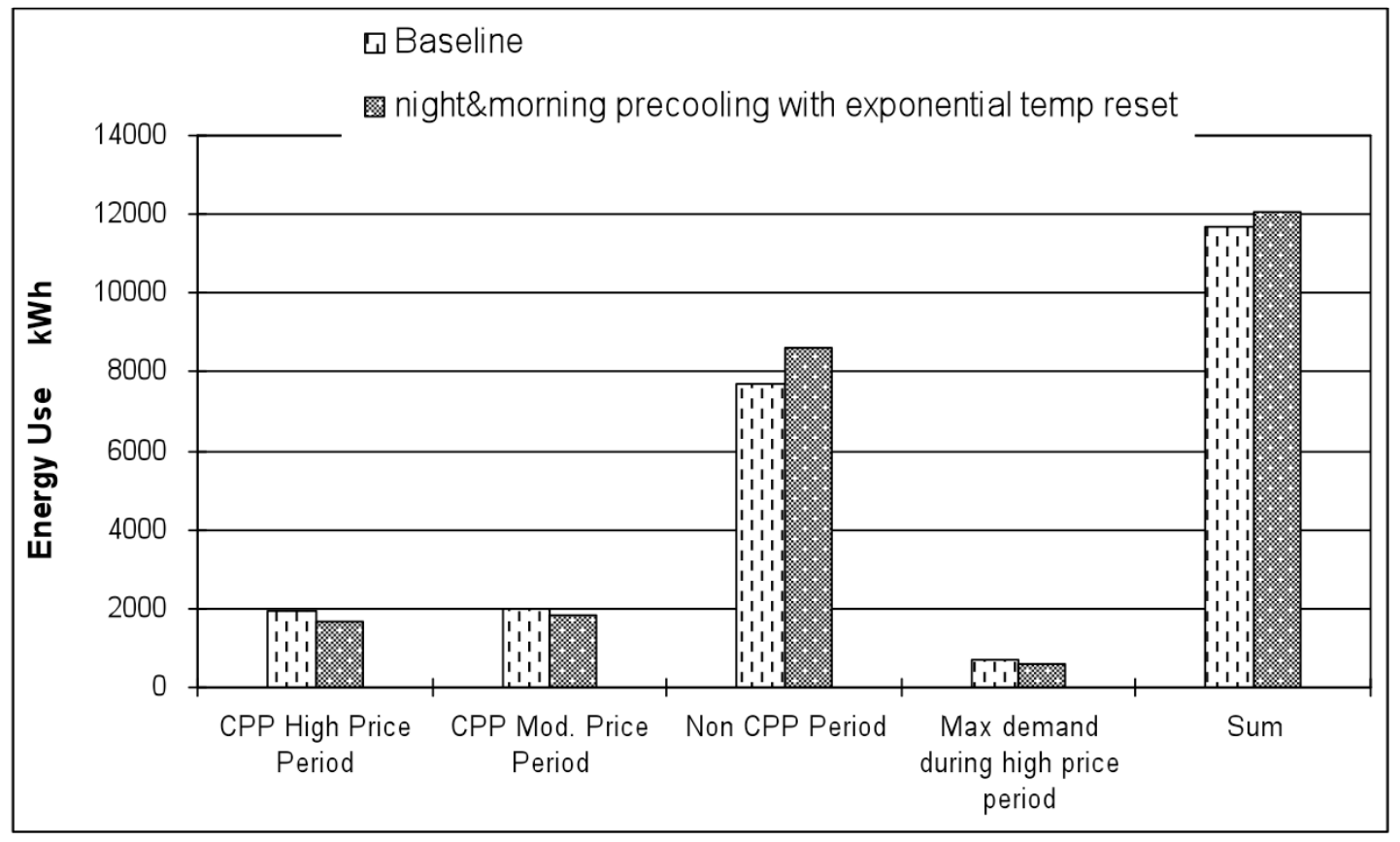

Figure 16. Night and morning pre-cooling with exponential temperature reset, CHCCC - Energy usages (kWh)

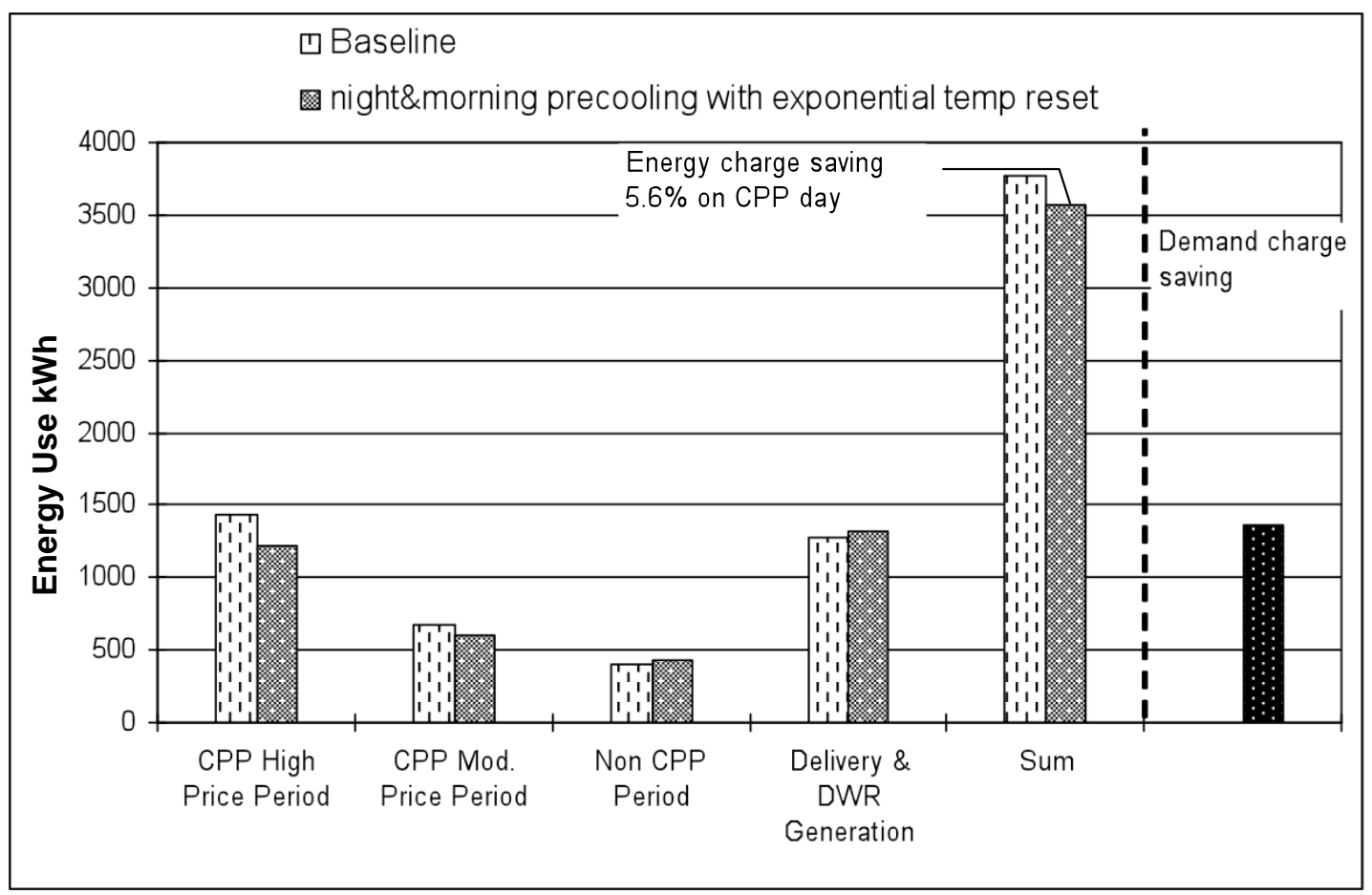

Figure 17. Night and morning pre-cooling with exponential temperature reset, CHCCC - Energy cost (\$) 


\subsubsection{Occupant Comfort}

\section{Participation}

In past years, participation in occupant comfort surveys had been rather low. Since the test was planned around kiosk voting, there was a concern that participation would be lower since users would need to vote during their breaks. Therefore, iPod Shuffles were raffled as an incentive. The users were informed that each vote gave them an entry in the raffle. Although users were able to vote at their desks in the end, it seems that the iPods were an effective incentive in general. In 2007, 844 valid votes were collected, 444 of which occurred on tests days. This was a significant increase from the previous year's results. In comparison, the Oakland site had 414 valid votes, and the Chabot Museum had even less. The e-mail about the survey and the iPod prizes went out on September 14, 2006. This day had the highest response, with 270 votes. Unfortunately because of the unexpected change to cubicle voting on this first day, the survey needed to be reworded. This change could not be implemented until noon, so the large turnout all occurred in the afternoon.

\section{Day Types}

Votes were collected on four test days: two days with pre-cooling and two days with only afternoon setup. Each test day was matched with a baseline day with the closest peak outside temperature and more than 10 votes. Table 9 shows the data associated with the matching days.

Table 9. Test days and their corresponding baseline days

\begin{tabular}{c|ccccc}
\hline Test Days & \# Votes & $\begin{array}{c}\text { Peak } \\
\text { Temp* }\end{array}$ & Test & $\begin{array}{c}\text { Baseline } \\
\text { Days }\end{array}$ & $\begin{array}{c}\text { \# } \\
\text { Votes }\end{array}$ \\
\hline $9 / 14 / 06$ & 270 & 102.0 & $\begin{array}{c}\text { Morn pre-cool } \\
\text { /Exponential Setup }\end{array}$ & $9 / 19 / 06$ & 78 \\
\hline $9 / 20 / 06$ & 52 & 95.0 & No pre-cool/No Setup & $9 / 22 / 06$ & 36 \\
\hline $9 / 21 / 06$ & 89 & 95.0 & $\begin{array}{c}\text { Morn pre-cool } \\
\text { /Exponential Setup }\end{array}$ & $9 / 27 / 06$ & 27 \\
\hline $9 / 26 / 06$ & 33 & 99.0 & No pre-cool/ No Setup & $9 / 19 / 06$ & 78 \\
\hline
\end{tabular}

${ }^{*}$ Measured from a HOBO sensor installed on the roof

\section{Overall Data}

Outdoor temperature was measured by a HOBO on the roof. Figure 18 shows the outdoor temperatures for the duration of the test. 


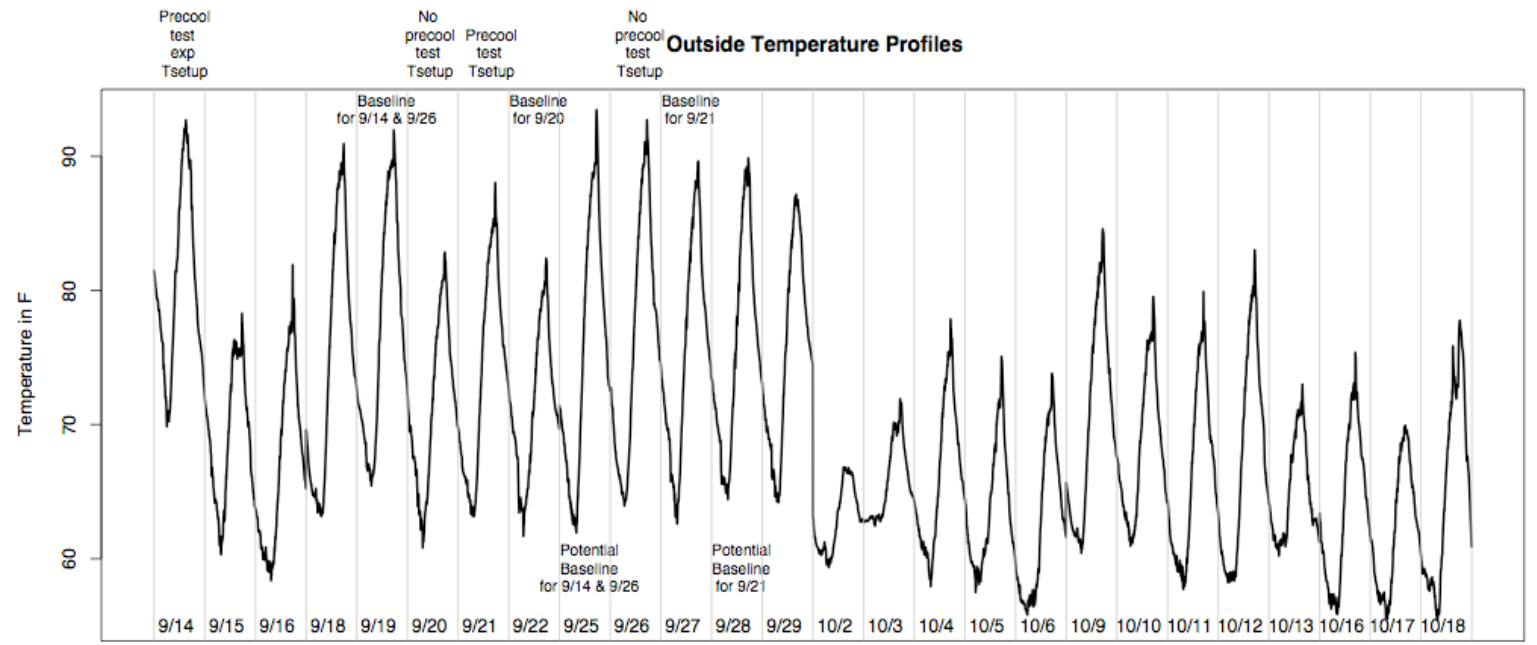

Dates

Figure 18. Outside temperature profiles through the surveyed period

Temperature votes are consolidated in Figure 19. The first e-mail was sent out on September 14, 2006 and several times after that. Users continued to submit votes through the middle of October. Note that some users voted on weekend days such at September 16, 2006. This figure shows both the distribution of votes over the study and the thermal levels on each day.

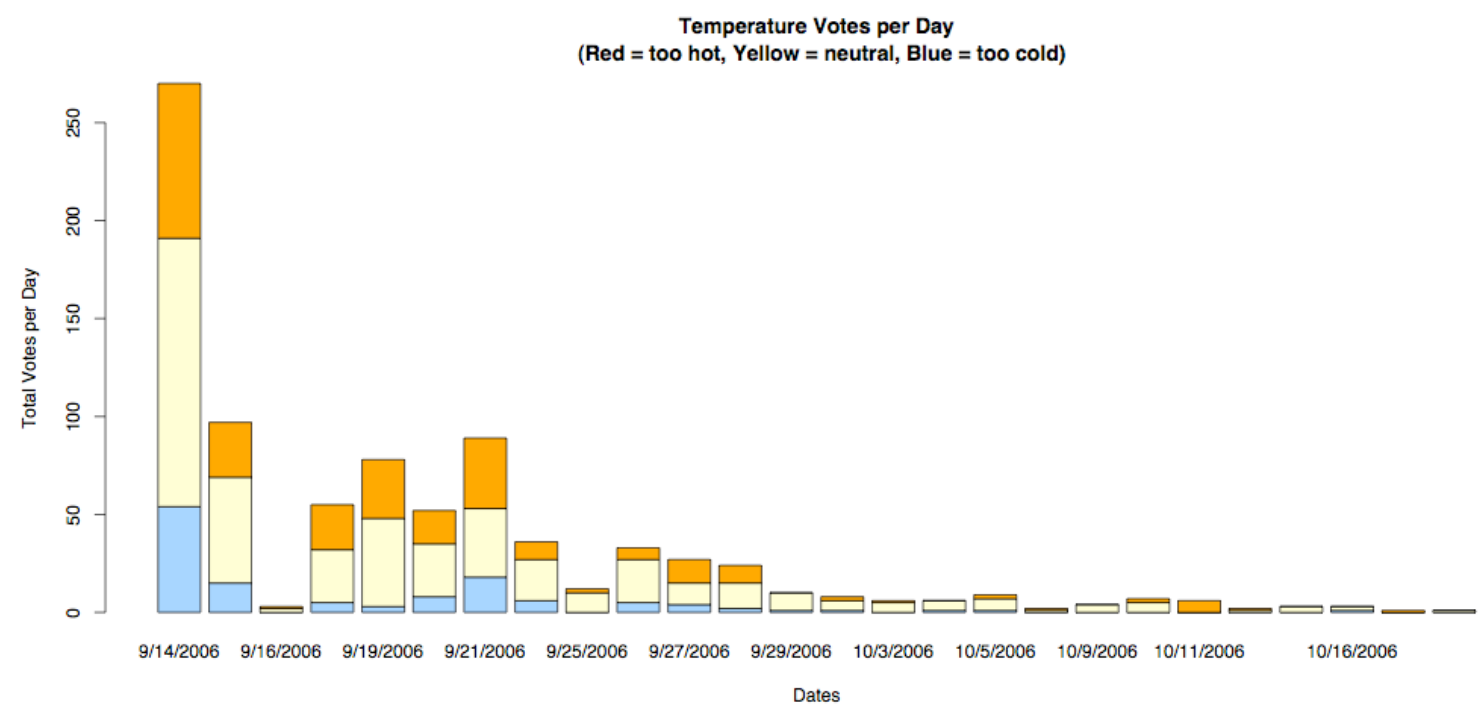

Figure 19. Temperature votes per day

There is often a close relationship between thermal comfort and self-reported productivity. Productivity is an important factor in this study because occupant salaries and benefits generally represent over $90 \%$ of a building's total cost. Management will be unlikely to 
implement demand shifting strategies if there is a concern that the occupants will be negatively affected. Figure 20 shows the relationship between thermal comfort and productivity throughout the study based on the survey data. The y-axis represents the productivity votes ranging from "temperature interferes" to "enhances the user's ability to get their job done." On the x-axis, temperature votes range from "much too cool" to "much too warm." The size of the circle is proportional to the number of votes, so the largest group voted that they were comfortable (neither warm nor cool) and that the temperature has a neutral effect on their ability to get their job done. In general, there is an inverse U-shape to this relationship. As users become cooler or warmer, they tend to feel an increasing negative effect of their productivity. The groups that said the temperature enhances their ability to get their job done usually fell in the neutral thermal zone. However, it is interesting to note that some users said they were much too cool, but that it enhanced their productivity. In contrast, no one who said that they were much too warm said that this enhanced their productivity.

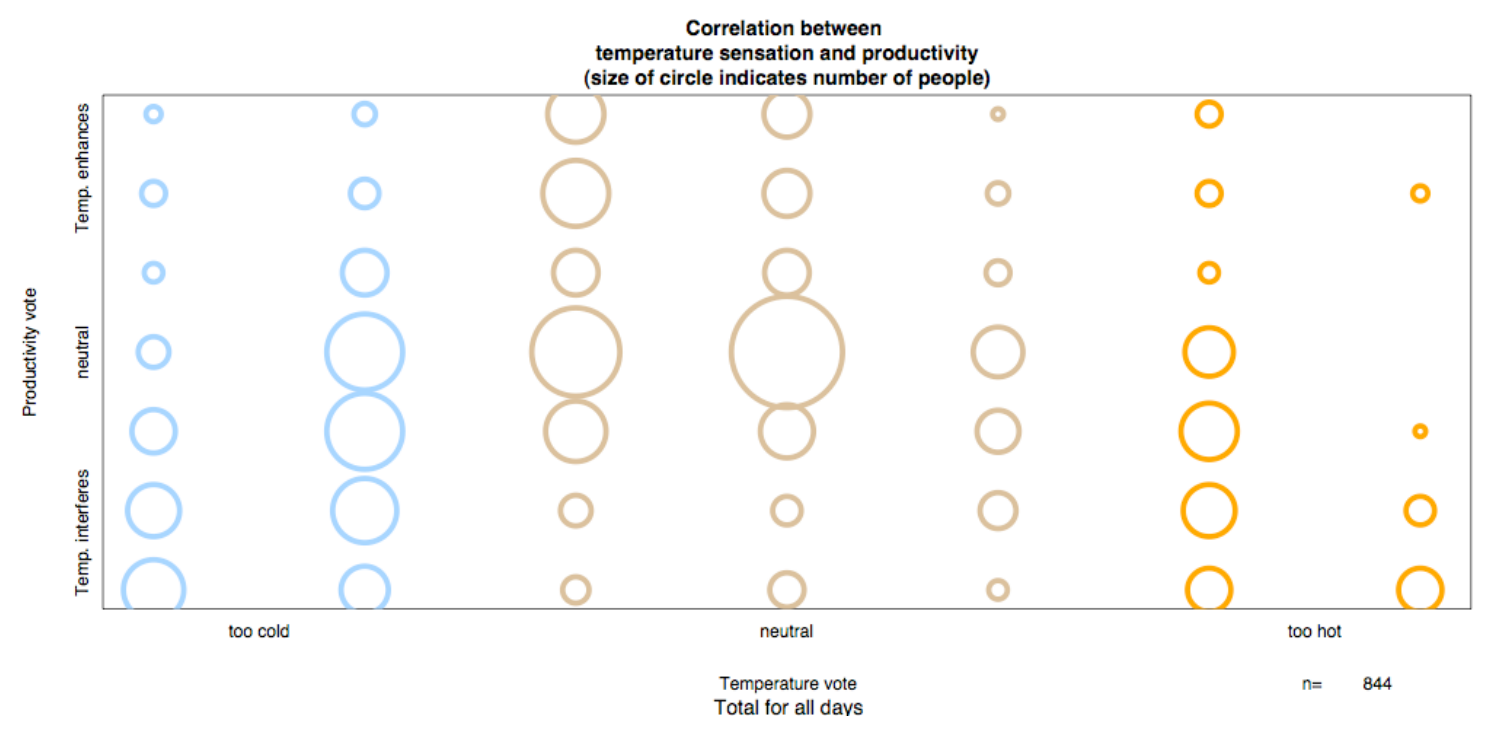

Figure 20. Correlation between temperature sensation and perceived productivity

Each user was matched to the closest $\mathrm{HOBO}$, based on the cubicle number that they entered in the survey. The overall relationship between indoor temperature and sensation is shown in Figure 21. The $y$-axis shows sensation again, ranging from much too cool $(-3)$ to much too warm (3). The red line on the graph is a linear fit to the data. This fit is shifted to the cooler sensation side, indicating that the users tend to vote on the cooler side more often than the warmer side. This corresponds to the user comments. Almost all of the user comments were cold complaints. These complaints were seen on both test days and baseline days. 


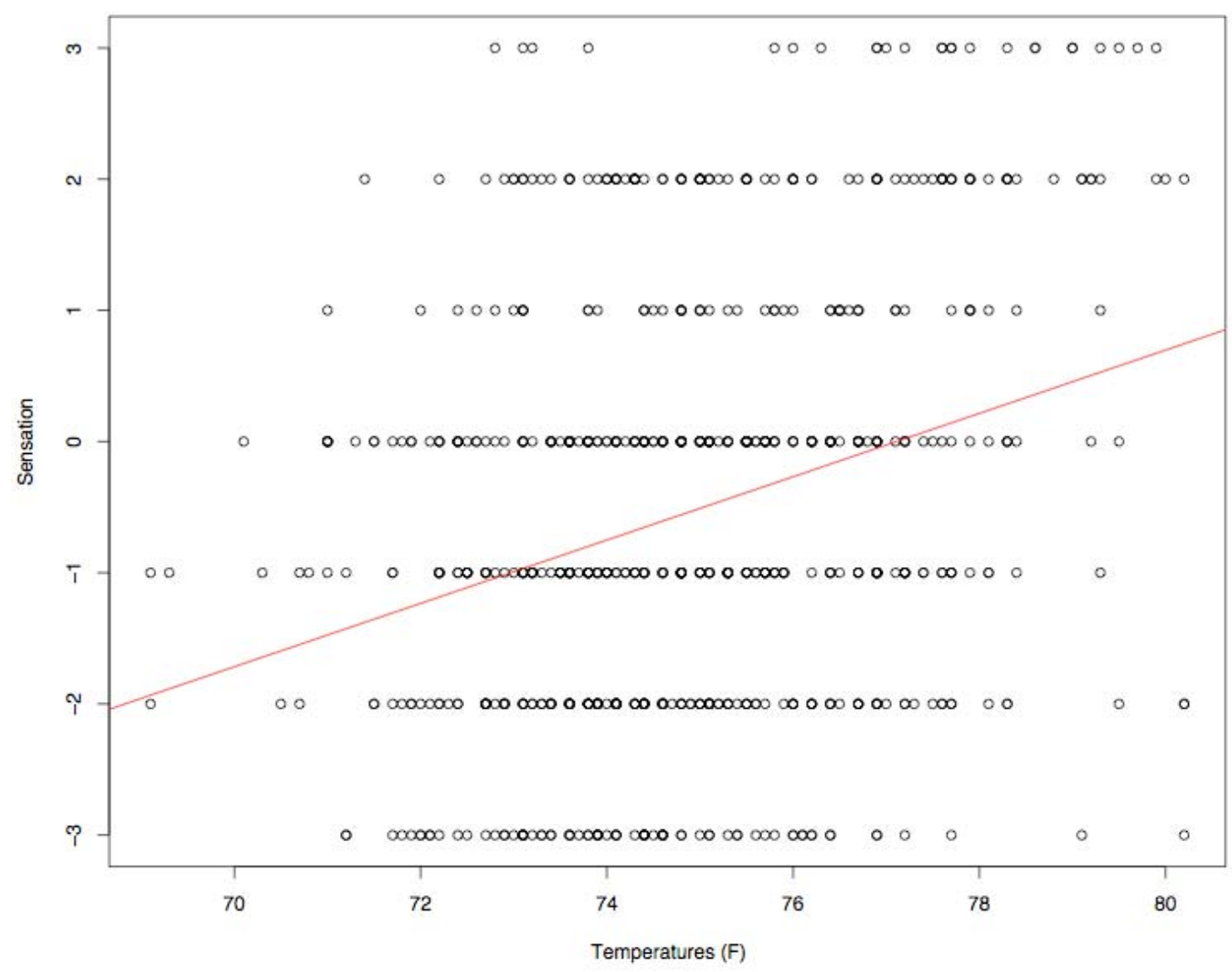

Figure 21. Thermal sensation vs. indoor temperature

\section{No Pre-cooling/Afternoon Setup}

Figure 22 shows the sensation votes for the test day (on the right) and the corresponding baseline day (on the left). The outdoor temperatures are also shown. For the sensation plots the $\mathrm{y}$-axis represents votes where a -3 is much too cool, 0 is comfortable (neither warm nor cool), and 3 is much too warm. These votes are plotted against the workday hours in the $x$-axis so that daily trends can be seen. 

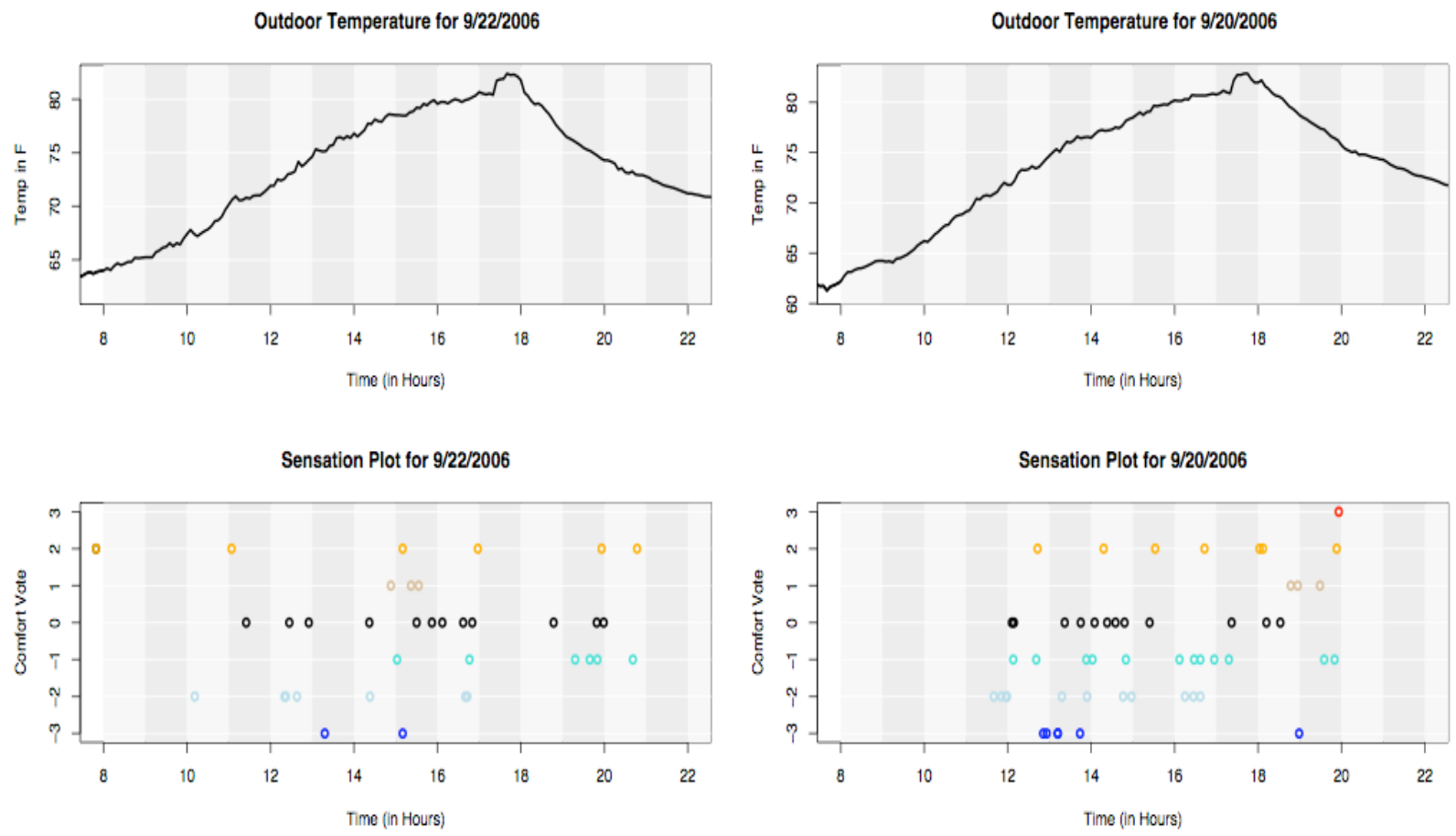

Figure 22. Daily outdoor temperature and sensation votes for 9/22/2006 baseline and $9 / 20 / 2006$ test day

Figure 23 shows the split of sensation votes on the test and baseline day. Much too warm and too warm votes are in orange; comfortably warm, comfortable, and comfortably cool votes are pale yellow; too cool and much too cool votes are in blue. The chart on the left shows the general split of the votes, with the baseline day on the left and the test day on the right. The chart on the right displays the same information, but with each category based on zero. This allows a quicker comparison between percentage changes in the categories. Both charts show the number of votes at the bottom of each bar. 

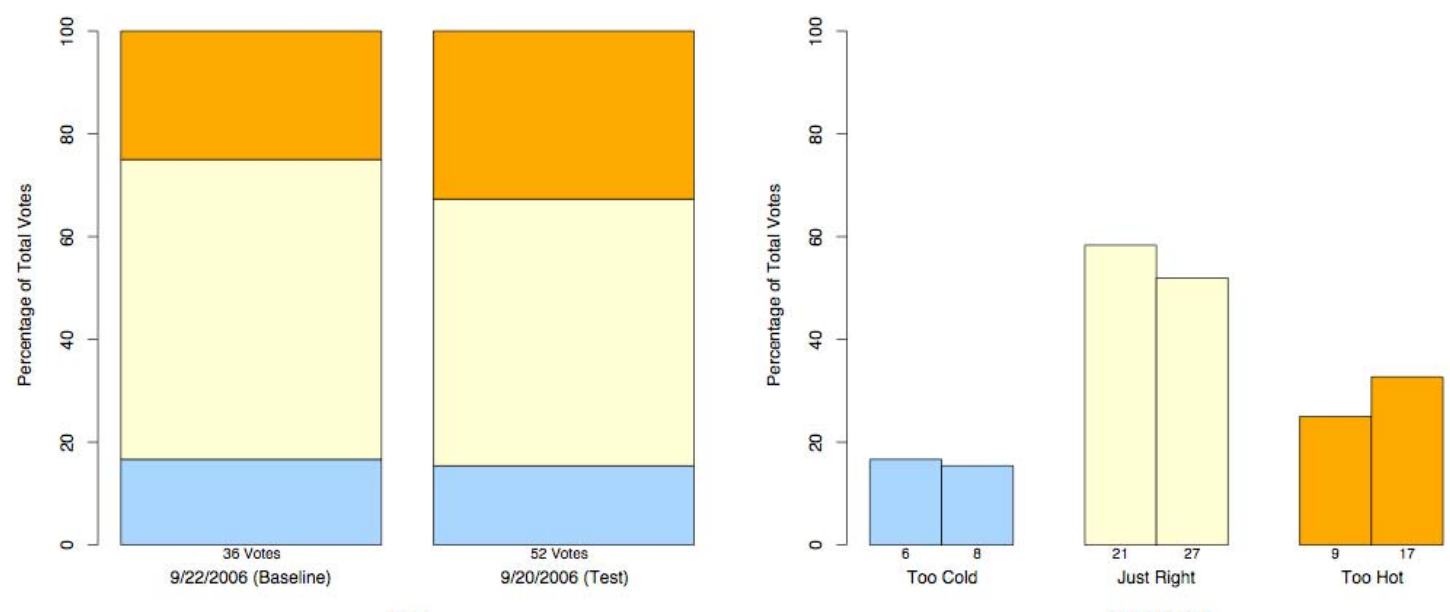

DAY

SENSATION

Figure 23. Breakdown of sensation votes for 9/22/2006 baseline and 9/20/2006 test

Figure 24 shows the breakdown of self-reported productivity for the test and baseline day. Here, the orange represents people who said that the temperature enhances their ability to get their work done. The pale yellow is the neutral group and blue is the group who said that the temperature interferes with their ability to get their work done. While increases in the "enhance" and "neutral" groups are good, the main concern of this study is that the "interferes" category does not increase on a test day.

Following the same pattern, Figures 25 to 33 show the survey results for the other test days.
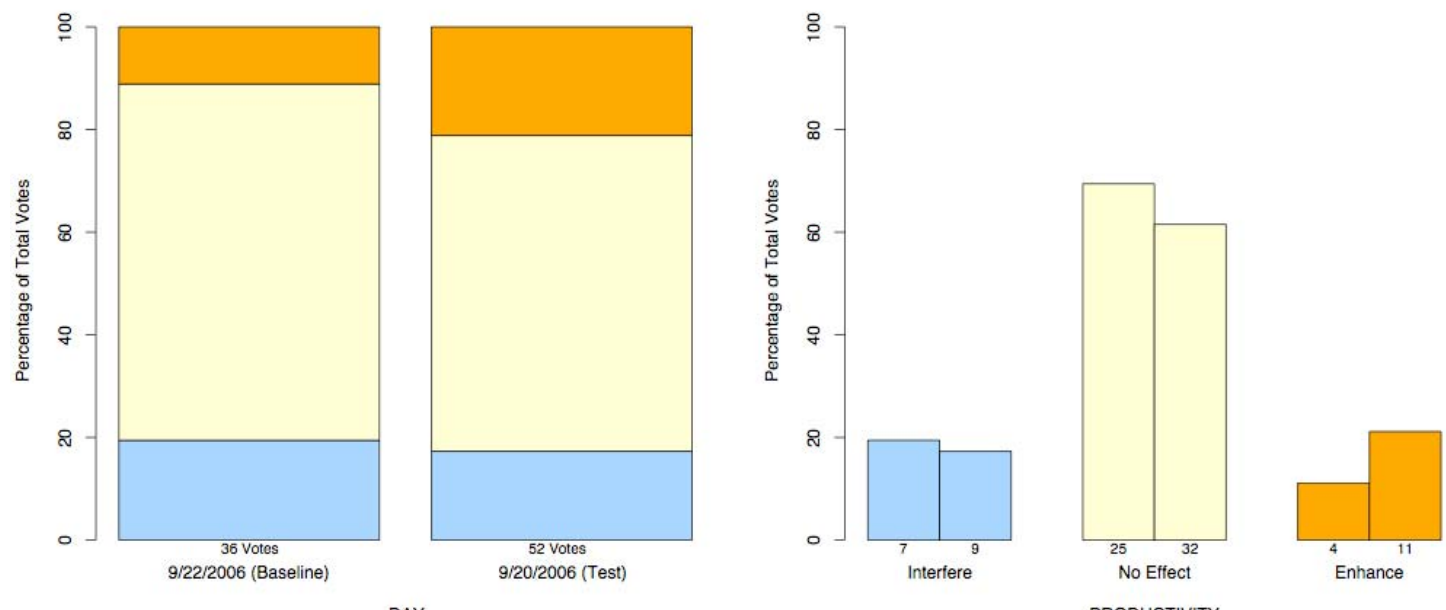

DAY

PRODUCTIVITY

Figure 24. Breakdown of productivity votes for 9/22/2006 baseline and 9/20/2006 test 

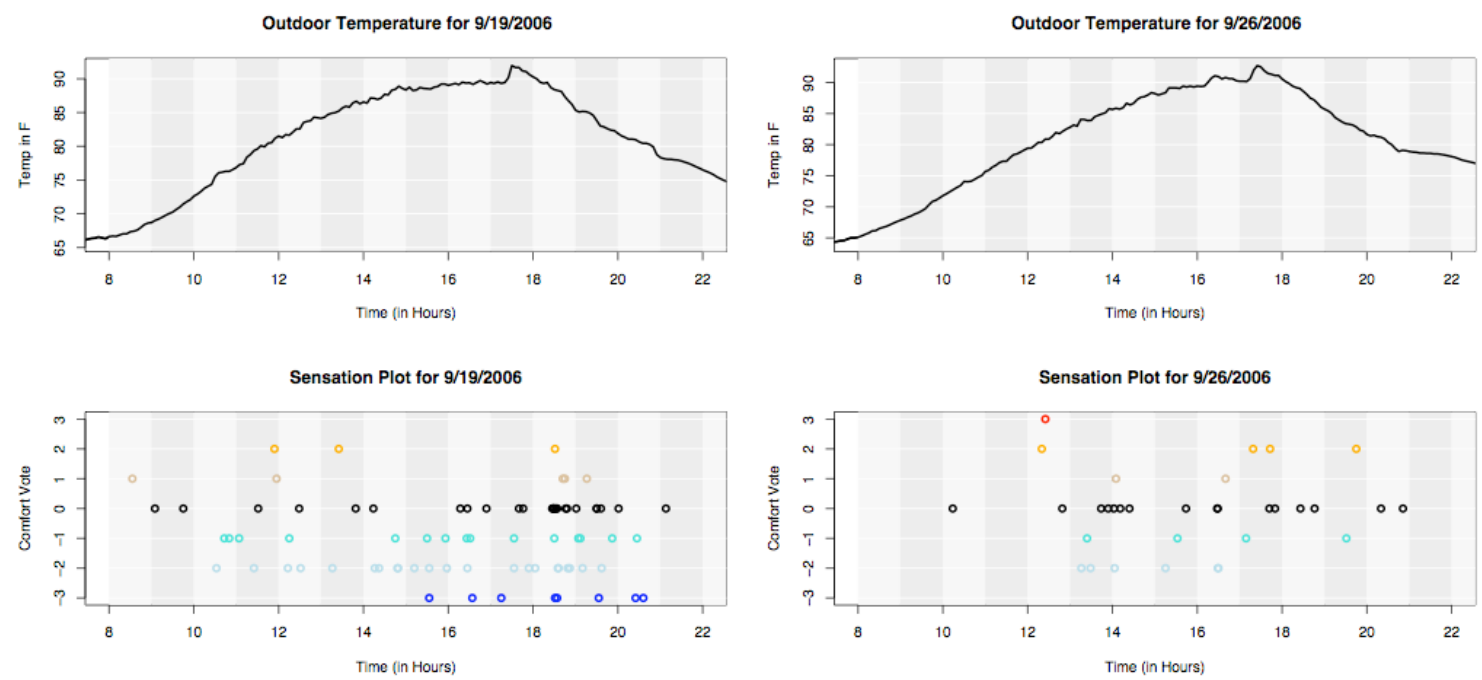

Figure 25. Daily outdoor temperature and sensation votes for 9/19/2006 baseline and 9/26/2006 test day
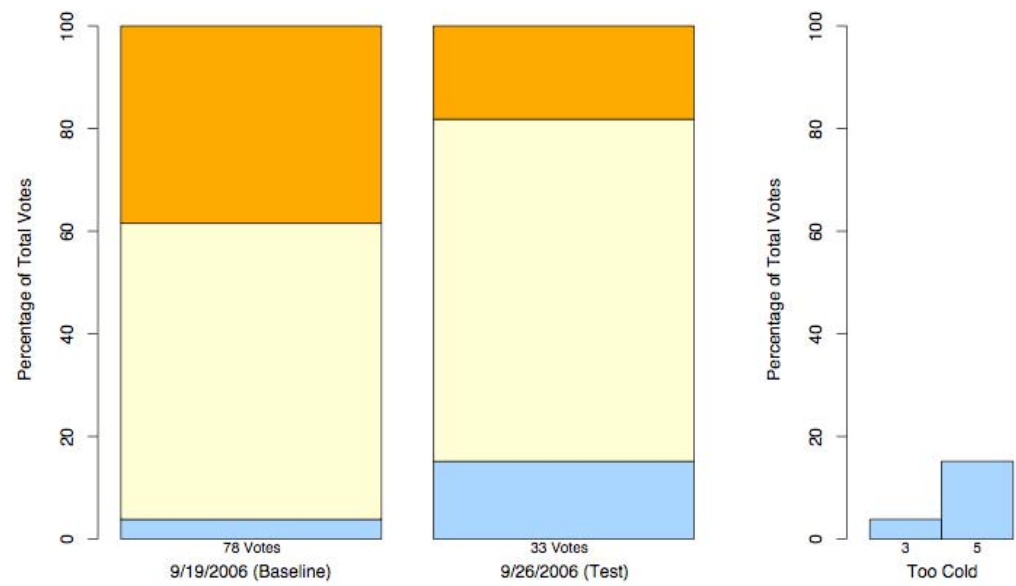

DAY
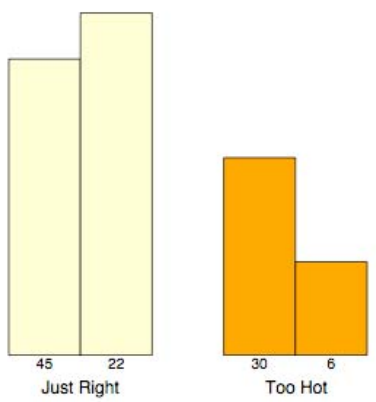

SENSATION

Figure 26. Breakdown of sensation votes for 9/19/2006 baseline and 9/26/2006 test 

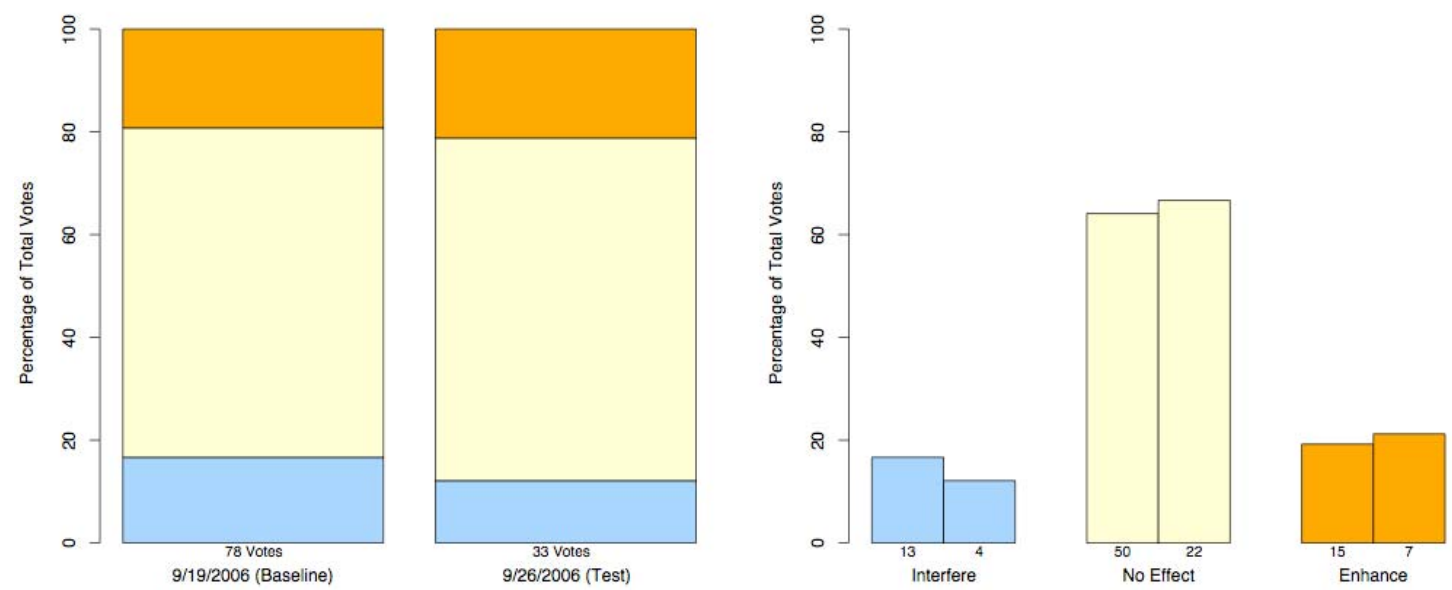

DAY

PRODUCTIVITY

Figure 27. Breakdown of productivity votes for 9/19/2006 baseline and 9/26/2006 test

Morning pre-cooling - September 19, 2006
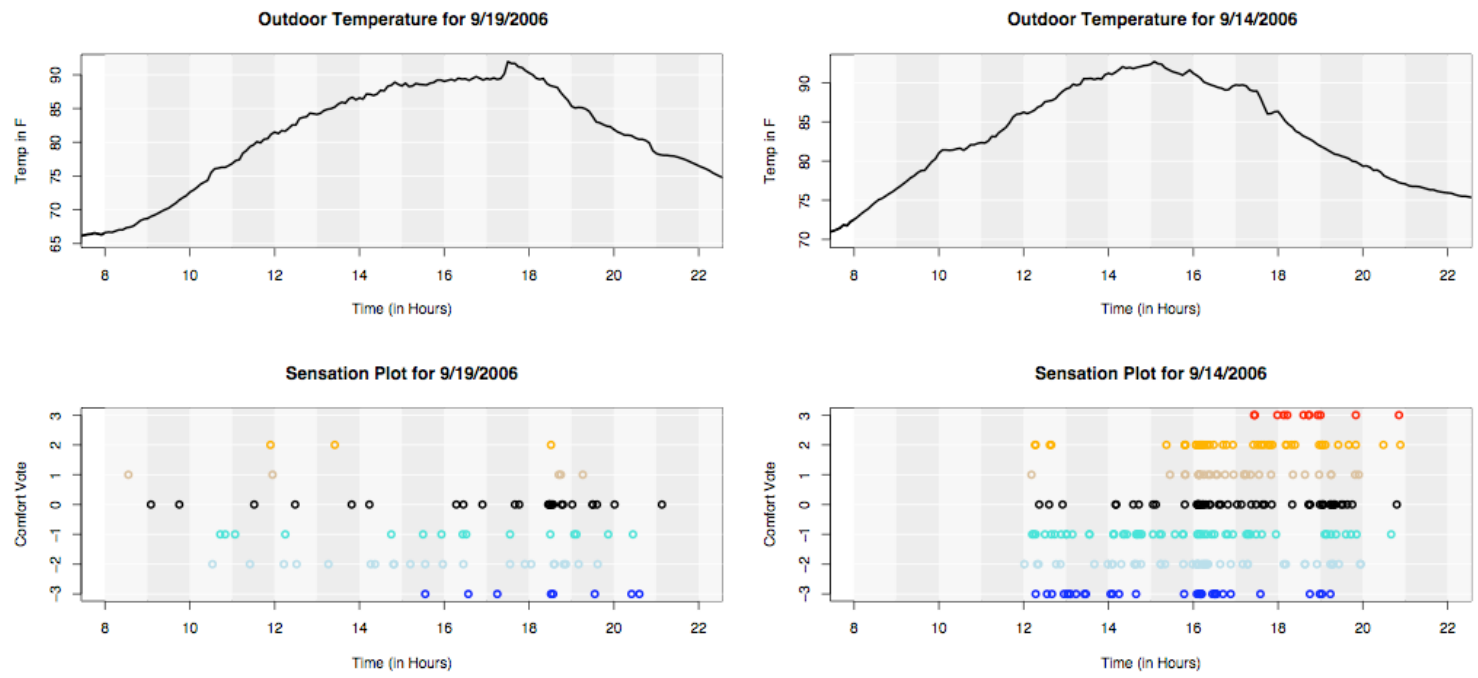

Figure 28. Daily outdoor temperature and sensation votes for 9/19/2006 baseline and 9/14/2006 test day 

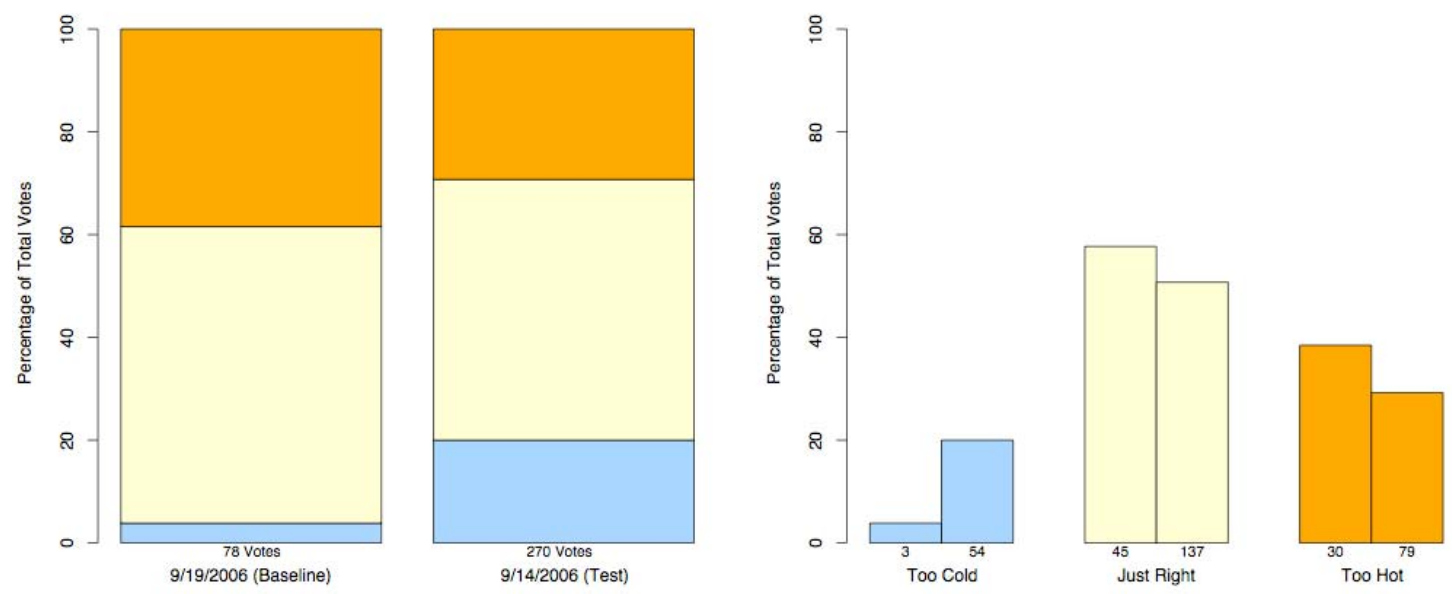

DAY

SENSATION

Figure 29. Breakdown of sensation votes for 9/16/2006 baseline and 9/14/2006 test
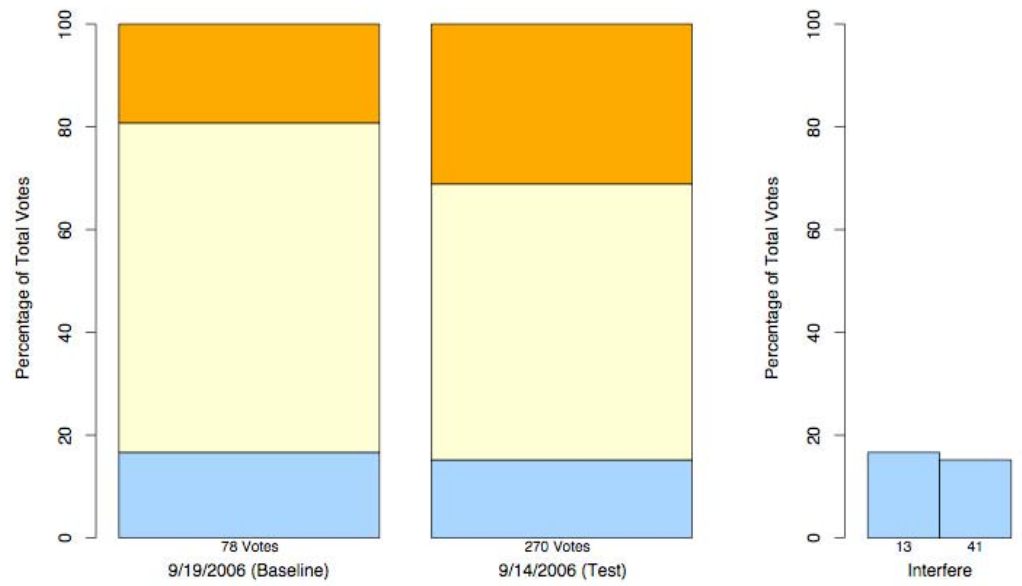

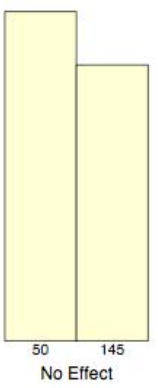

PRODUCTIVITY
DAY

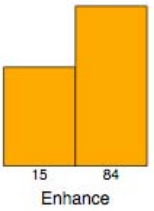

Figure 30. Breakdown of productivity votes for 9/19/2006 baseline and 9/14/2006 test 
Morning pre-cooling - September 27, 2009

Outdoor Temperature for 9/27/2006

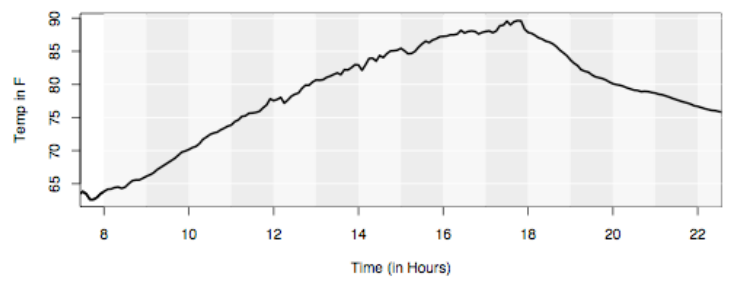

Sensation Plot for 9/27/200

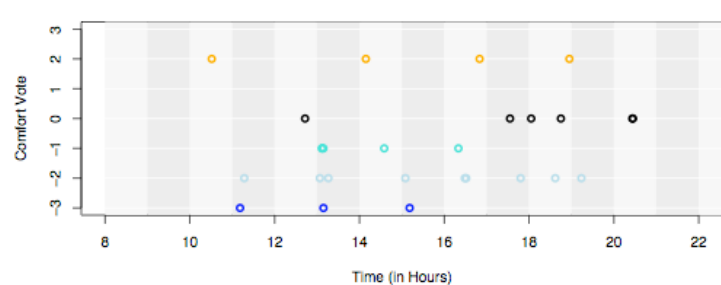

Outdoor Temperature for 9/21/2006

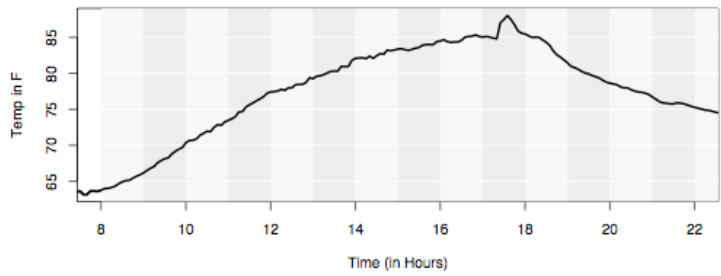

Sensation Plot for 9/21/2006

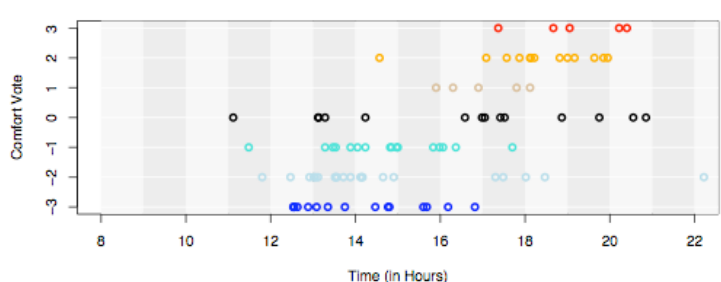

Figure 31. Daily outdoor temperature and sensation votes for $9 / 27 / 2006$ baseline and 9/22/2006 test day
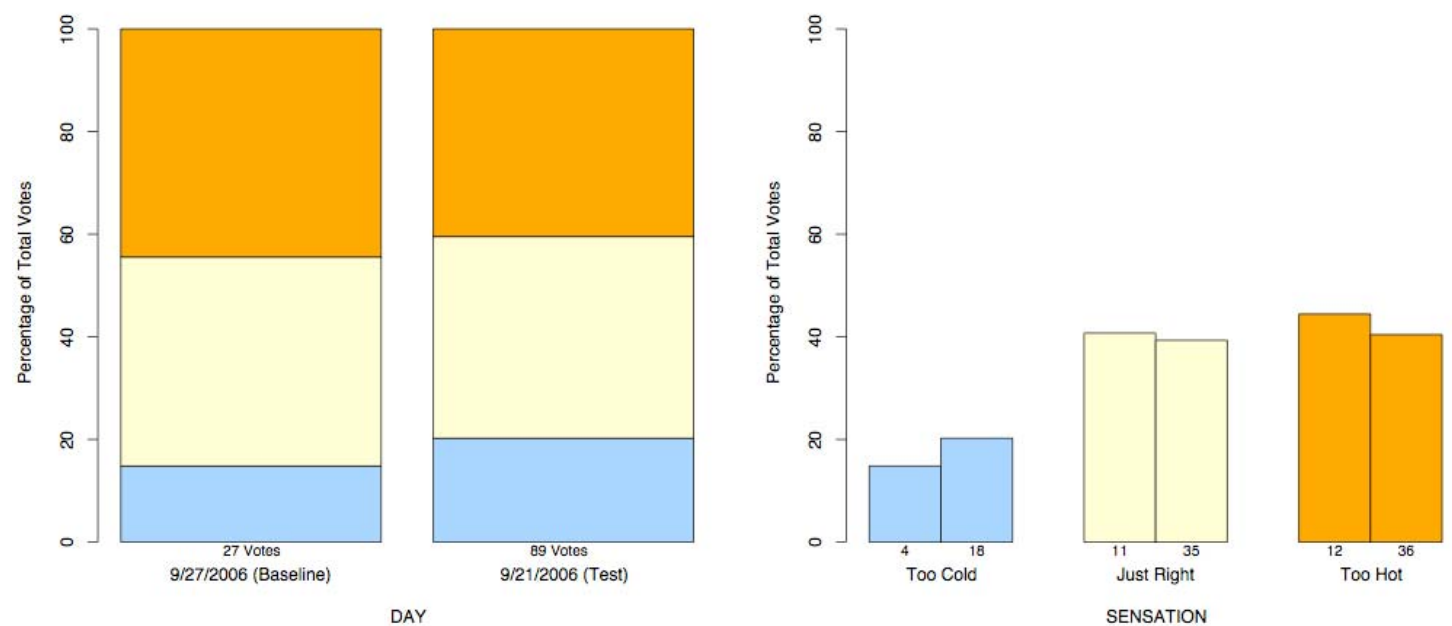

DAY

Figure 32. Breakdown of sensation votes for 9/27/2006 baseline and 9/22/2006 test 

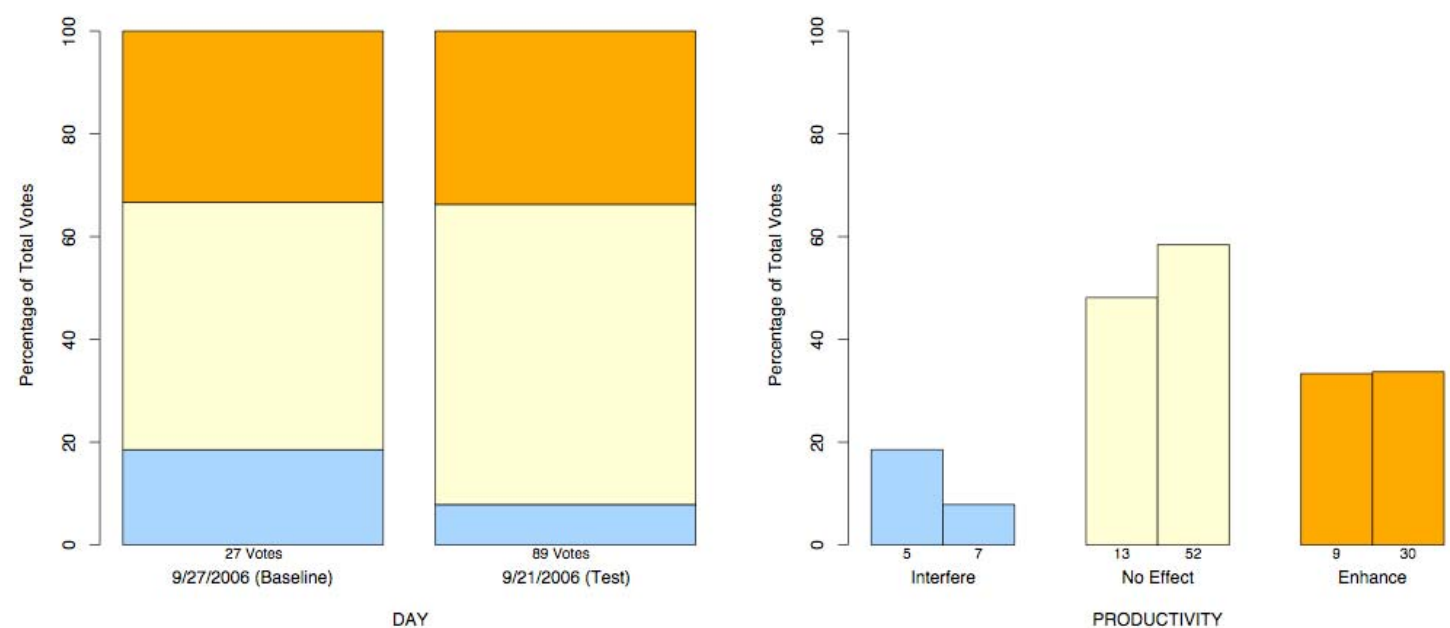

PRODUCTIVITY

Figure 33. Breakdown of productivity votes for 9/27/2006 baseline and 9/22/2006 test

\subsection{Test Site II - Typical Office Building in San Bernardino, TCCSB}

\subsubsection{Test Site Description}

The TCCSB test site, in San Bernadino, California, is a 104,500 $\mathrm{ft}^{2}$ three story curtain wall office building with carpeted floor. The windows are single paned with tinted glass. The building has no external shading and uses internal blinds to manually control glare.

The building has three DX air-handling rooftop units that condition outside air and provide air circulation. Each unit serves one floor space. The distribution systems are single-duct VAV systems. In total, the system has roughly 150 zones. An AutomatedLogic Webctrl 3.0 DDC control system provides indoor comfort control.

The building's operation is typical of that of many offices, except the early start in the morning. The program has an optimal start and will decide when to start the HVAC system automatically, depending on the outdoor and indoor temperatures in early mornings. The majority of employees come to work after 8 a.m. The female-to-male occupant ratio in the building is about 40:60. In normal operation, the HVAC system starts at $5 \mathrm{a} . \mathrm{m}$. and pre-heats or pre-cools the building until 8 a.m., depending on the outside weather conditions. The building does not have dedicated operators. The mechanical engineers of the Center are responsible for the daily building operation and the maintenance. The team has worked at the building for a while and was quite confident and familiar with its mechanical system.

\subsubsection{Test Strategies}

The pre-cooling and zone temperature reset strategies tested were the same as that of the CHCCC building. The strategies are listed in Table 10. The building was normally operated at a constant setpoint of $74^{\circ} \mathrm{F}$ throughout the startup and occupied hours. After 6 p.m., the system was shut off and zone temperatures started to float. Under normal operation, the setpoints in individual zones ranged from $72^{\circ} \mathrm{F}$ to $76^{\circ} \mathrm{F}$, with an average value of about $74^{\circ} \mathrm{F}$. 
The first strategy was called no pre-cooling + zonal reset. There was no pre-cooling in the early morning. The zone temperature setpoints were increased by $1^{\circ} \mathrm{F}$ at $1: 00 \mathrm{p} \cdot \mathrm{m}$ and by another $1^{\circ}$ at 2:00 p.m.

The second strategy tested was termed pre-cooling + linear zonal reset. The HVAC system was turned on at 5 a.m. to pre-cool the building to $72^{\circ} \mathrm{F}$. This is $2^{\circ} \mathrm{F}$ lower than this time period's normal operating zone setpoint. At 12 p.m., the zone temperature setpoint was raised $1^{\circ} \mathrm{F}$ to $73^{\circ} \mathrm{F}$. One hour later, at 1 p.m., the room temperature setpoint was raised by $1^{\circ} \mathrm{F}$ to $74^{\circ} \mathrm{F}$. From 12 p.m. to 6 p.m. (the CPP moderate and high price periods), the setpoints were raised linearly to $78^{\circ} \mathrm{F}$. The setpoints were kept at $78^{\circ} \mathrm{F}$ until the system was shut off for the night.

The third strategy was termed pre-cooling + exponential reset. The temperatures were raised up exponentially rather than linearly in the afternoon period. The temperature raise was more aggressive at the beginning and tailed off at the end.

The temperature setpoint offset is summarized in the table below.

Table 10. Demand response temperature setpoint offset $\left({ }^{\circ} \mathrm{F}\right)$

\begin{tabular}{c|ccccccccccccccc}
\hline Type & \multicolumn{10}{c}{ Time of the day (military time) } \\
& $\mathbf{4}$ & $\mathbf{5}$ & $\mathbf{6}$ & $\mathbf{7}$ & $\mathbf{8}$ & $\mathbf{9}$ & $\mathbf{1 0}$ & $\mathbf{1 1}$ & $\mathbf{1 2}$ & $\mathbf{1 3}$ & $\mathbf{1 4}$ & $\mathbf{1 5}$ & $\mathbf{1 6}$ & $\mathbf{1 7}$ & $\mathbf{1 8}$ \\
\hline $\begin{array}{c}\text { No-precooling, } \\
\text { zonal reset }\end{array}$ & off & 0 & 0 & 0 & 0 & 0 & 0 & 0 & 0 & 1 & 2 & 2 & 2 & 2 & off \\
\hline $\begin{array}{c}\text { Pre-cooling, } \\
\text { linear reset }\end{array}$ & off & -2 & -2 & -2 & -2 & -2 & -2 & -2 & -1 & 0 & 1 & 2 & 3 & 4 & off \\
\hline $\begin{array}{c}\text { Pre-cooling, } \\
\text { exp reset }\end{array}$ & off & -2 & -2 & -2 & -2 & -2 & -2 & -2 & 2 & 2 & 2 & 3 & 3 & 3 & off \\
\hline
\end{tabular}

\subsubsection{Monitoring}

The building has a whole building power meter and no other sub-meters. There is a weather station measuring outside air temperature and humidity. The control system has a dedicated outside air temperature sensor to measure the temperature. The HVAC performance data were recorded using the building control system. Roughly 50 data points were collected at 15 -minute intervals. Three power meters were installed on the rooftop units to determine the impact of control strategies on the cooling load and cooling power. Temperatures in the zones were recorded through the building control system. These temperature data were compared with indoor air temperature measurements from devices installed by CBE in both the office and exhibition areas.

\subsubsection{Confirm the Baseline}

\section{Method}

The baseline selection was similar to that used at the CHCCC test site. Baseline days for each test day were selected based on similarity of outside air temperature. For this field test, the research team not only tried to match the peak outside air temperature but also tried to minimize the hourly temperature difference between the baseline days and the test days. 
The outside temperature data of these days were analyzed starting August 13 to September 30, 2007. In this period the peak outside air temperature was between $70^{\circ} \mathrm{F}$ and $115^{\circ} \mathrm{F}$. This time period covered different weather conditions that are characterized as Cool Days, Hot Days, and Extreme Hot Days.

Seven tests in total were conducted, as listed in Table 11. Each test lasted for one day. There were five pre-cooling and zonal reset tests: three of these were on Hot Days, one was on an Extreme Hot Day, and one was on a Cool Day. There was one no-pre-cooling + zonal reset test, one pre-cooling + linear zonal reset test, and three pre-cooling + exponential reset tests. The remaining two days were baseline survey days on which no intervention occurred but with the system starting earlier than on normal days. Table 11 shows the dates, strategies, and weather conditions for the tests.

Table 11. Test schedule and scenarios

\begin{tabular}{c|ccc}
\hline Number & Date & Strategies & $\begin{array}{c}\text { Peak Outside Air } \\
\text { temp }\end{array}$ \\
\hline 1 & $8 / 14 / 2007$ & no-pre-cooling + zonal reset & $104^{\circ} \mathrm{F}$ \\
2 & $8 / 15 / 2007$ & pre-cooling + linear zonal reset & $104^{\circ} \mathrm{F}$ \\
3 & $8 / 16 / 2007$ & pre-cooling + exponential zonal reset & $104^{\circ} \mathrm{F}$ \\
4 & $8 / 17 / 2007$ & Baseline, no comfort survey & $101^{\circ} \mathrm{F}$ \\
5 & $8 / 28 / 2007$ & Baseline, comfort survey & $103^{\circ} \mathrm{F}$ \\
6 & $8 / 29 / 2007$ & pre-cooling + exponential zonal reset & $111^{\circ} \mathrm{F}$ \\
7 & $9 / 18 / 2007$ & pre-cooling + exponential zonal reset & $84^{\circ} \mathrm{F}$ \\
\hline
\end{tabular}

Note: Peak outside air temperature is measured from the DDC system

The test days were divided into three different weather conditions periods: "Hot Days," when the peak outside temperatures were about $104^{\circ} \mathrm{F}$; "Extreme Hot Days," with the peak outside temperatures at $111^{\circ} \mathrm{F}$; and "Cool Days," with peak temperatures at about $84^{\circ} \mathrm{F}$.

The peak outside temperature and AVHOAT for each test day and possible baseline days are shown in Table 12 (Hot Days), Table 13 (Extreme Hot Days), and Table 14 (Cool Days).

Table 12. Hot Days (8/14/07, 8/15/07, 8/16/07)

\begin{tabular}{c|c|c|c|c|c|c}
\hline & Test day & \multicolumn{5}{|c}{ Baseline days } \\
\hline Date & $8 / 15 / 07$ & $8 / 17 / 07$ & $8 / 20 / 07$ & $8 / 21 / 07$ & $8 / 28 / 07$ & $9 / 04 / 07$ \\
\hline $\begin{array}{c}\text { Peak Outside Air } \\
\text { Temperature }\left({ }^{\circ} \mathrm{F}\right)\end{array}$ & 103.5 & 100.6 & 102.1 & 103.2 & 102.6 & 103.8 \\
\hline AVHOAT & - & 4.63 & 13.58 & 23.85 & 9.78 & 13.14 \\
\hline
\end{tabular}




\begin{tabular}{c|c|c|c|c|c|c}
\hline & Test day & \multicolumn{6}{|c}{ Baseline days } \\
\hline Date & $8 / 16 / 07$ & $8 / 17 / 07$ & $8 / 20 / 07$ & $8 / 21 / 07$ & $8 / 28 / 07$ & $9 / 04 / 07$ \\
\hline $\begin{array}{c}\text { Peak Outside Air } \\
\text { Temperature }\left({ }^{\circ} \mathrm{F}\right)\end{array}$ & 103.5 & 100.6 & 102.1 & 103.2 & 102.6 & 103.8 \\
\hline AVHOAT & - & 4.71 & 12.44 & 22.13 & 9.01 & 13.07 \\
\hline
\end{tabular}

Table 13. Extreme Hot Days (8/29/07)

\begin{tabular}{c|c|c|c|c|c|c}
\hline & Test day & \multicolumn{5}{|c}{ Baseline days } \\
\hline Date & $8 / 29 / 07^{4}$ & $8 / 28 / 07$ & $8 / 30 / 07$ & $8 / 31 / 07$ & $9 / 03 / 07$ & $9 / 04 / 07$ \\
\hline $\begin{array}{c}\text { Peak Outside Air } \\
\text { Temperature }\left({ }^{\circ} \mathrm{F}\right)\end{array}$ & 110.7 & 102.6 & 109.1 & 108.6 & 111.1 & 103.8 \\
\hline AVHOAT & - & 23.26 & 43.53 & 28.40 & 54.59 & 37.75 \\
\hline
\end{tabular}

Table 14. Cool Days (9/18/07)

\begin{tabular}{c|c|c|c|c|c|c}
\hline & Test day & \multicolumn{6}{|c}{ Baseline days } \\
\hline Date & $9 / 18 / 07$ & $9 / 06 / 07$ & $9 / 17 / 07$ & $9 / 19 / 07$ & $9 / 21 / 07$ & $9 / 24 / 07$ \\
\hline $\begin{array}{c}\text { Peak Outside Air } \\
\text { Temperature }\left({ }^{\circ} \mathrm{F}\right)\end{array}$ & 83.8 & 89.9 & 78.8 & 71.3 & 82.2 & 88.0 \\
\hline AVHOAT & - & 250.1 & 4.41 & 16.84 & 35.96 & 19.00 \\
\hline
\end{tabular}

Notes:

The outside air temperature, measured from the DDC system from 1 a.m. to about 12 p.m. on $8 / 14 / 07$ was missing. All the baseline days were weekdays: weekend days and holidays are not included in the samples. On the test day, the AHU serving the third floor was tripped at approximately 4 p.m.

Table 12, Table 13, and Table 14 show comparisons of the peak and hourly outside air temperature between the test and baseline days. The calculation confirms that August 17, 2007 is the best baseline day for the "Hot Days" weather condition (August 14-16, 2007). According to Table 13 and Table 14, similarly the research team confirmed August 28, 2007 as the baseline for "Extreme Hot Days" weather condition (August 29, 2007) and September 17, 2007 as the baseline day for the "Cool Days" weather condition (September 18, 2007). Though the peak outside air temperature of September 17, 2007 was about $5^{\circ} \mathrm{F}$ lower than that of September 18, 2007, it has the closest weather condition to that of September 18, 2007.

\subsubsection{Results}

\subsubsection{Total Energy Use}

\section{Hot Weather Conditions}

No pre-cooling + zonal reset. Figure 34 shows the demand $(\mathrm{kW})$ measurement of the whole building for the "baseline" and "no pre-cooling with zonal reset" on August 14, 2007. The HVAC system started roughly at 3 a.m. on the baseline day (August 17, 2007), which was earlier than the test days by two hours. Starting at 1 p.m., the electrical demand was reduced by about $30 \mathrm{~kW}$ on average during the peak period. However, the average outside temperatures from 12 p.m. to 6 p.m. on the test day were higher than that of the baseline day by $3^{\circ} \mathrm{F}$, and the peak 
outside temperature was higher than that of the baseline day by $6^{\circ} \mathrm{F}$. The savings were not so obvious compared with the baseline, though the demand was reduced dramatically during the zonal reset period. These zonal reset strategy savings would have been more obvious if the test day period's temperature profile had been more similar to that of the baseline day.

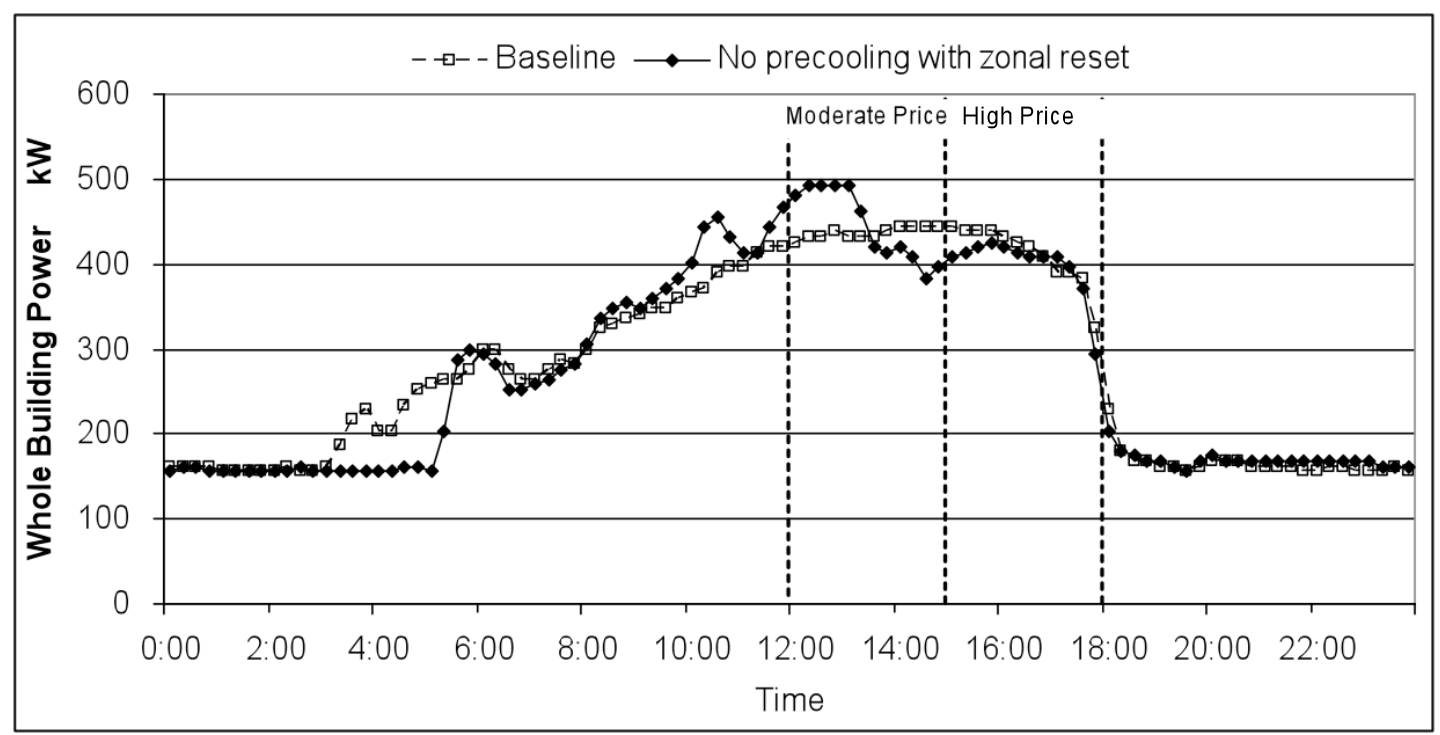

Figure 34. No pre-cooling with zonal reset in peak hours, TCCSB

Table 15 presents the demand shed in the CPP period. Due to the lower outside temperature of the baseline, the demand shed in the high price period was not obvious, and the average demand shed was only $3 \%$ relative to the baseline.

\begin{tabular}{|c|c|c|c|c|c|c|}
\hline \multirow[t]{2}{*}{ Price Level } & \multicolumn{2}{|c|}{$k W$} & \multicolumn{2}{|c|}{$W / s q f t$} & \multicolumn{2}{|c|}{ WBP\% } \\
\hline & Max & Ave & Max & Ave & Max & Ave \\
\hline $\begin{array}{c}\text { Moderate } \\
\text { Price }\end{array}$ & 60 & -10 & 0.68 & 0.69 & $14 \%$ & $-2 \%$ \\
\hline High Price & 36 & 12 & 0.41 & 0.41 & $8 \%$ & $3 \%$ \\
\hline
\end{tabular}

Pre-cooling with linear temperature reset. Figure 35 shows the effect of "pre-cooling with linear temperature reset" on August 15, 2007. The power usage on the baseline day (August 17, 2007) was lower than that of the test day (August 15, 2007) from 5 a.m. to 12 p.m. because of the precooling. At 2 p.m., when the zone temperature setpoints started to rise, the electrical demand was reduced dramatically on the pre-cooling test day (August 15, 2007). The afternoon demand was reduced by as much as $19 \%$ in the moderate price period and $15 \%$ in high price period. However, rebound did happen at around 2 p.m. 
The total energy used on the pre-cooling test day was slightly higher than that of the baseline day. The research team studied the comparison of the hourly outside temperature between the baseline day and pre-cooling test day and found that the average outside air temperature of the pre-cooling test day from 1 p.m. to 6 p.m. was higher than that of the baseline day by $2^{\circ} \mathrm{F}$. That finding means that the comparison presented here under predicts the afternoon peak load saving. Table 16 presents the summary of the demand shed. The average demand shed during the high price reached $53 \mathrm{~kW}$.

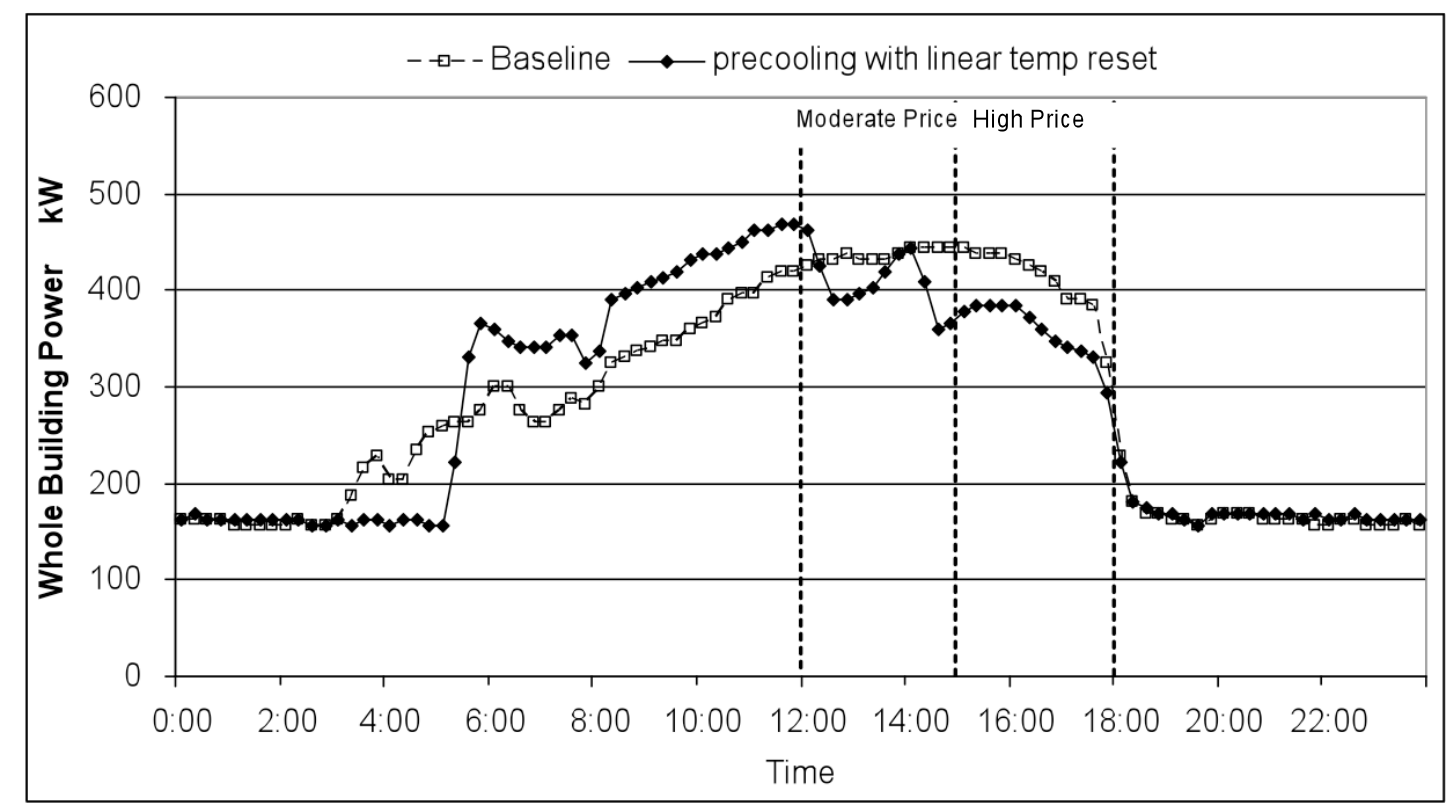

Figure 35. Pre-cooling with linear temperature reset in peak hours, TCCSB

\begin{tabular}{|c|c|c|c|c|c|c|}
\hline \multirow[t]{2}{*}{ Price Level } & \multicolumn{2}{|c|}{$k W$} & \multicolumn{2}{|c|}{$W / s q f t$} & \multicolumn{2}{|c|}{ WBP\% } \\
\hline & Max & Ave & Max & Ave & Max & Ave \\
\hline $\begin{array}{l}\text { Moderate } \\
\text { Price }\end{array}$ & 84 & 28 & 0.97 & 0.32 & $19 \%$ & $6 \%$ \\
\hline High Price & 64 & 53 & 0.76 & 0.61 & $15 \%$ & $13 \%$ \\
\hline
\end{tabular}

Pre-cooling with exponential temperature reset. Figure 36 shows the effect of "pre-cooling with exponential temperature reset" on August 16, 2007. Pre-cooling with exponential temperature reset strategy reduced the load in the afternoon more drastically than that of linear temperature reset. The load increased rapidly at 2 p.m. on the "pre-cooling with linear temperature reset" test day when the room temperature met the new setpoint. But it did not occur on the "precooling with exponential temperature reset" test day. The package units ran a lot steadier than they had during the linear temperature reset strategy and no rebound was observed before 6 p.m. 


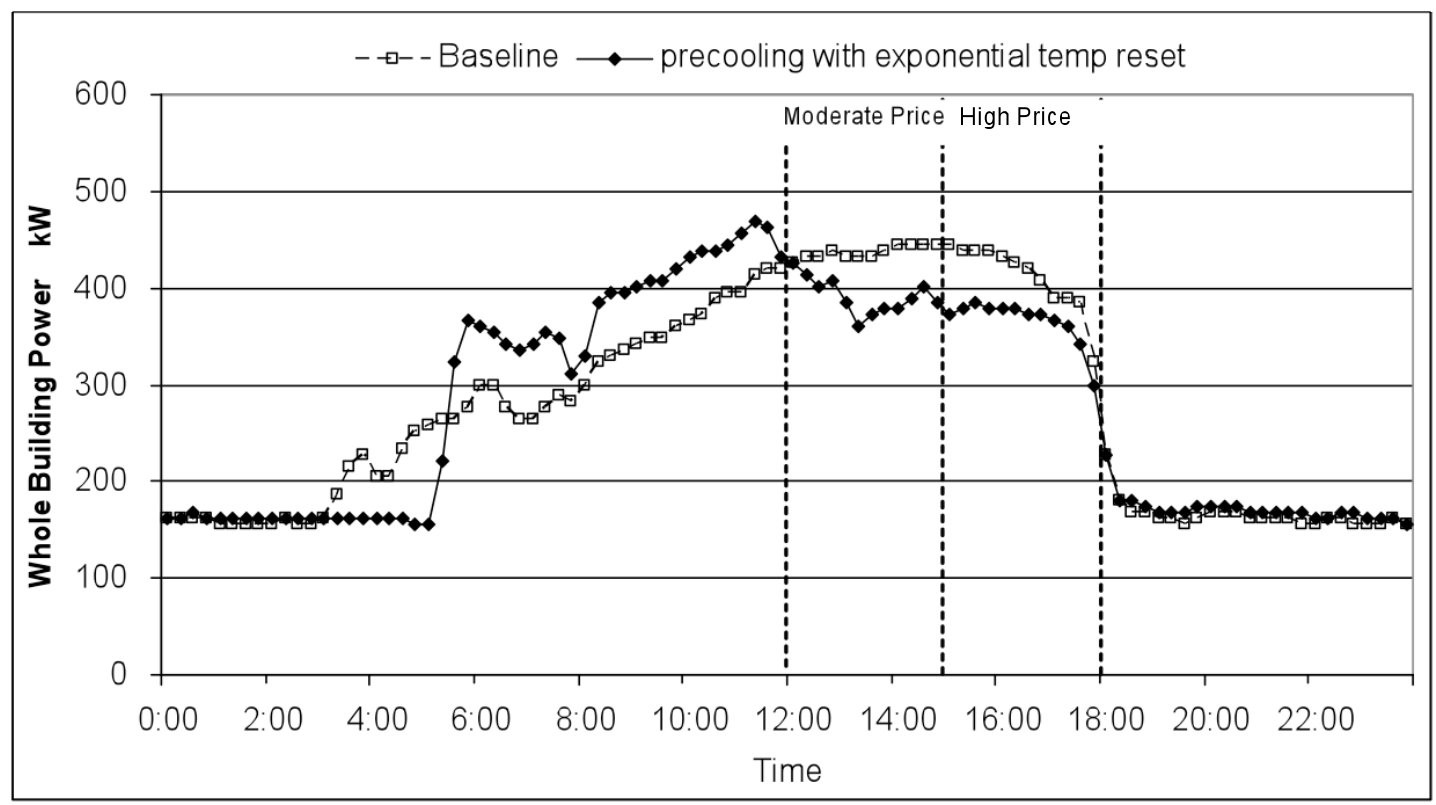

Figure 36. Pre-cooling with exponential temperature reset in peak hours, TCCSB

By comparing the demand shed presented in Table 16 and Table 17, the demand shed in the high price period was almost equal between these two pre-cooling strategies. Moreover, for the "pre-cooling with exponential temperature reset" strategy, the demand shed in the moderate price period was much more than that of the "pre-cooling with linear temperature reset" Strategy.

\begin{tabular}{|c|c|c|c|c|c|c|}
\hline \multirow[t]{2}{*}{ Price Level } & \multicolumn{2}{|c|}{$k W$} & \multicolumn{2}{|c|}{$W / s q f t$} & \multicolumn{2}{|c|}{ WBP\% } \\
\hline & Max & Ave & Max & Ave & Max & Ave \\
\hline $\begin{array}{l}\text { Moderate } \\
\text { Price }\end{array}$ & 72 & 45 & 0.83 & 0.52 & $16 \%$ & $10 \%$ \\
\hline High Price & 72 & 46 & 0.83 & 0.53 & $17 \%$ & $11 \%$ \\
\hline
\end{tabular}

\section{Extreme Hot Days Weather Condition}

Pre-cooling with exponential temperature reset.

Figure 37 shows, for hot days, the outside air temperature profile on the "pre-cooling with exponential temperature reset" and the baseline day. Figure 38 shows the effect of "pre-cooling with exponential temperature reset" on August 28, 2007, an extreme hot day. The outside air temperature of the baseline is slightly lower than the test days. This is the closest baseline that the team could find. However, the saving was still significant, even with a slightly cool baseline. 
The "Pre-cooling with exponential temperature reset" strategy savings were obvious on the hot days. The afternoon electrical demand was reduced by as much as $30 \%$ in the high price period from 3 p.m. to 6 p.m. The peak demand appeared at around 3 p.m. During the test, an AHU serving the third floor tripped off at around 4 p.m., resulting in a small rebound when it came back in. The maximum difference of the peak electrical demand during the on-peak period was $84 \mathrm{~kW}$. The effect of pre-cooling with exponential temperature reset was more obvious on the Extreme Hot Day than that of the same strategy on the Hot Days for this building.

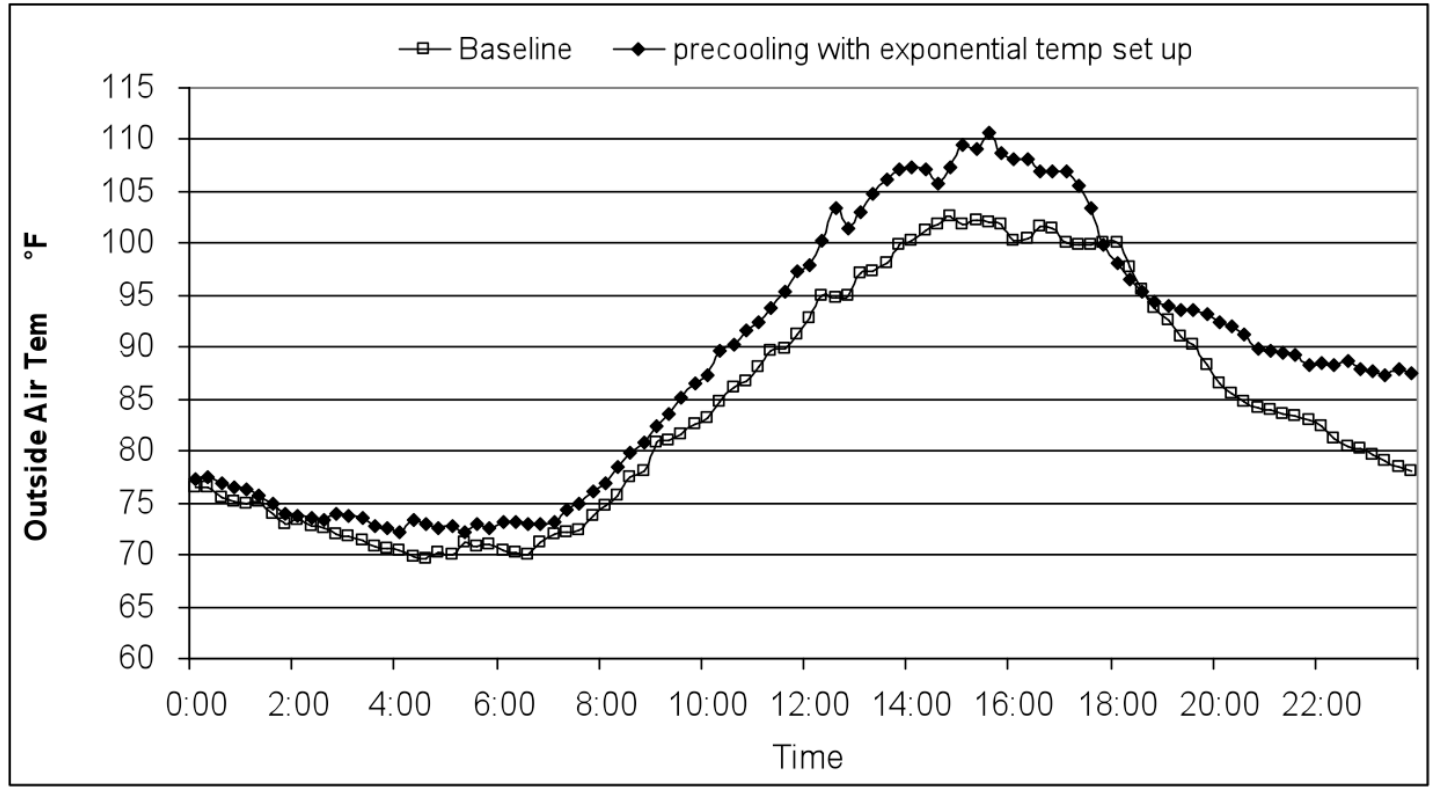

Figure 37. Outside air temperature - Hot Days

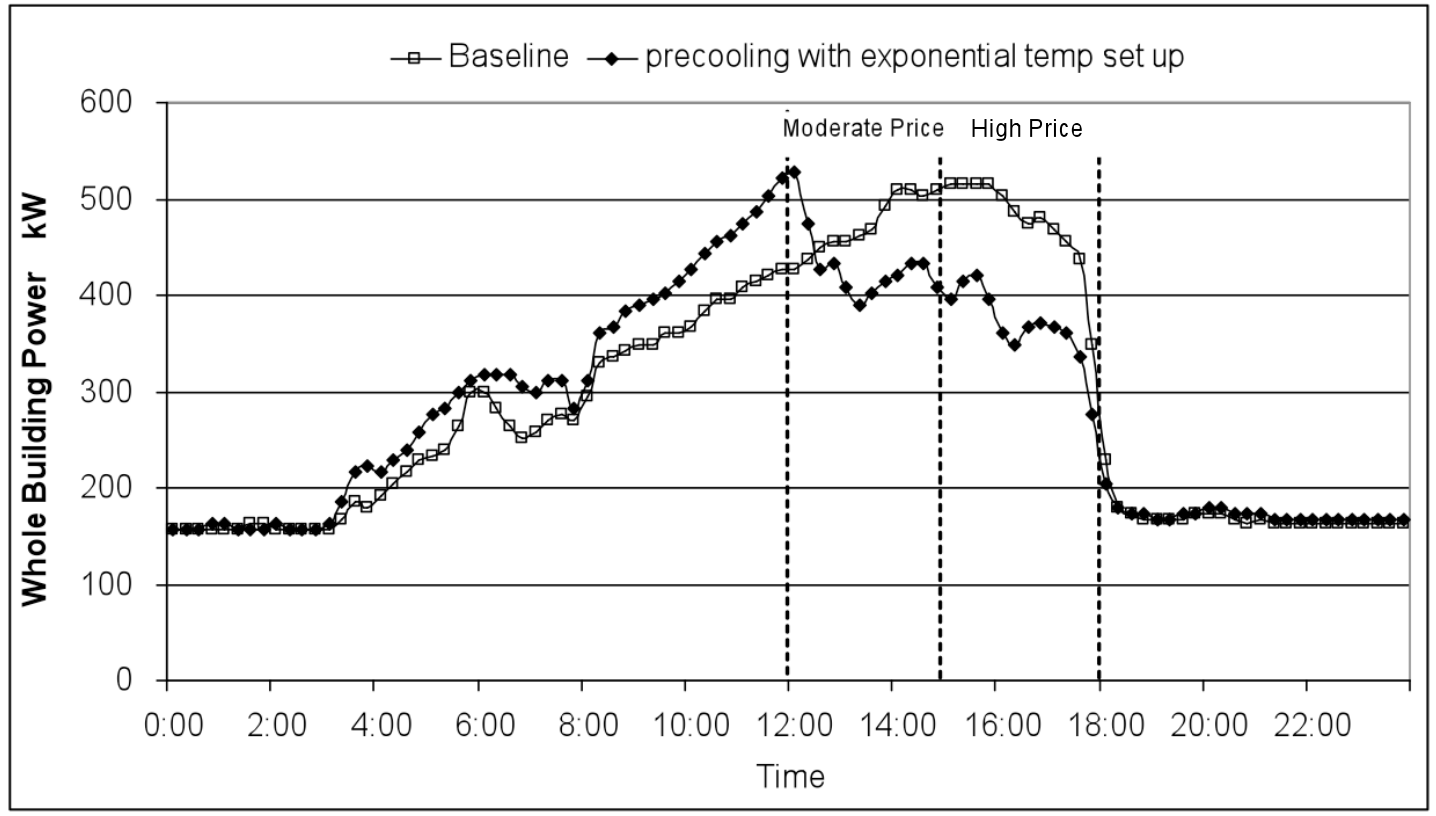

Figure 38. Pre-cooling with exponential temperature reset in peak hours Ext. Hot Days

Note: On the test day, the AHU serving the third floor was tripped off at around 4 p.m. 
Table 18. Demand shed - Pre-cooling with exponential temperature reset (Ext. Hot days)

\begin{tabular}{c|cccccc}
\hline Price Level & \multicolumn{2}{|c}{$\boldsymbol{k} \boldsymbol{W}$} & \multicolumn{2}{c}{$\boldsymbol{W} / \mathbf{s q} \boldsymbol{f t}$} & \multicolumn{2}{c}{$\boldsymbol{W B P} \%$} \\
\cline { 2 - 7 } & Max & Ave & Max & Ave & Max & Ave \\
$\begin{array}{c}\text { Moderate } \\
\text { Price }\end{array}$ & 102 & 43 & 1.17 & 0.49 & $20 \%$ & $9 \%$ \\
$\begin{array}{c}\text { High Price } \\
\text { Pignyyyyy}\end{array}$ & 144 & 109 & 1.66 & 1.25 & $30 \%$ & $23 \%$ \\
\hline
\end{tabular}

\section{Cool Day Weather Condition}

Pre-cooling with exponential temperature reset.

Figure 39 shows, for cool days, the outside air temperature profile on the "pre-cooling with exponential temperature reset" and the baseline day. As shown in Figure 40, the amount of reduced electrical usage during the on-peak period was more than that of increased electrical usage with pre-cooling in the morning on the test day. The afternoon electrical demand was reduced by as much as $15 \%$ throughout the moderate and high price period from 12 p.m. to 6 p.m. Compared to test results on the hot days, the shed during the on-peak period on the cool days was smaller than the shed on the hot days with same strategy, but still significant.

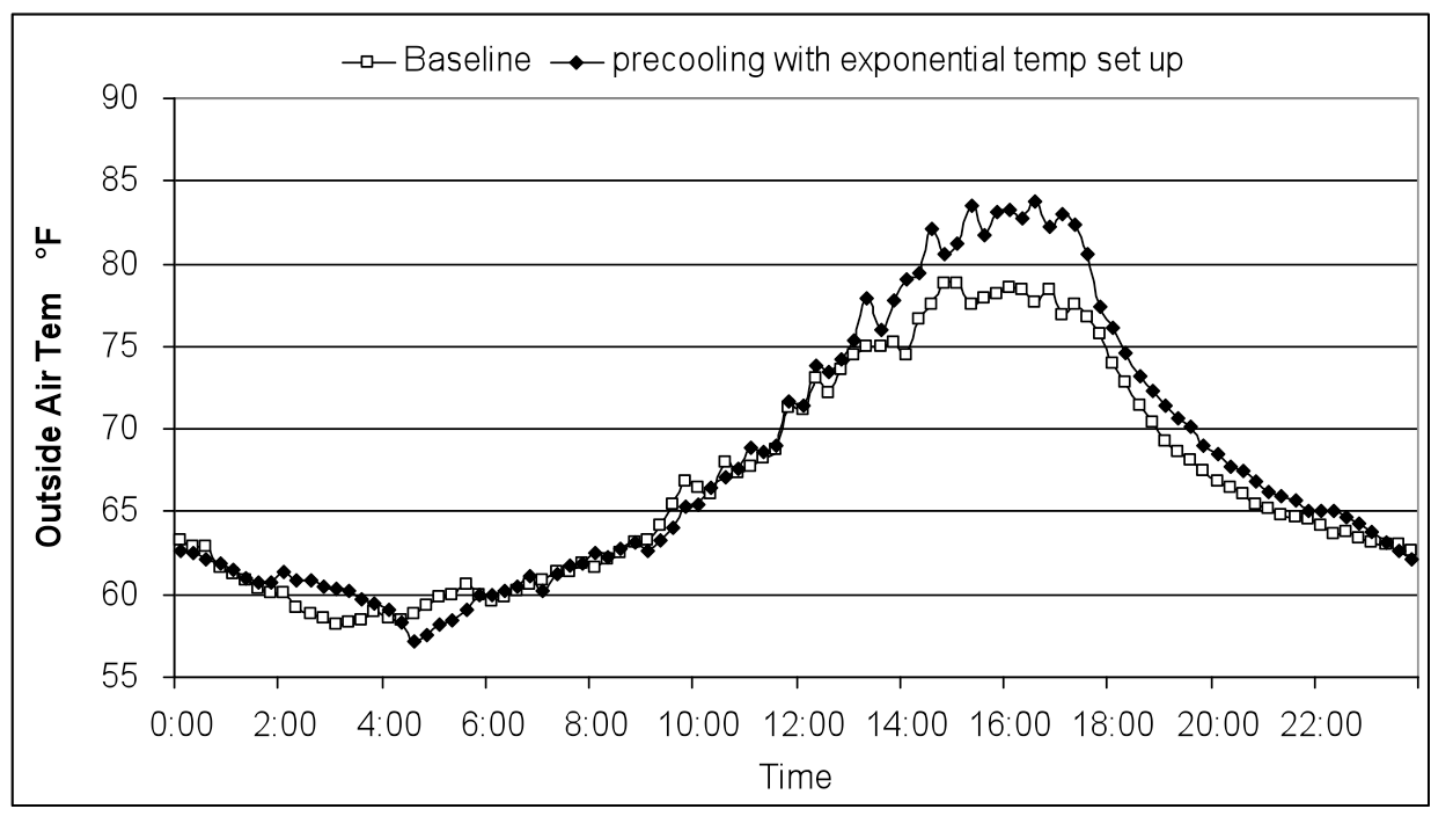

Figure 39. Outside air temperature - Cool weather conditions, TCCSB 


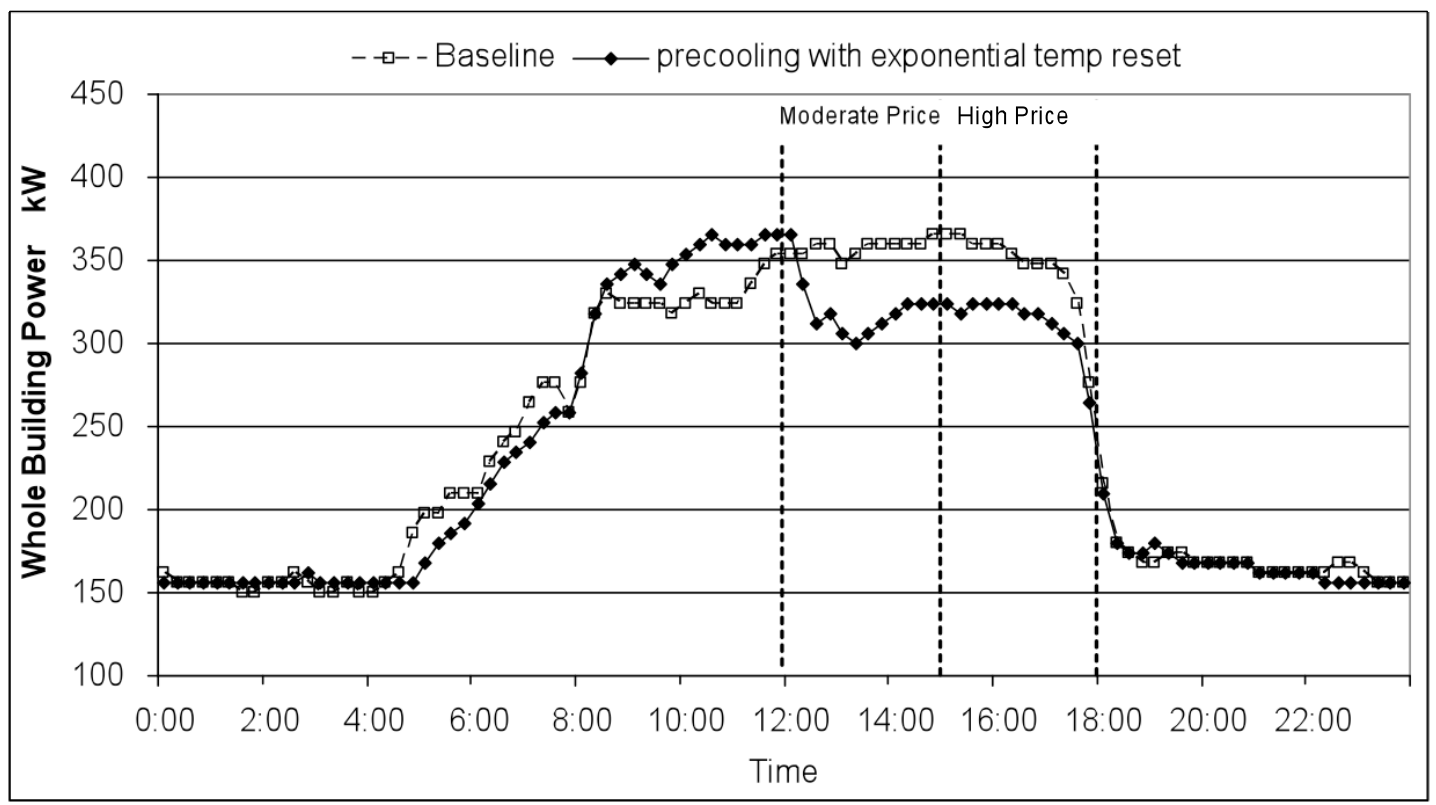

Figure 40. Pre-cooling with exponential temperature reset in peak hours - Cool Days, TCCSB

Table 19 shows that the demand shed in the moderate price period was almost equal to that in the high price period. There was no rebound throughout the moderate and high price periods.

Table 19. Demand shed - Pre-cooling with exponential temperature reset (cool days)

\begin{tabular}{|c|c|c|c|c|c|c|}
\hline \multirow[t]{2}{*}{ Price Level } & \multicolumn{2}{|c|}{$k W$} & \multicolumn{2}{|c|}{$W / s q f t$} & \multicolumn{2}{|c|}{ WBP\% } \\
\hline & Max & Ave & Max & Ave & Max & Ave \\
\hline $\begin{array}{c}\text { Moderate } \\
\text { Price }\end{array}$ & 54 & 38 & 0.62 & 0.43 & $15 \%$ & $10 \%$ \\
\hline High Price & 48 & 33 & 0.55 & 0.38 & $14 \%$ & $10 \%$ \\
\hline
\end{tabular}

\section{Rooftop Units' Total Energy Use}

\section{Hot Weather Conditions}

No pre-cooling with zonal reset. Figure 41 shows the comparison of the total electricity demand of the rooftop units between the baseline and the test day with "No pre-cooling with linear temperature reset." The average outside air temperature was higher than that of the baseline by $3^{\circ} \mathrm{F}$ during "zonal temperature reset" period and the max outside air temperature was higher than that of the baseline by nearly $6^{\circ} \mathrm{F}$ at 1 a.m. At the beginning of the "zonal temperature reset" period, the electrical demand decreased rapidly. Compared to the baseline, the electricity demand was decreased by as much as $75 \mathrm{~kW}$ at 2:30 p.m., which was equal to the $32 \%$ of the total electrical demand of the baseline. However the test results indicated that the shed with 
zonal temperature reset did not last a long time. The electricity demand increased quickly and rose to a higher level, still lower than the peak demand of baseline.

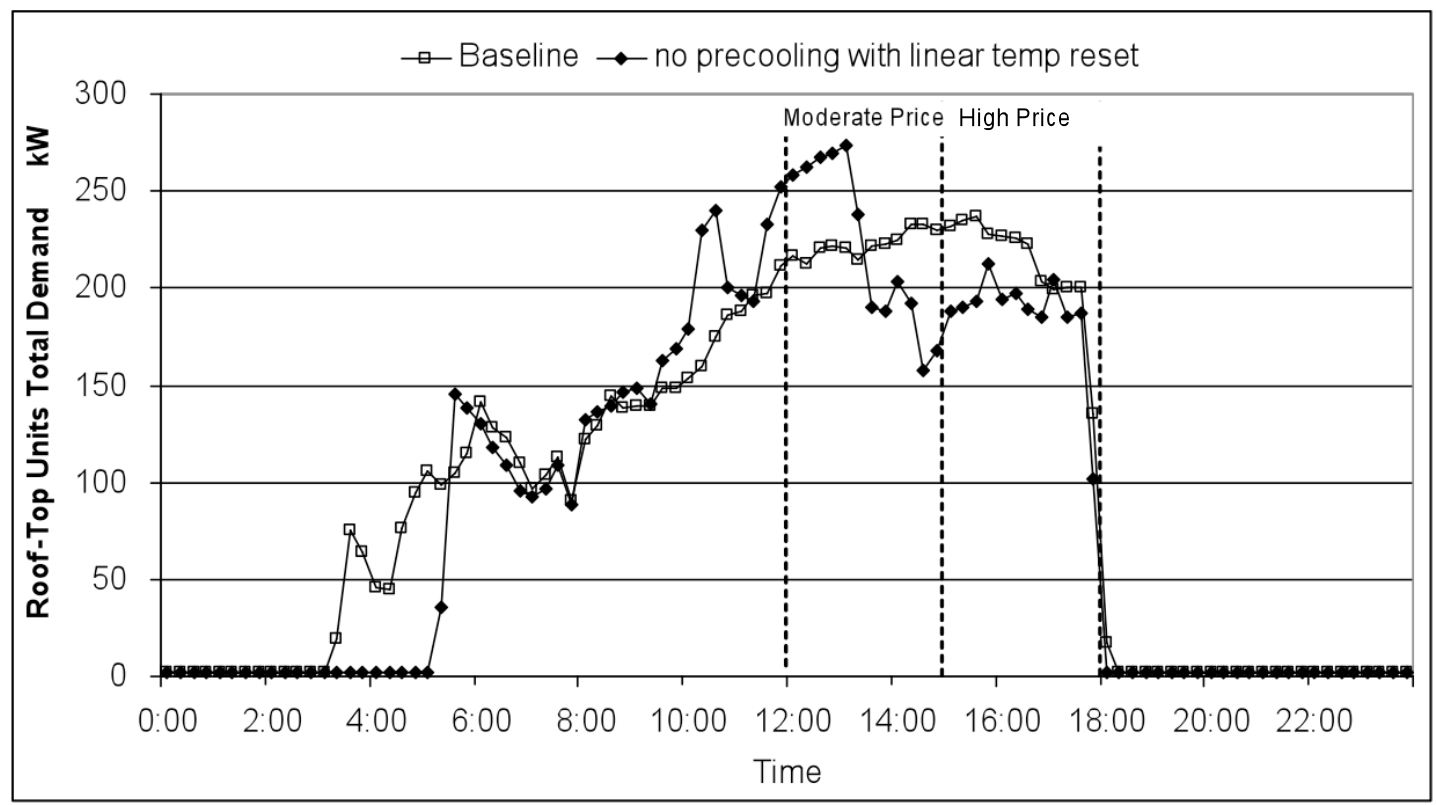

Figure 41. No pre-cooling with zonal reset in peak hours, TCCSB

Pre-cooling with linear temperature reset. As shown in Figure 42, the rooftop units' electricity consumption was higher than that of the baseline in the morning before the peak period. The total electricity consumption was slightly higher than the baseline by $2.4 \%$ from 5 a.m. to 6 p.m., which indicated that almost equal electricity consumption was moved from the on-peak period to the off-peak period. However, there was a big rebound just during the temperature reset period. After 2 p.m., the total electricity demand was reduced by about $30 \%$, on average, in the high price period. 


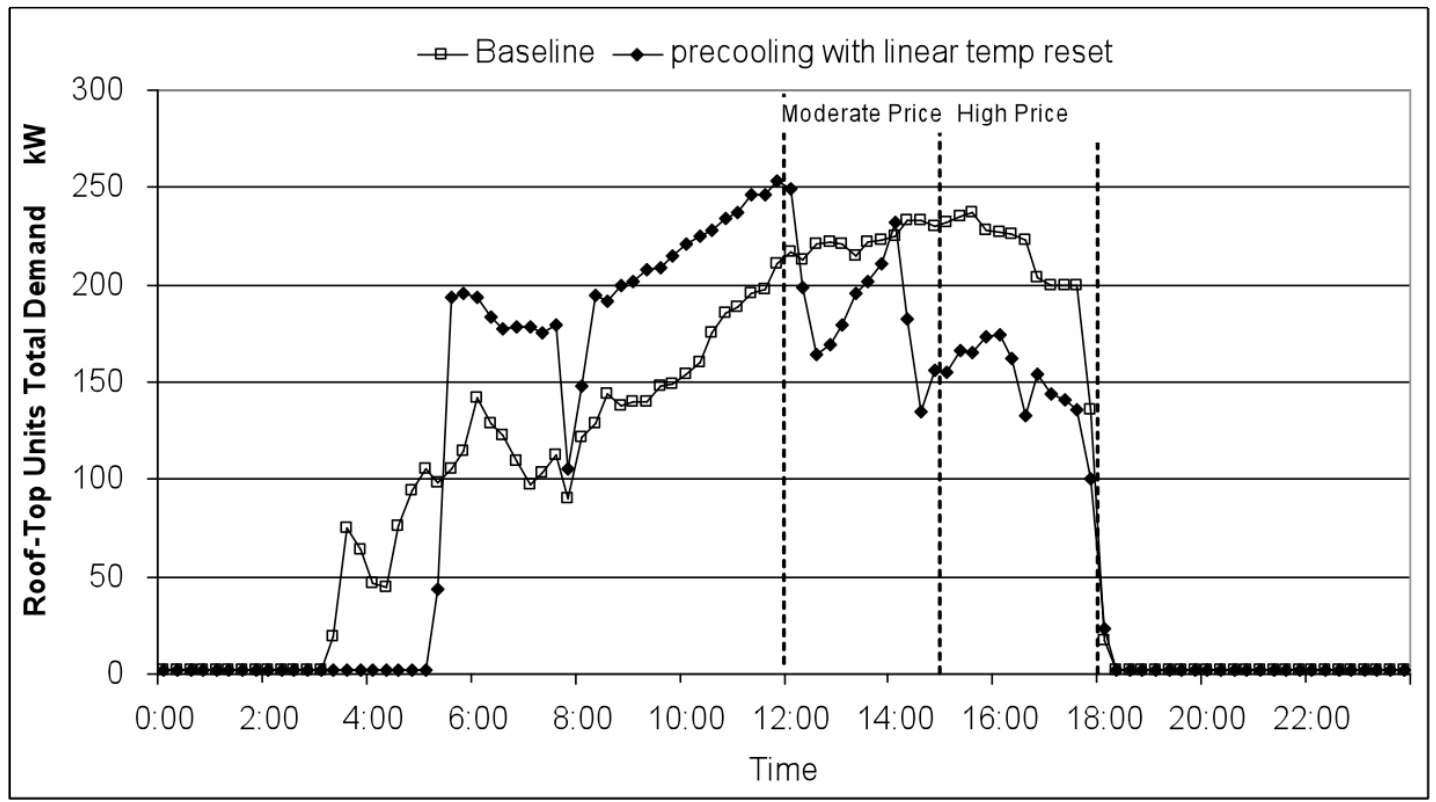

Figure 42. Pre-cooling with linear temperature reset in peak hours, TCCSB

Pre-cooling with exponential temperature reset. Figure 43 shows the effect of "pre-cooling with exponential temperature reset." The total electricity consumption was slightly higher than the baseline by $1.7 \%$ from 5 a.m. to 6 p.m., which also indicated that almost equal electricity consumption was moved from the on-peak period to the off-peak period. The shed during the on-peak period was almost identical to that of "pre-cooling with linear temperature reset." But the rebound was significantly reduced and the shed during the on-peak period lasted a long time. The rooftop units' power was essentially constant while slightly floating during the onpeak period.

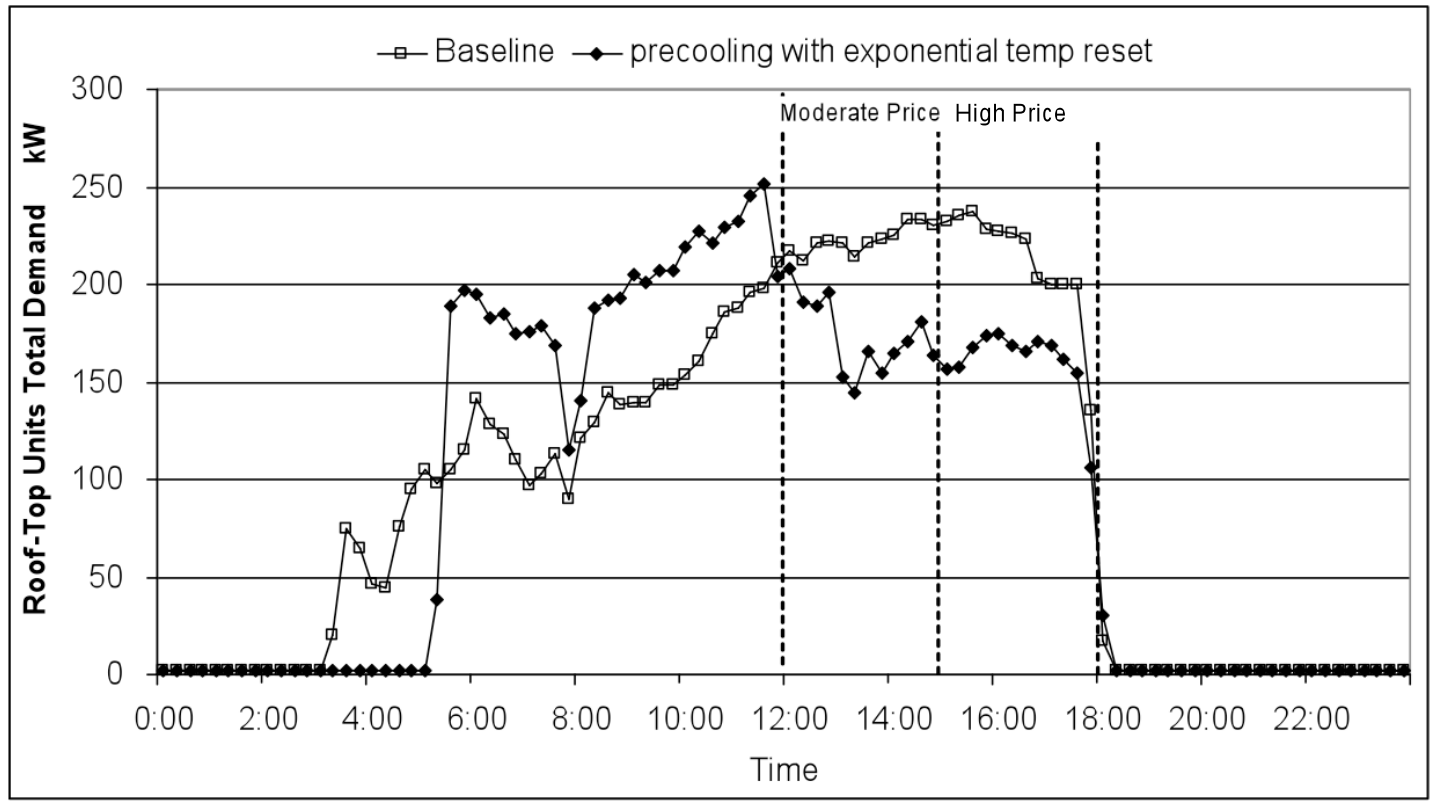

Figure 43. Pre-cooling with exponential temperature reset in peak hours, TCCSB 


\section{Extremely Hot Weather Conditions}

Pre-cooling with exponential temperature reset. Figure 44 shows the rooftop units electricity usage under pre-cooling with exponential temperature reset strategy in hot weather conditions. The total electricity consumption was slightly lower than the baseline by $1.7 \%$ from 3 a.m. to 6 p.m. The total electricity demand was reduced by about $30 \%$ on average throughout the moderate and high price period. Especially in high price period, the peak demand of rooftop units was reduced by as much as $100 \mathrm{~kW}$.

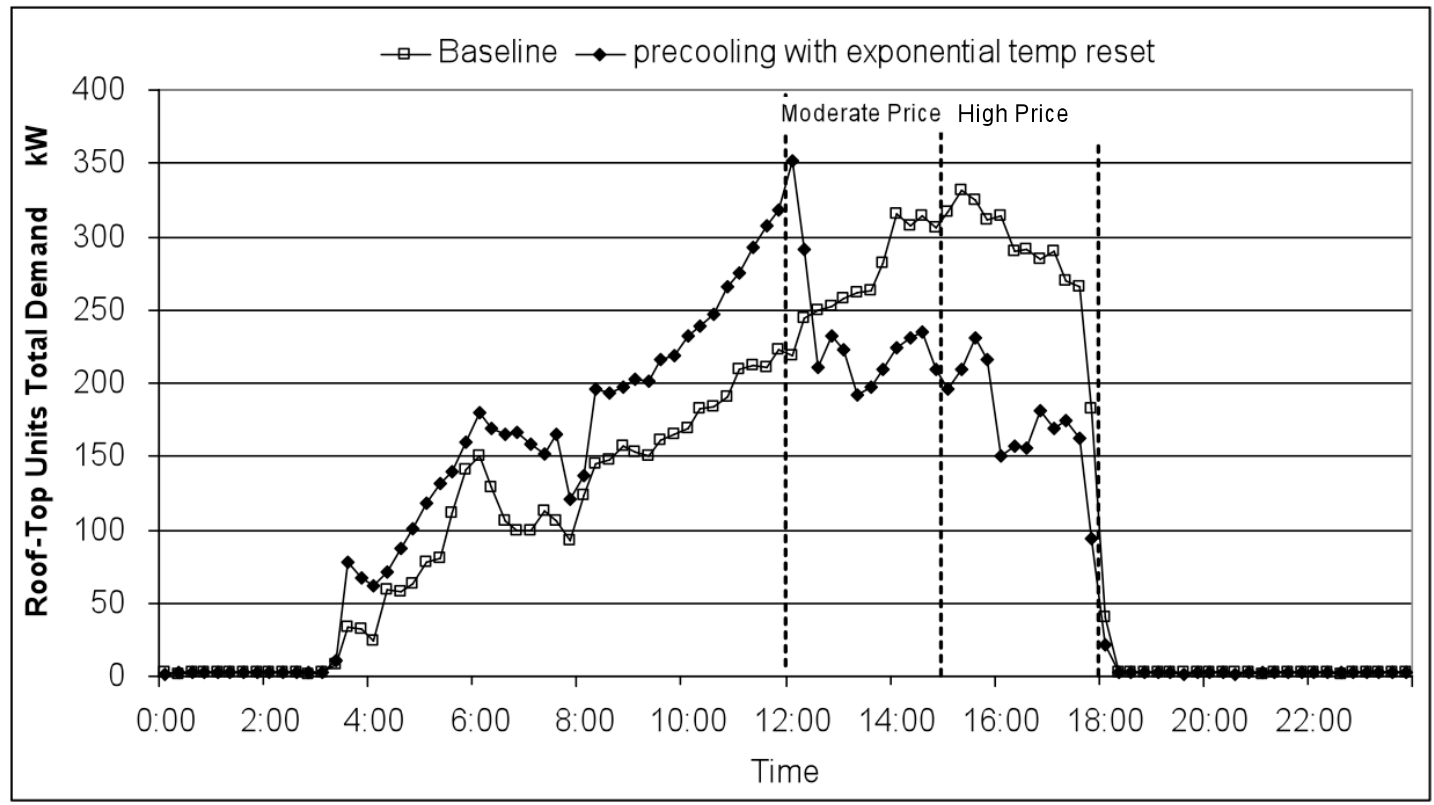

Figure 44. Pre-cooling with exponential temperature reset in peak hours, TCCSB

\section{Cool Weather Conditions}

Pre-cooling with exponential temperature reset. Figure 45 shows the rooftop units total electricity under pre-cooling with exponential temperature reset strategy on a Cool Day weather condition. The total electricity consumption was lower than the baseline by as much as $11.1 \%$ from 4 a.m. to 6 p.m. This result was not same as that under pre-cooling strategies in Hot Day weather conditions and Extremely Hot Day weather conditions. The total electricity demand was reduced by about $27.5 \%$ on average from 12 p.m. to 6 p.m. It can be assumed that precooling in the morning in the cool weather condition was not useful. 


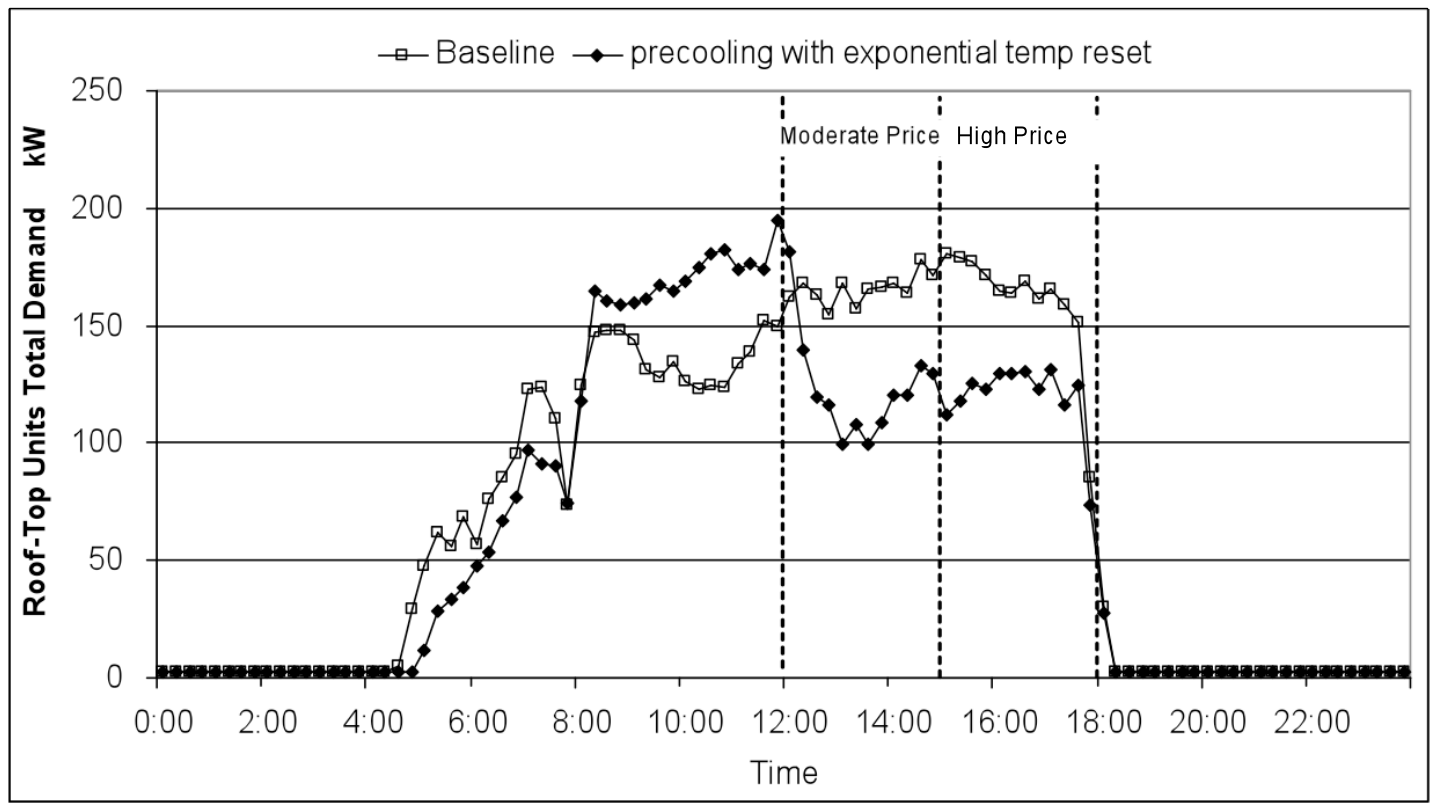

Figure 45. Pre-cooling with exponential temperature reset in peak hours, TCCSB

\section{Return Air Temperature}

\section{Hot Weather Condition}

Return air temperature. Figure 46 shows the return air temperature on three strategies' test days. On the "no pre-cooling with zonal temperature reset" test day, the value was higher than $76^{\circ} \mathrm{F}$, which was the building setpoint by the end of the peak hour. On "pre-cooling with linear temperature reset" and "pre-cooling with exponential temperature reset" test days, the values were never higher than $76^{\circ} \mathrm{F}$. Return air temperature increased rapidly at 8 a.m. However, a half hour later the return air temperature began to decrease to normal building setpoints. During the pre-cooling period, the return air temperature was not "too low" (> 73.2 $\left.{ }^{\circ} \mathrm{F}\right)$ for the occupants, and also it would be more comfortable on such a hot day.

Figure 47 and Figure 48 show the return air temperature on the "Extreme Hot Day" and "Cool Day," respectively. For the "pre-cooling with exponential temperature reset" on the Extreme Hot Day, the return air temperature was never higher than $76^{\circ} \mathrm{F}$ through the on-peak period. After 6 p.m., the zone temperature reached $77^{\circ} \mathrm{F}$. 


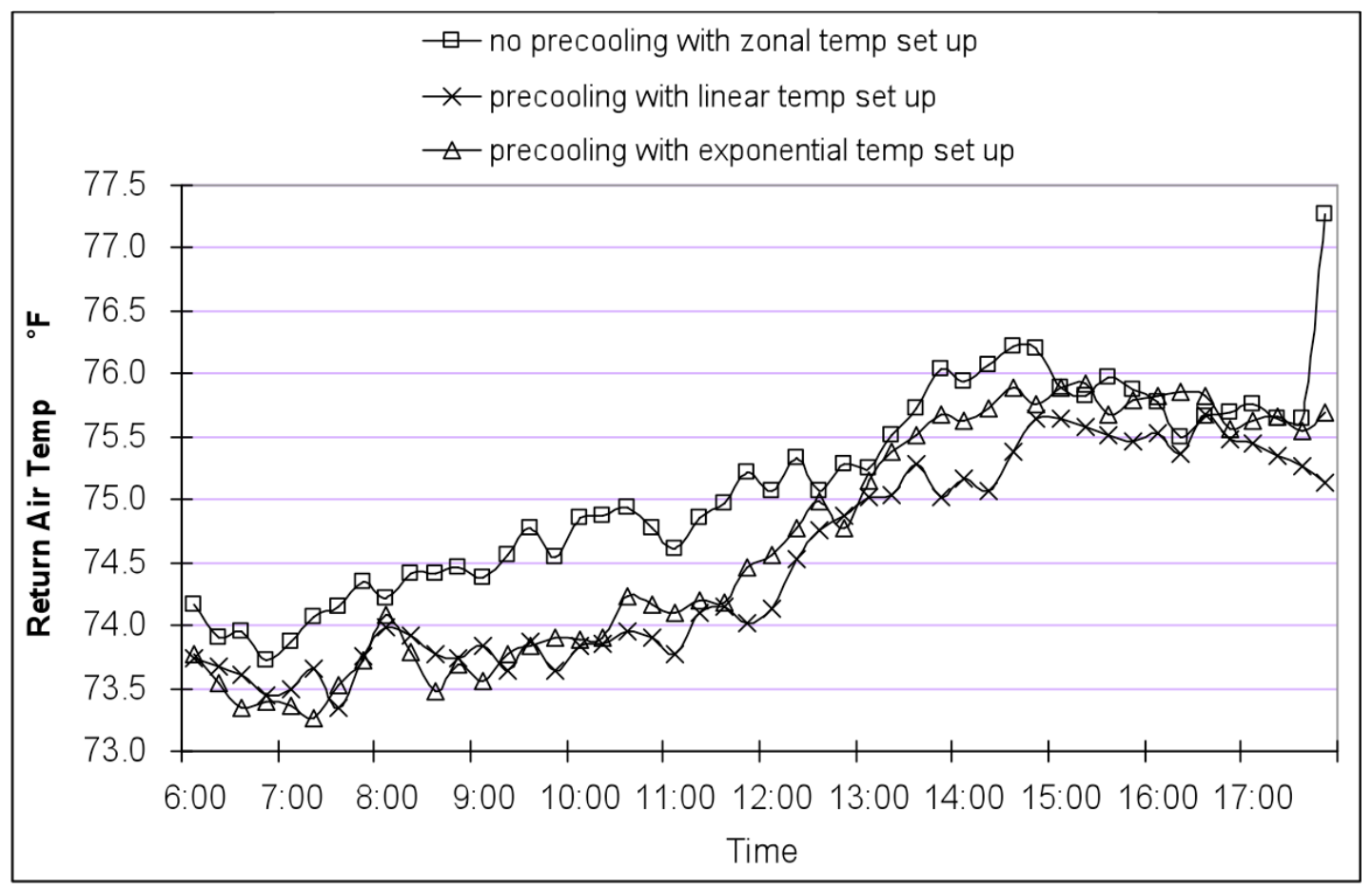

Figure 46. Return air temperature under three strategies on test days - Hot Days, TCCSB

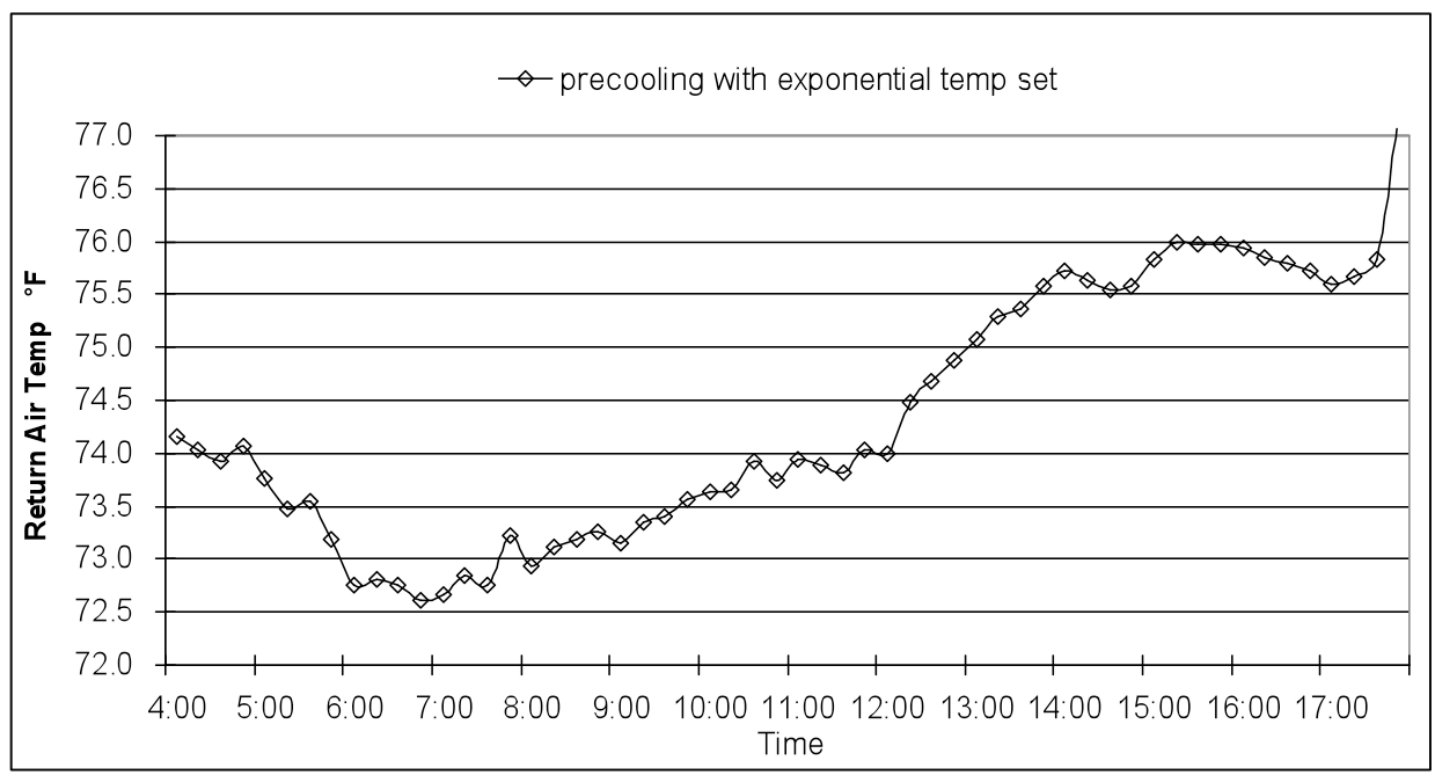

Figure 47. Return air temperature on test days - Extreme Hot Day, TCCSB 


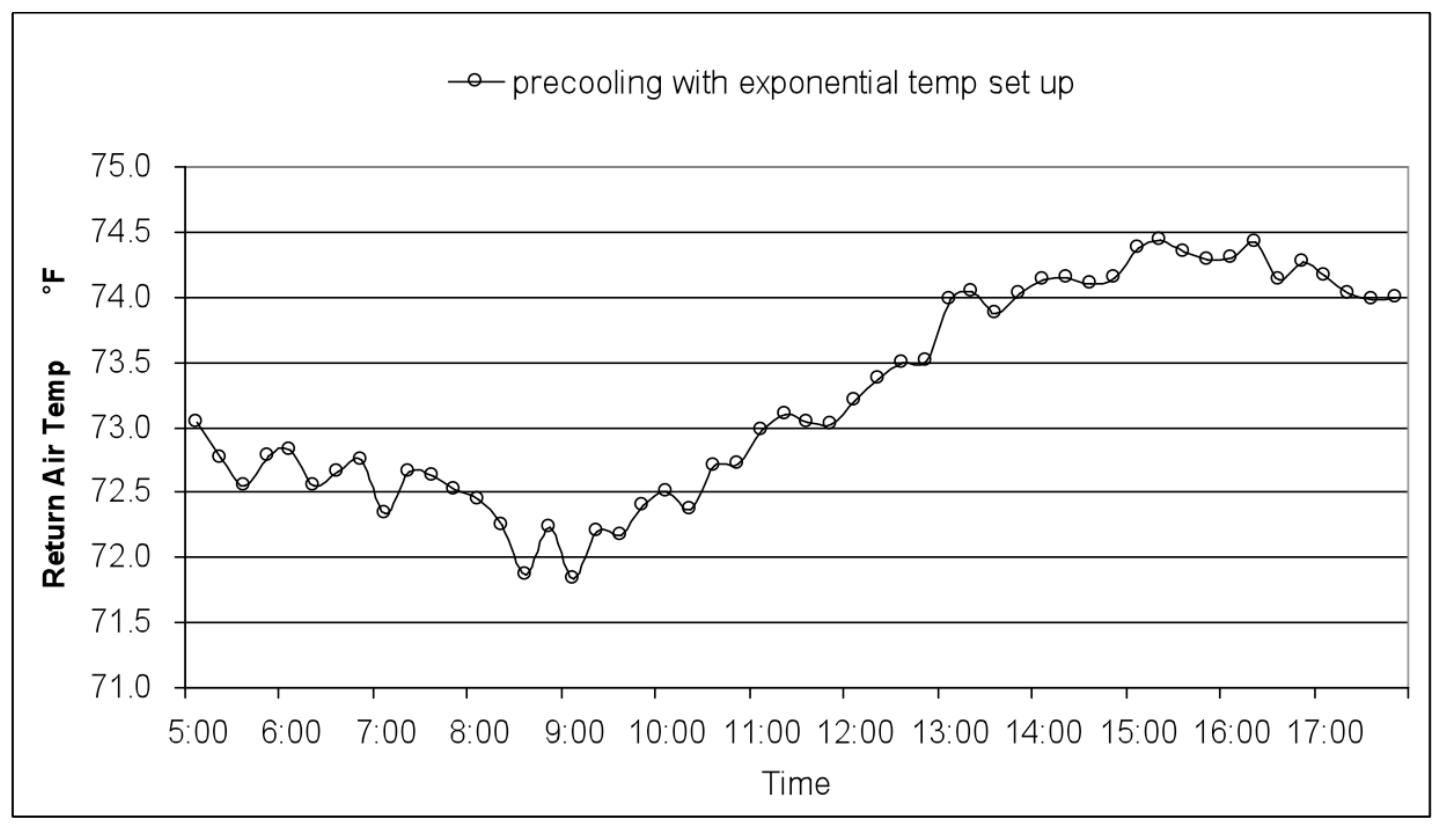

Figure 48. Return air temperature on test days - Cool Day, TCCSB

\section{Billing Energy Use and Demand \\ Hot Weather Conditions}

Figure 49 shows the energy usage of this building in detail. The total energy consumption for these different strategies was almost the same. It seems that a near equal amount of the energy was shifted from the on-peak period (including CPP High and Moderate Price) to the off-peak period.

The research team applied the rate schedule and calculated the energy cost of the test days. Figure 50 shows the energy cost in detail. Compared to the baseline, the energy charge of the "pre-cooling with exponential temperature reset" test days was reduced by $11.2 \%$. The energy cost includes the energy charge and the demand charge. For the energy charge, it was reduced by $\$ 128$; the effect of these "pre-cooling with zonal temperature reset" strategies was obvious, as shown in this figure. The peak electrical demand charge also decreased a lot. For demand charge, the rate for on-peak demand is $\$ 15.37$ per $\mathrm{kW}$. I $\mathrm{f}$ the building used the pre-cooling setting on CPP days in such weather conditions, the demand charge saving would amount to approximately $\$ 922$ per month. 


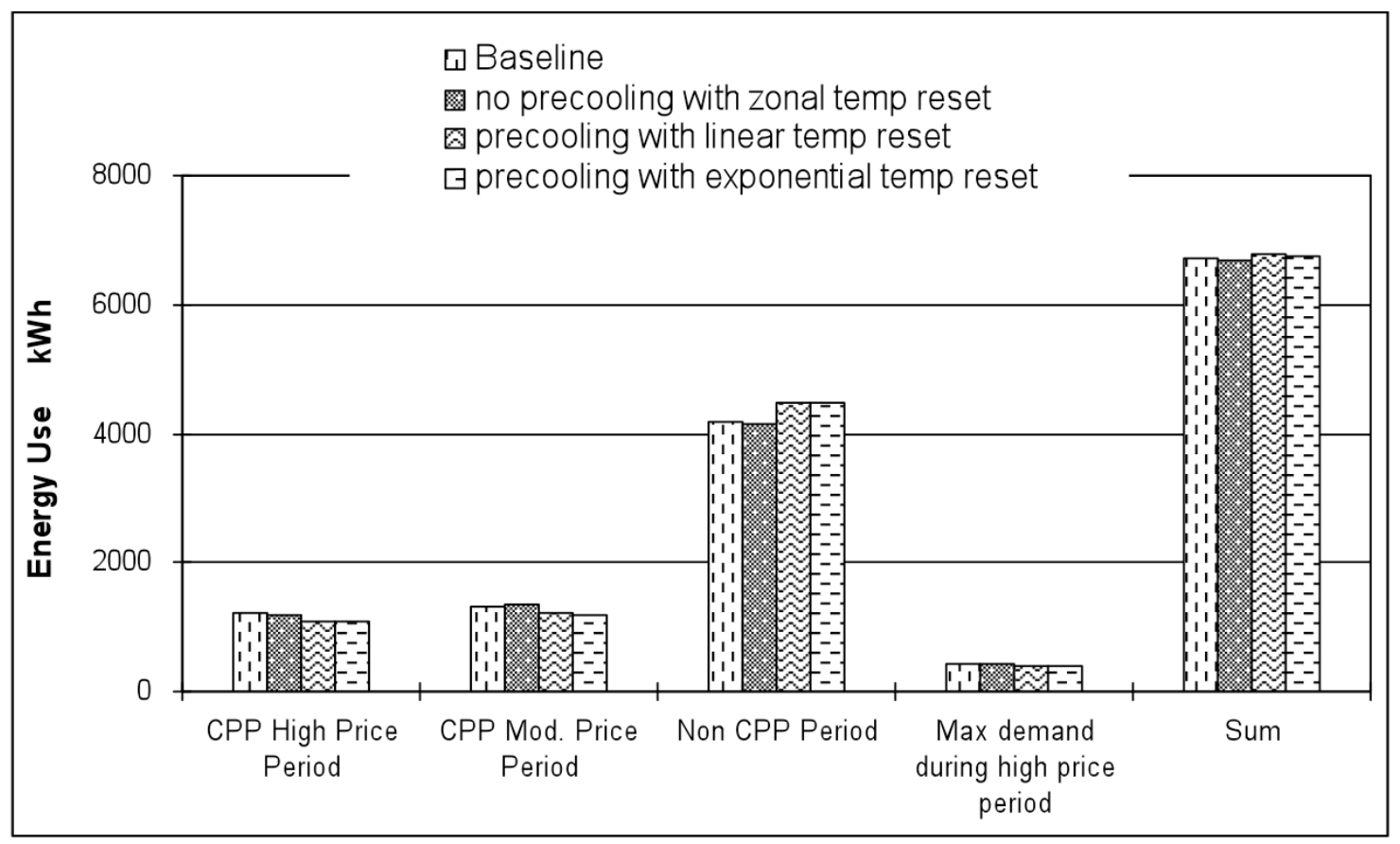

Figure 49. Energy usages (kWh) on test days - Hot Days, TCCSB

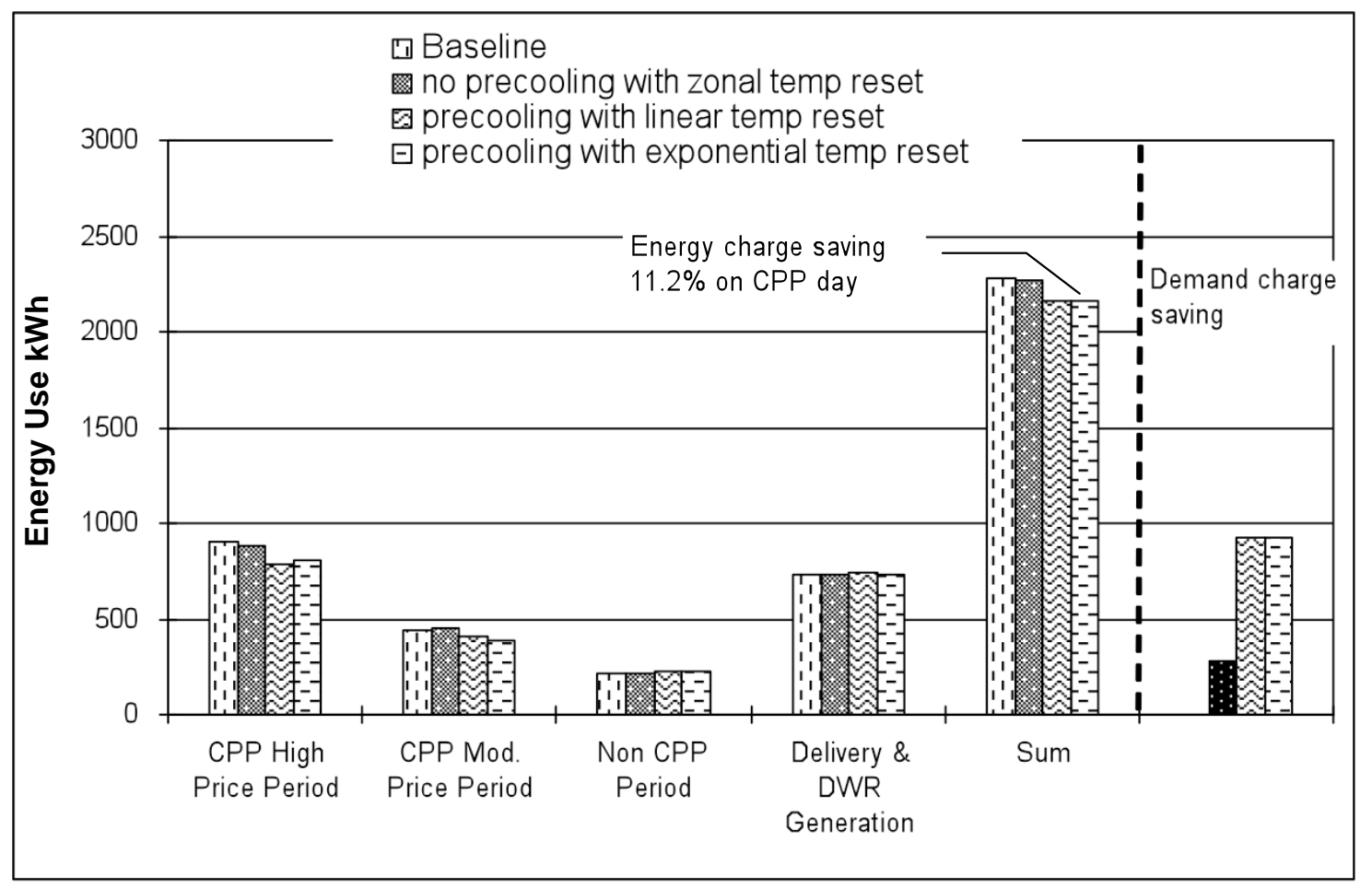

Figure 50. Energy cost on test days - Hot Days, TCCSB 


\section{Extremely Hot Weather Conditions}

Figure 51 shows the energy use of this building on Extreme Hot Day weather condition. The energy consumption was shifted from the CPP high price and moderate price period to Non$\mathrm{CPP}$ period. The energy use during the high price period was reduced by as much as $23 \%$. It indicated that pre-cooling under extreme hot weather conditions was effective.

Figure 52 shows the energy charge. Compared the same strategy on the Hot Days, the shed of energy charge during high price period is larger. The energy charge on the "pre-cooling with exponential temperature reset" test day was reduced by $14.3 \%$, compared with the baseline. The total energy cost includes energy charge and the demand charge. As to the demand charge, the maximum electrical demand during high price period was reduced by $96 \mathrm{~kW}$; if the building operating in pre-cooling mode on CPP days in summer season, as seen in Figure 52, the demand charge would be reduced by $\$ 1476$ per month in extreme hot day weather conditions, and the energy charge would be reduced by $\$ 263$ on test days. The potential of this strategy applied on the Extreme Hot Day is greater than that on the Hot Days.

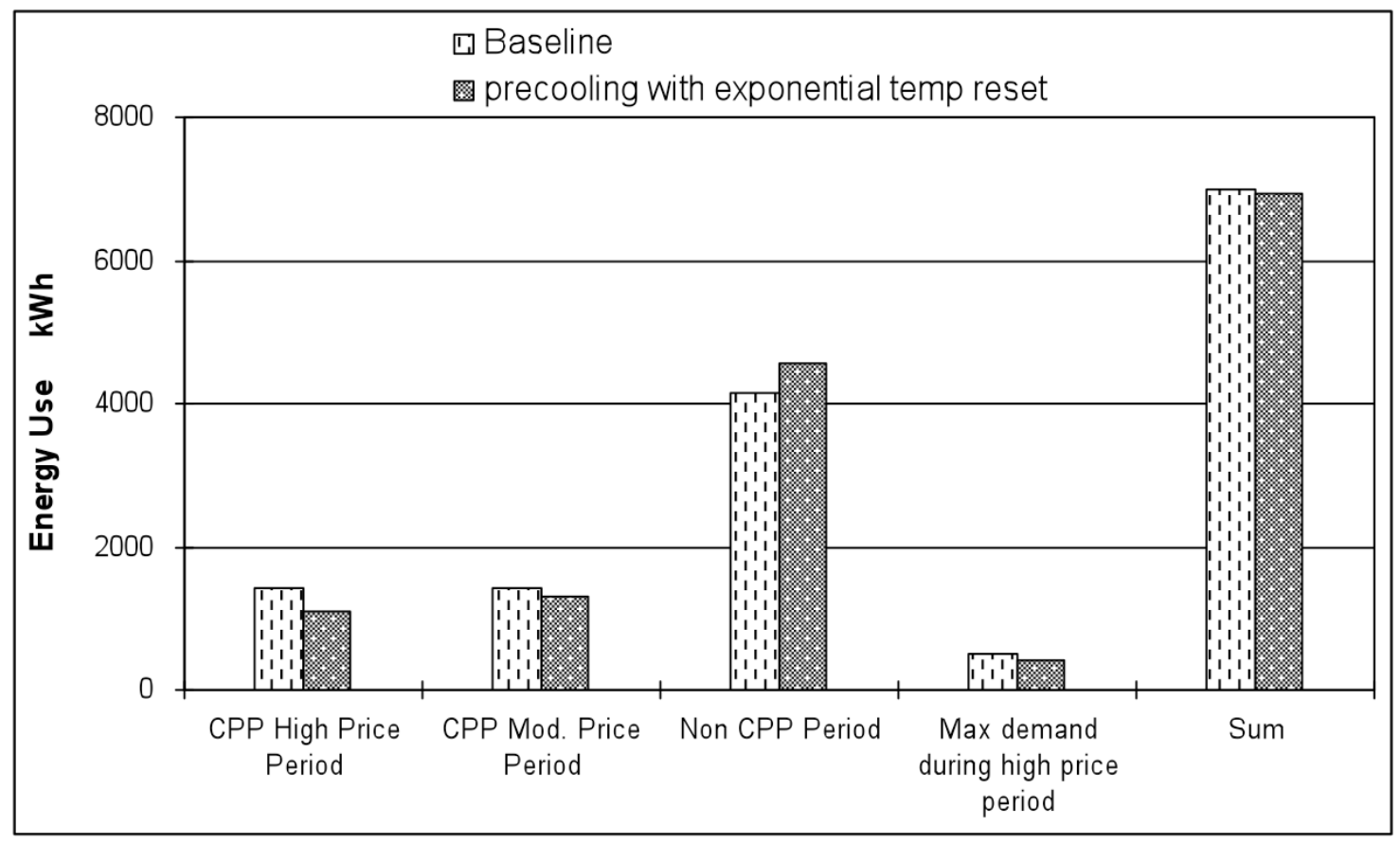

Figure 51. Energy use (kWh) on test day - Extreme Hot Day, TCCSB 


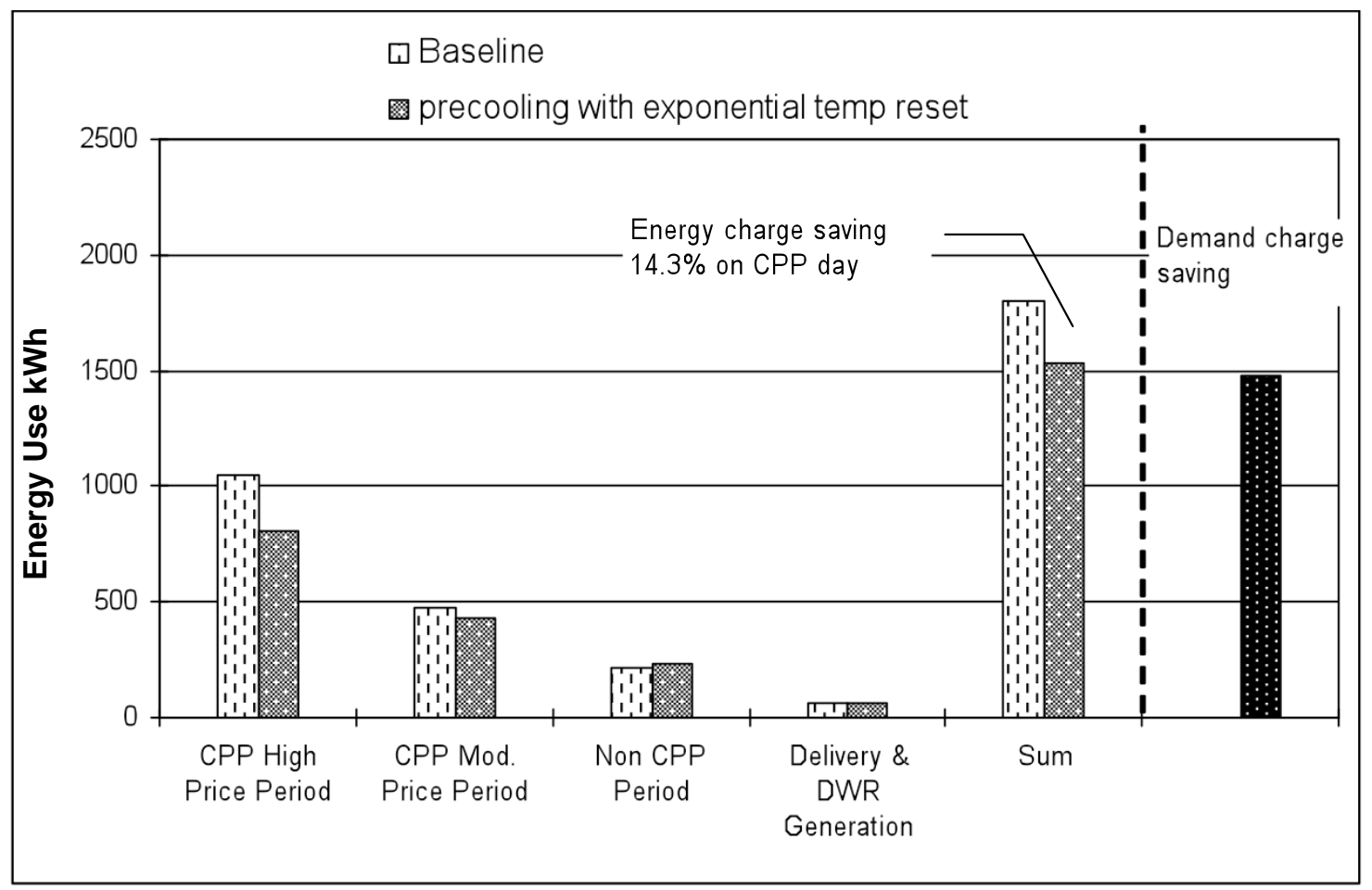

Figure 52. Energy cost (\$) on test days - Extreme Hot Day, TCCSB

Figure 53 shows the energy use of this building. The energy use during the high price period was reduced by as much as $10 \%$, and the total energy use through the test day was reduced by $3.1 \%$. Figure 54 shows the energy cost on test day. The energy charge of this building was reduced by $\$ 127(6.5 \%)$. If the customer would use the strategy all month long in such weather conditions, it would achieve a demand charge saving of approximately $\$ 646$ per month. 


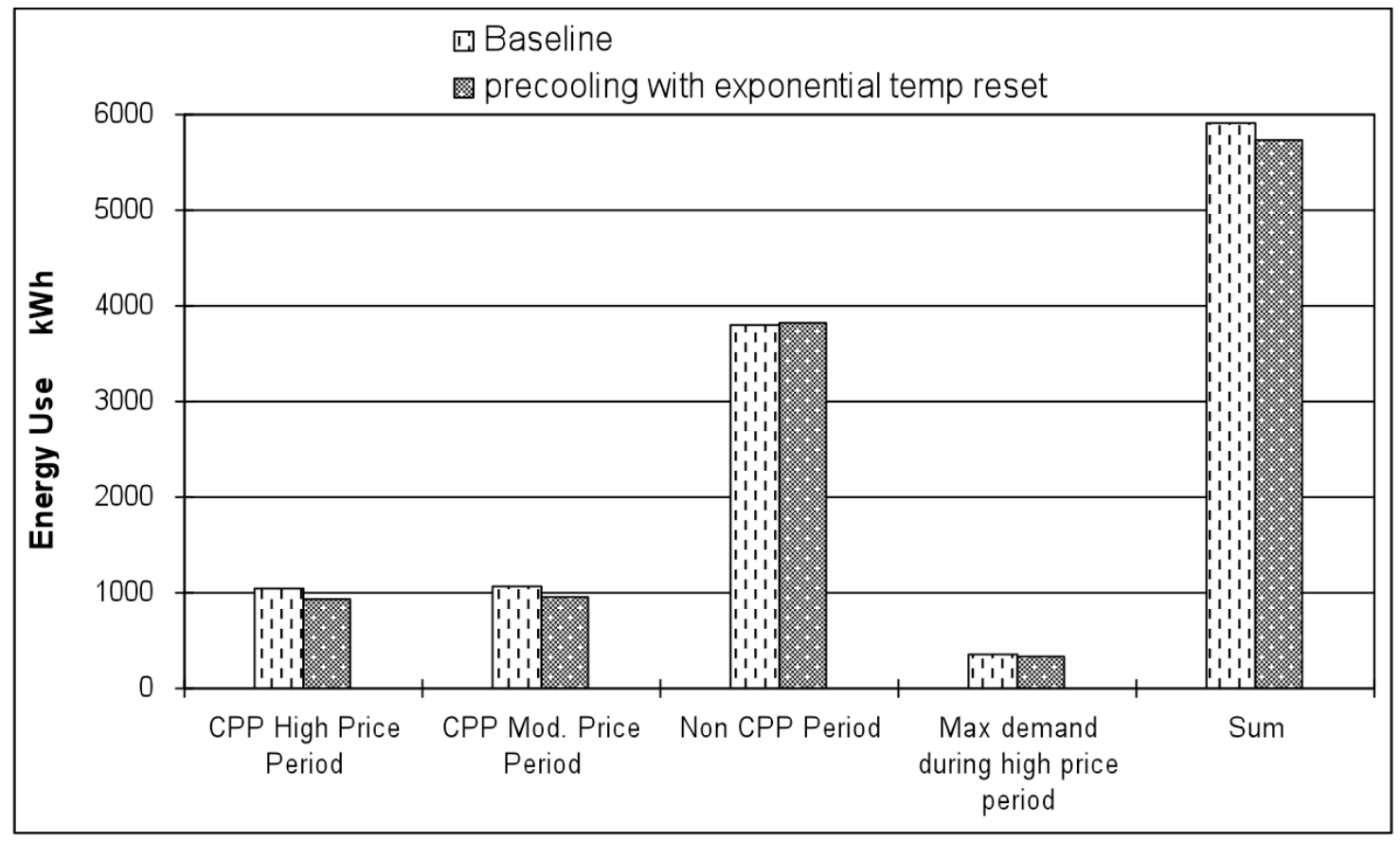

Figure 53. Energy use (kWh) on test days - Cool Day, TCCSB

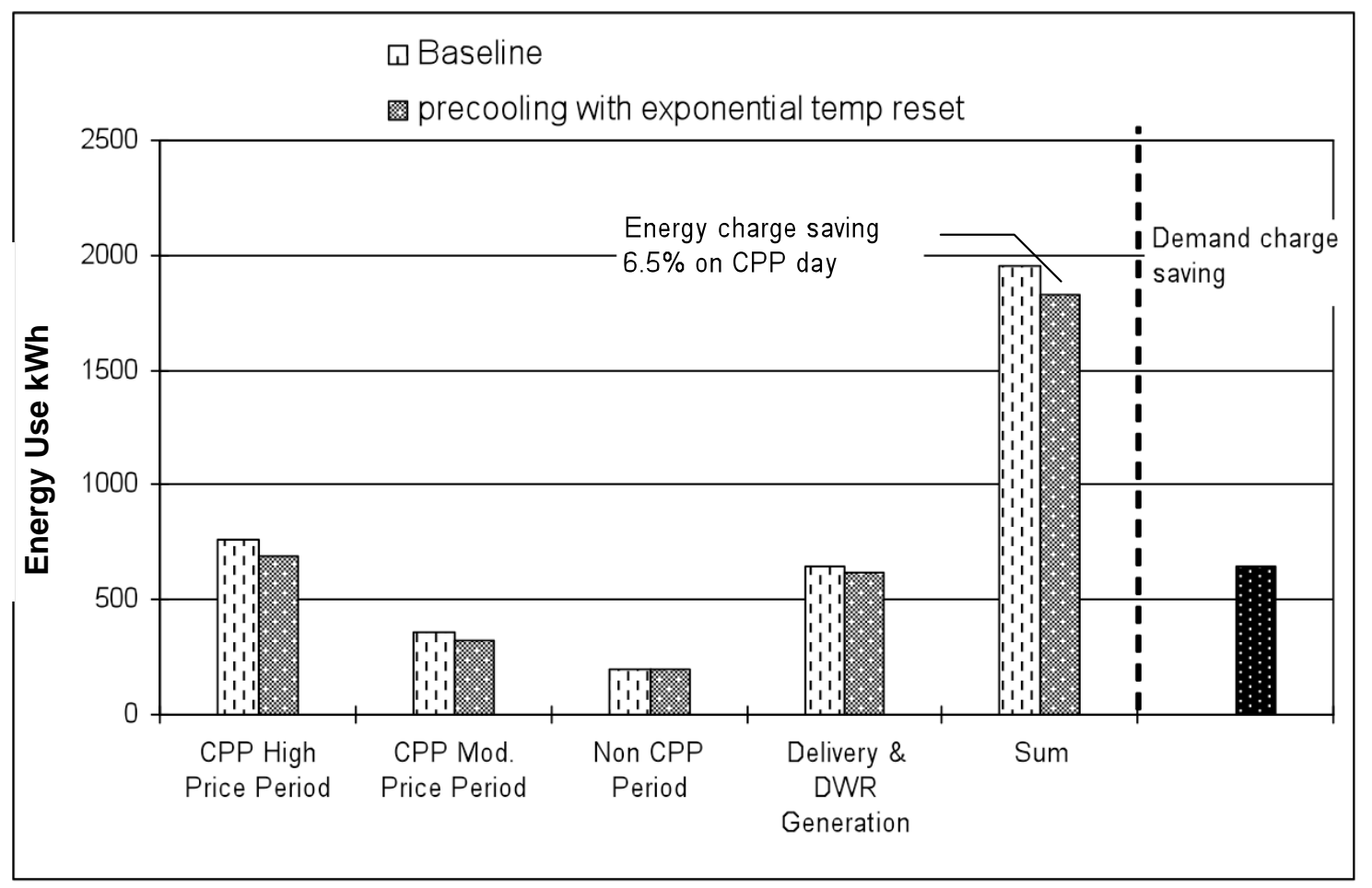

Figure 54. Energy cost (\$) on test days - Cool Day, TCCSB 


\subsubsection{Comfort Analysis}

The method for the comfort analysis was the same as that used in 2006, but with improved data collection.

\section{Occupant Comfort}

Votes were collected on a regular basis, including both baseline and test days. The first e-mail was sent out on August 14, and reminders were sent several times after that. Users continued to submit votes through September 19. Unlike the 2006 test, no users responded on weekend days.

The five test days represent weather conditions; three hot-weather days, one extreme hotweather day, and one cool-weather day. The test days are matched with a baseline day for comparison. Dates are shown in Table 20.

The thermal sensation survey responses were primarily collected during the afternoon temperature-setup period, not in the morning, following the observation during the test that no cold complaints were reported during the morning pre-cooling.

CBE offered 10 iPod Shuffles in a lottery for survey respondents, since this incentive had proven successful in 2006. In 2007, response rates were lower, probably a function of the type of occupancy in this building. Response rates on test days vary from $25 \%$ to under $1 \%$.

Table 20. Number of responses on test days and their corresponding baseline days

\begin{tabular}{c|ccccc}
\hline Test Days & Test & Test Days & $\begin{array}{c}\# \\
\text { Votes }\end{array}$ & $\begin{array}{c}\text { Baseline } \\
\text { Days }\end{array}$ & $\begin{array}{c}\# \\
\text { Votes }\end{array}$ \\
\hline \multirow{2}{*}{ Hot Days } & $\begin{array}{c}\text { No pre-cooling with } \\
\text { zonal reset }\end{array}$ & $8 / 14 / 07$ & 54 & $8 / 28 / 07$ & 70 \\
\cline { 2 - 6 } & $\begin{array}{c}\text { Morning pre-cooling } \\
\text { with linear reset }\end{array}$ & $8 / 15 / 07$ & 8 & $8 / 28 / 07$ & 70 \\
\cline { 2 - 6 } & $\begin{array}{c}\text { Morning pre-cooling } \\
\text { with exponential reset }\end{array}$ & $8 / 16 / 07$ & 37 & $8 / 28 / 07$ & 70 \\
\hline \multirow{2}{*}{$\begin{array}{c}\text { Extreme Hot } \\
\text { days }\end{array}$} & $\begin{array}{c}\text { Morning pre-cooling } \\
\text { with exponential reset }\end{array}$ & $8 / 29 / 07$ & 74 & $8 / 28 / 07$ & 70 \\
\hline Cool Day & $\begin{array}{c}\text { Morning pre-cooling } \\
\text { with exponential reset }\end{array}$ & $9 / 18 / 07$ & 37 & $8 / 28 / 07$ & 70 \\
\hline
\end{tabular}




\section{Temperature Measurements}
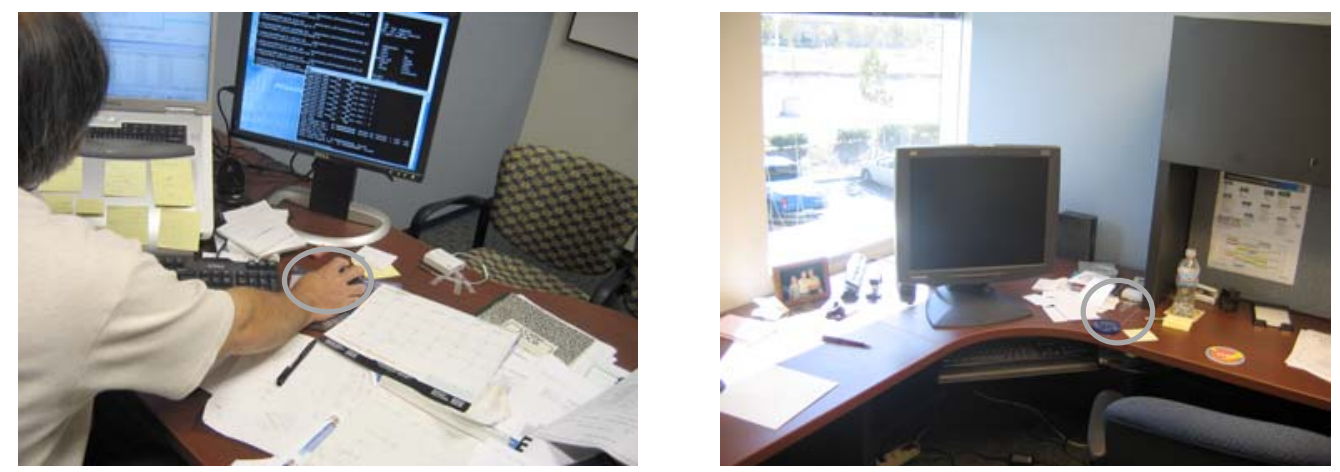

Figure 55. Location of HOBO data loggers at the office

Figure 55 shows the location of the HOBO data loggers in the offices. During the study period, CBE logged thermal measurements in the spaces every 10 minutes using $118 \mathrm{HOBO}$ data loggers. Two different types of HOBO data loggers were used: 66 U-10 temperature loggers, 52 U-12 loggers with internal temperature, external temperature, and relative humidity sensors. The loggers were placed in a regular grid pattern throughout the building, but the density of $\mathrm{HOBO}$ in the perimeter zone was higher than interior zone.

HOBO data loggers were attached on the desks of office occupants, avoiding the spots near office equipment. Each user was matched to the HOBO on his or her desk based on the HOBO number the user entered in the survey.

\section{Results}

Thermal Sensation

All the thermal sensation votes are consolidated in Figure 56. This figure shows both the distribution of votes over the study and the thermal levels on each day. Respondents most often reported a thermally comfortable environment. The individual test days are described in the sections describing the test days below. 


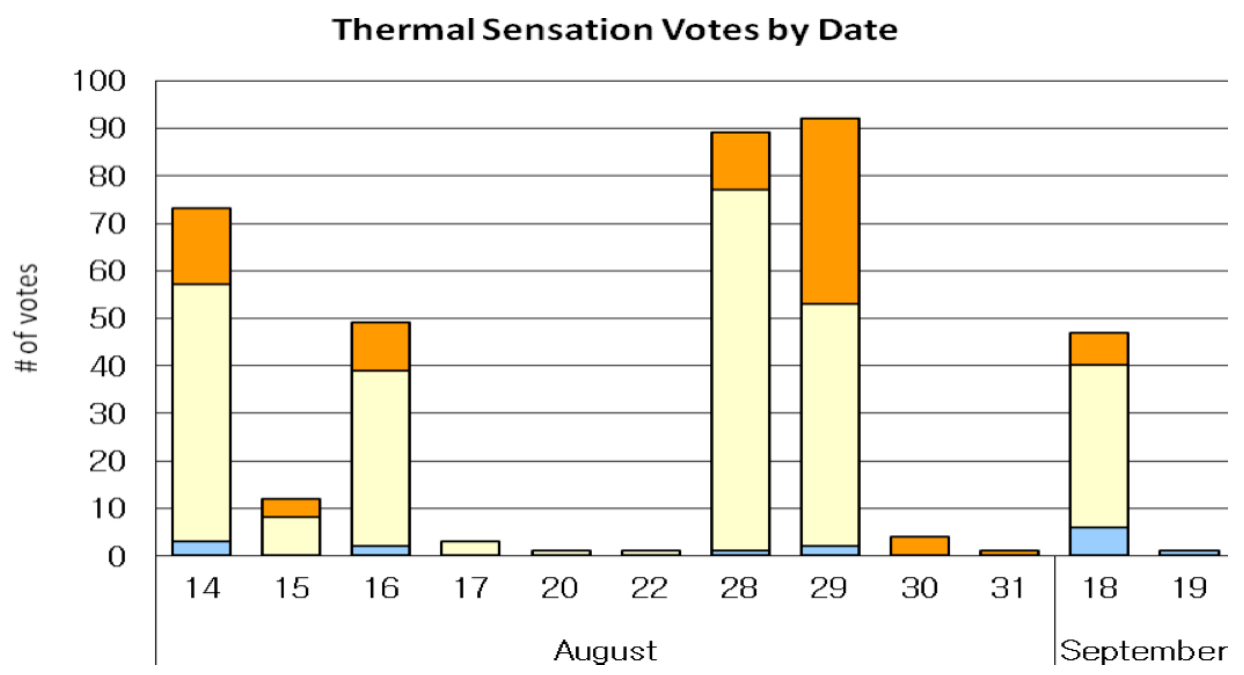

Figure 56. Temperature votes per day (orange = too warm; yellow = just right;

blue $=$ too cool)

\section{Productivity}

There is often a close relationship between thermal comfort and self-reported productivity. Productivity is an important factor in this study because occupant salaries and benefits generally represent over $90 \%$ of a building's total cost. Management will be unlikely to implement demand shifting strategies if there is a concern that the occupants will be negatively affected.

Figure 57 shows the relationship between thermal comfort and productivity throughout the study. The z-axis represents the total number of votes at each intersection of productivity and thermal sensation. Productivity votes range from "temperature interferes" to "enhance" the user's ability to get their job done. On the x-axis, temperature votes range from "much too cool" to "much too warm." The y-axis represents the corresponding productivity rating.

The largest group voted that they were comfortable (neither warm nor cool) and that the temperature has a positive effect on their ability to get their job done. In general, as users become cooler or warmer, they tend to feel an increasing negative effect of their productivity. This relationship is a skewed one however, as too-warm occupants report a much larger negative effect on their productivity than do their too-cool counterparts. A large number of people who felt that the thermal environment was comfortable also said that their productivity was not affected. 


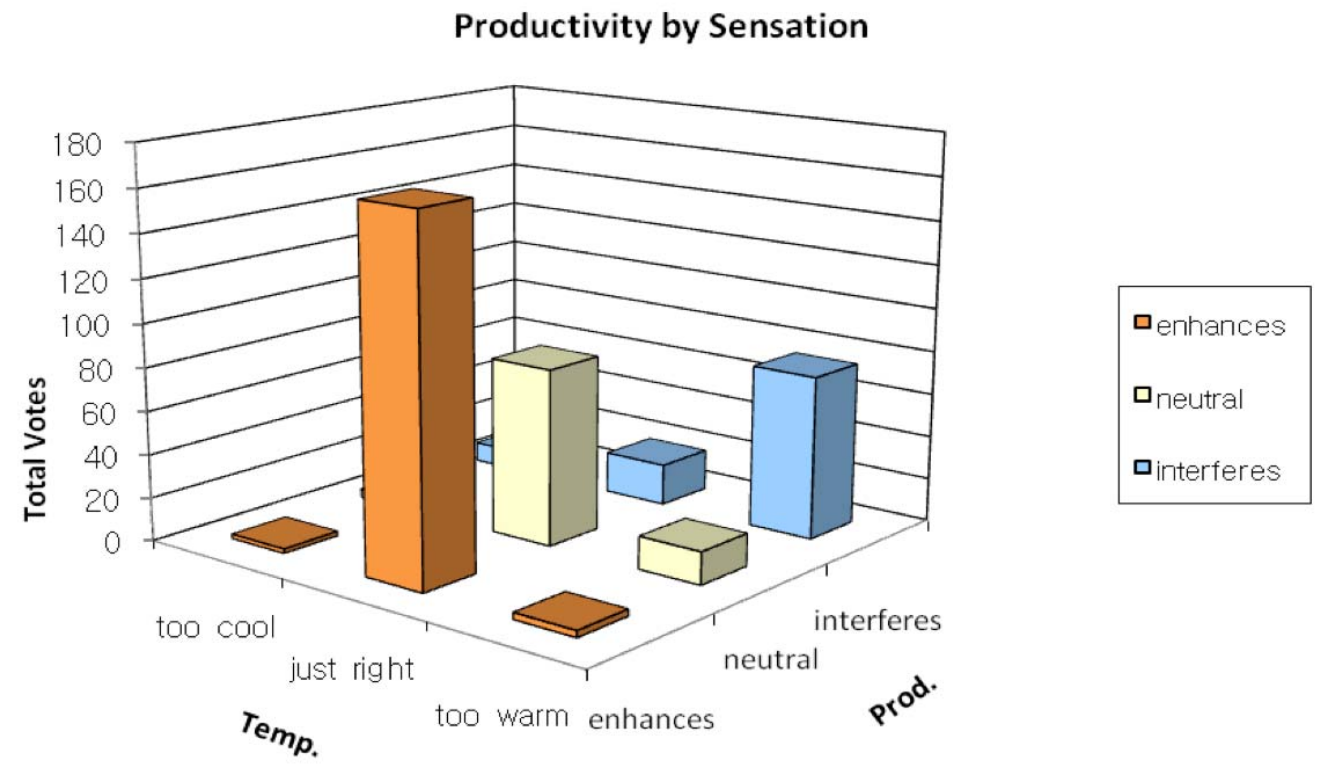

Figure 57. Correlation between thermal sensation and perceived productivity. 
Thermal Sensation Related to Temperature

The overall relationship between desktop level indoor temperature and sensation is shown in Figure 58. The scale of y-axis shows sensation ranging from "much too cool" (-3) to "much too warm" (3). The line on the graph is a linear fit to the data. This fit is toward the warmer side, indicating that the survey users tend to be warmer during the observed period.

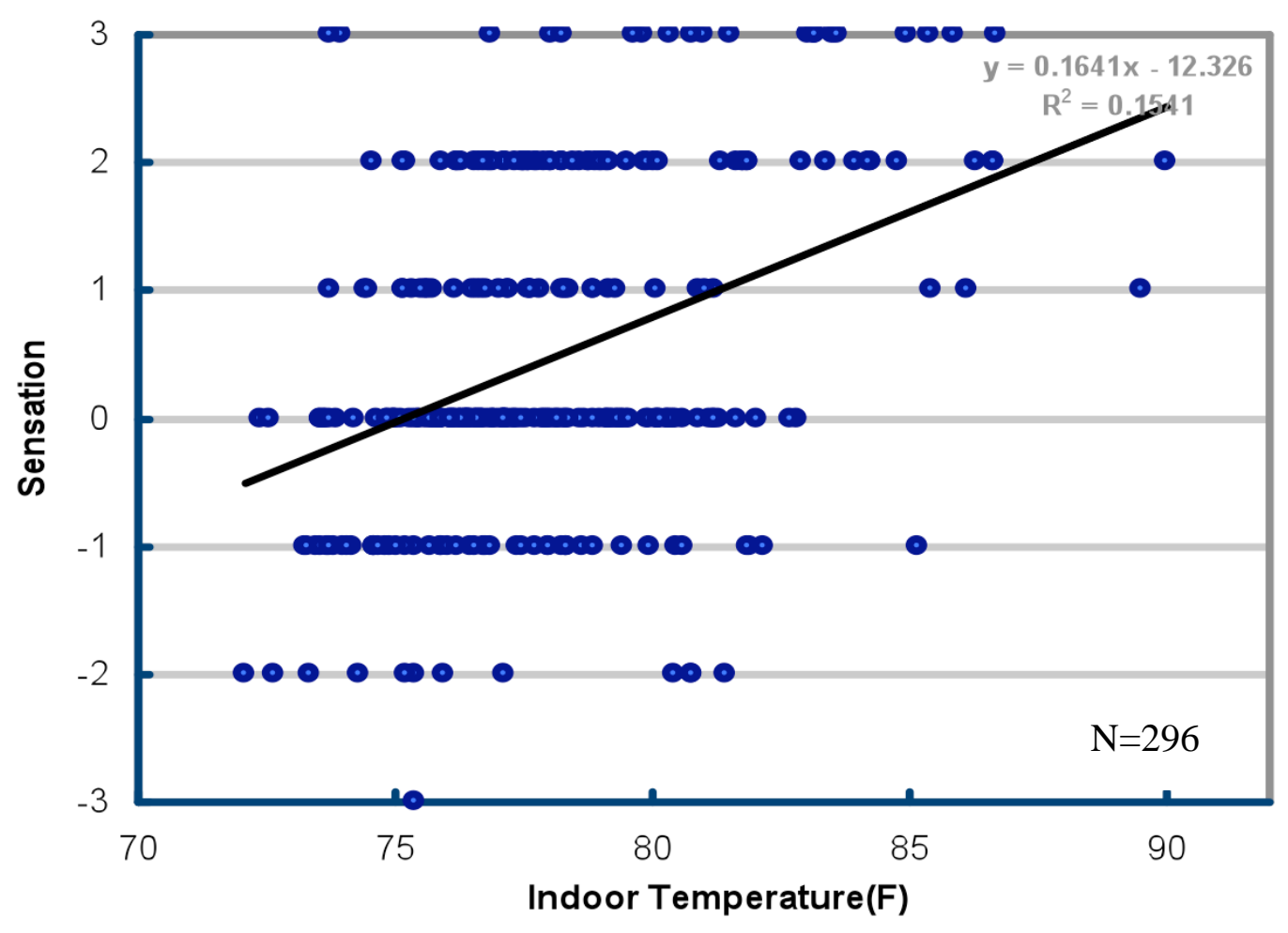

Figure 58. Thermal sensations vs. indoor temperature 


\section{Hot Day - weather test \#1}

Figure 59 shows the outdoor temperature and the sensation votes for the test day (on the right) and the corresponding baseline day (on the left). For the sensation plots, the y-axis represents votes where a -3 is "much too cool," 0 is "comfortable" (neither warm nor cool), and 3 is "much too warm." Figure 59 indicates that the survey responses are becoming warmer during the course of the day, for both the August 28 baseline and the August 14 test day. There is no significant difference between the baseline and test day votes.
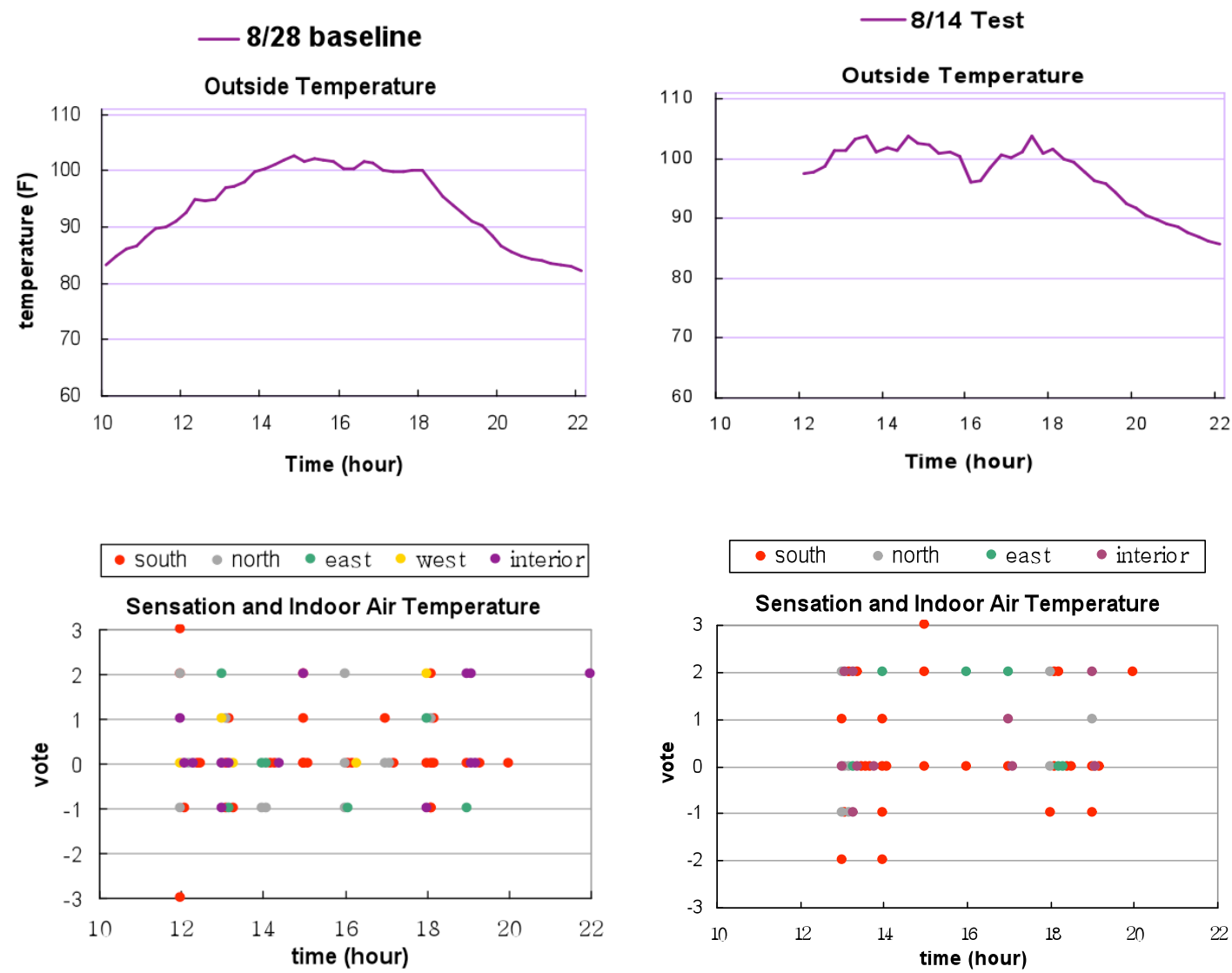

Figure 59. Daily outdoor temperature and sensation votes in the five zones for the $8 / 28 / 2007$ baseline and the $8 / 14 / 2007$ test day

Figure 60 indicates the average indoor air temperatures of each hour in the five zones for the test day (on the right) and the corresponding baseline day (on the left). The figure explains the similarity in thermal sensation to that seen in Figure 58 by showing that the trend that the indoor temperatures of the five zones are increasing on both baseline and test days. The indoor temperatures of the test day are slightly higher than the temperatures on the baseline day. 

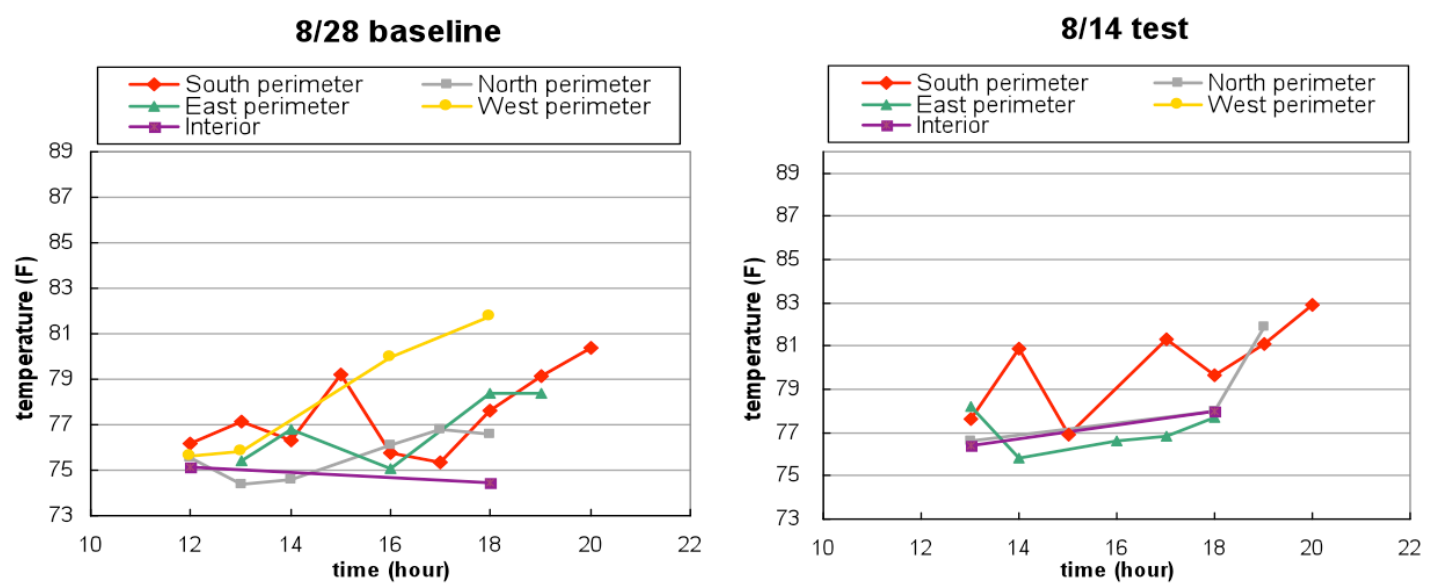

Figure 60. Average indoor air temperatures in the five zones for the $8 / 28 / 2007$ baseline and the $8 / 14 / 2007$ test day

Figure 61 shows the split of sensation votes on the test and baseline day. "Much too warm" and "too warm" votes are in orange; "comfortably warm," "comfortable," and "comfortably cool" votes are pale yellow; and "too cool" and "much too cool" votes are in blue. The chart on the left shows the general split of the votes with the baseline day on the left and the test day on the right. The chart on the right displays the same information, but with each category based on zero. This allows a quicker comparison between percentage changes in the categories. Figure 61 indicates an increase in votes for "too cool" and "too warm" in comparison to the baseline day while "just right" votes are decreasing.
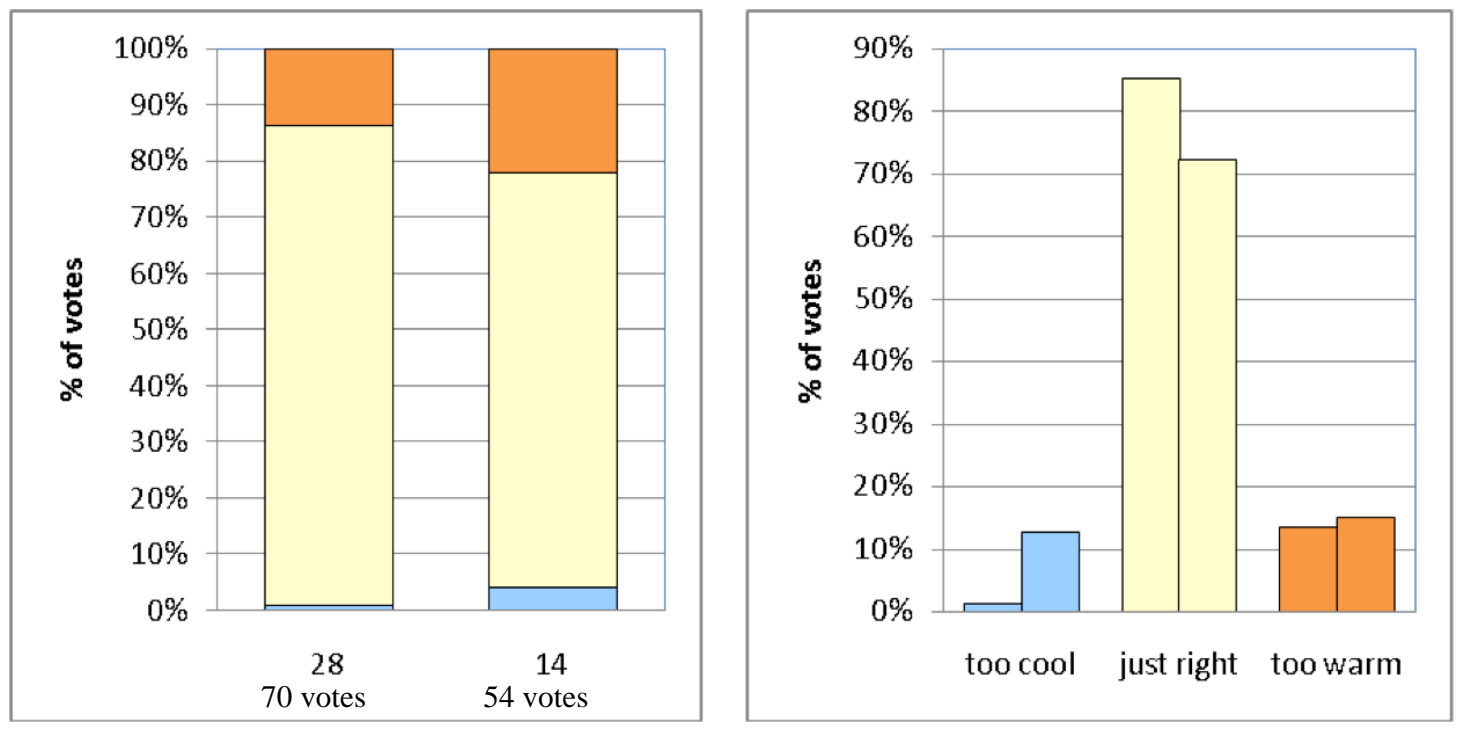

Figure 61. Breakdown of sensation votes for the $8 / 28 / 2007$ baseline and the $8 / 14 / 2007$ test

Figure 62 shows the breakdown of self-reported productivity for the test and baseline day. Here, the orange represents people who said that the temperature enhances their ability to get their work done. The pale yellow represents the neutral group, and blue represents the group 
who said that the temperature interferes with their ability to get their work done. The percentage of neutral responses decreases on the test day. The number of "enhance" votes however, remains about the same on both the test and baseline days, while the number of "interfere" vote increases.
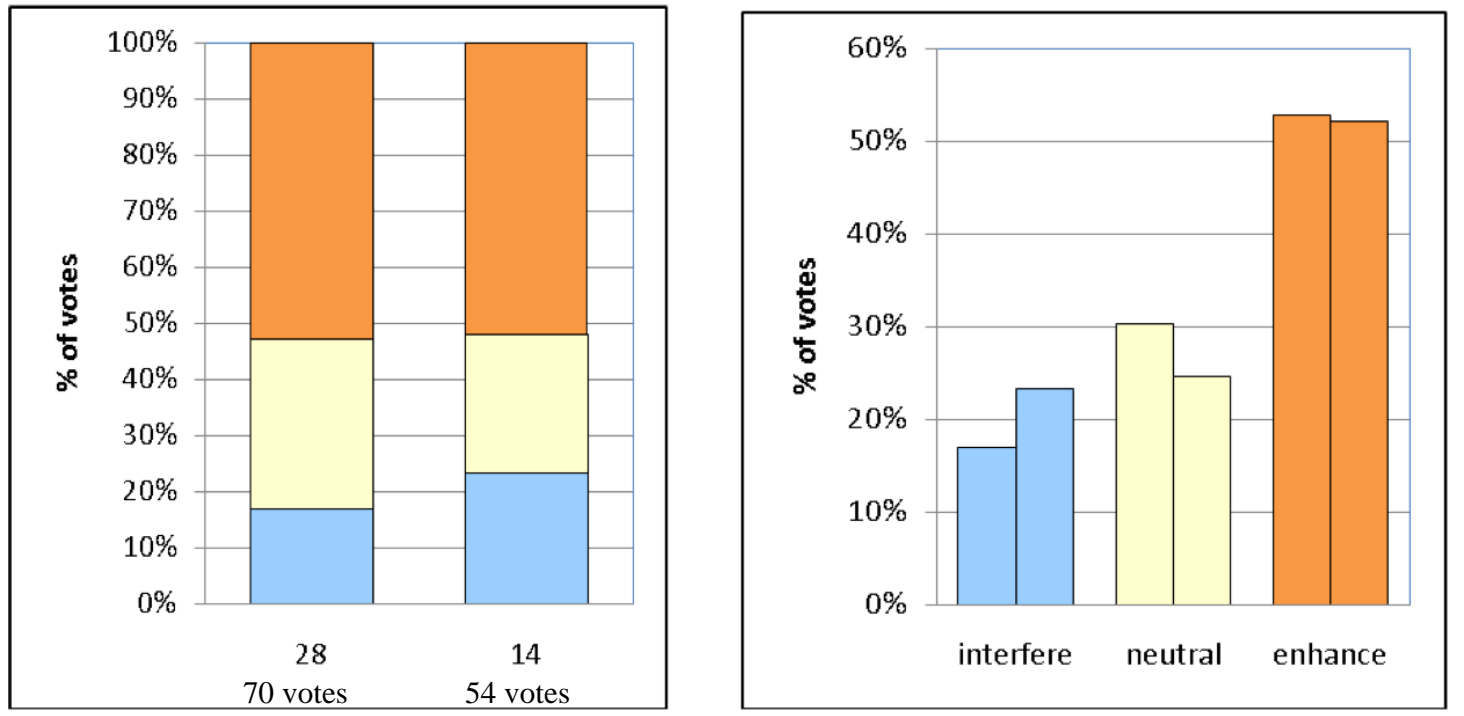

Figure 62. Breakdown of productivity votes for the $8 / 28 / 2007$ baseline and the $8 / 14 / 2007$ test 
Hot Day - weather test \#2

Figure 63 indicates that the survey responses shifted to "too warm" during the afternoon of the periods August 15 and August 16 test days.
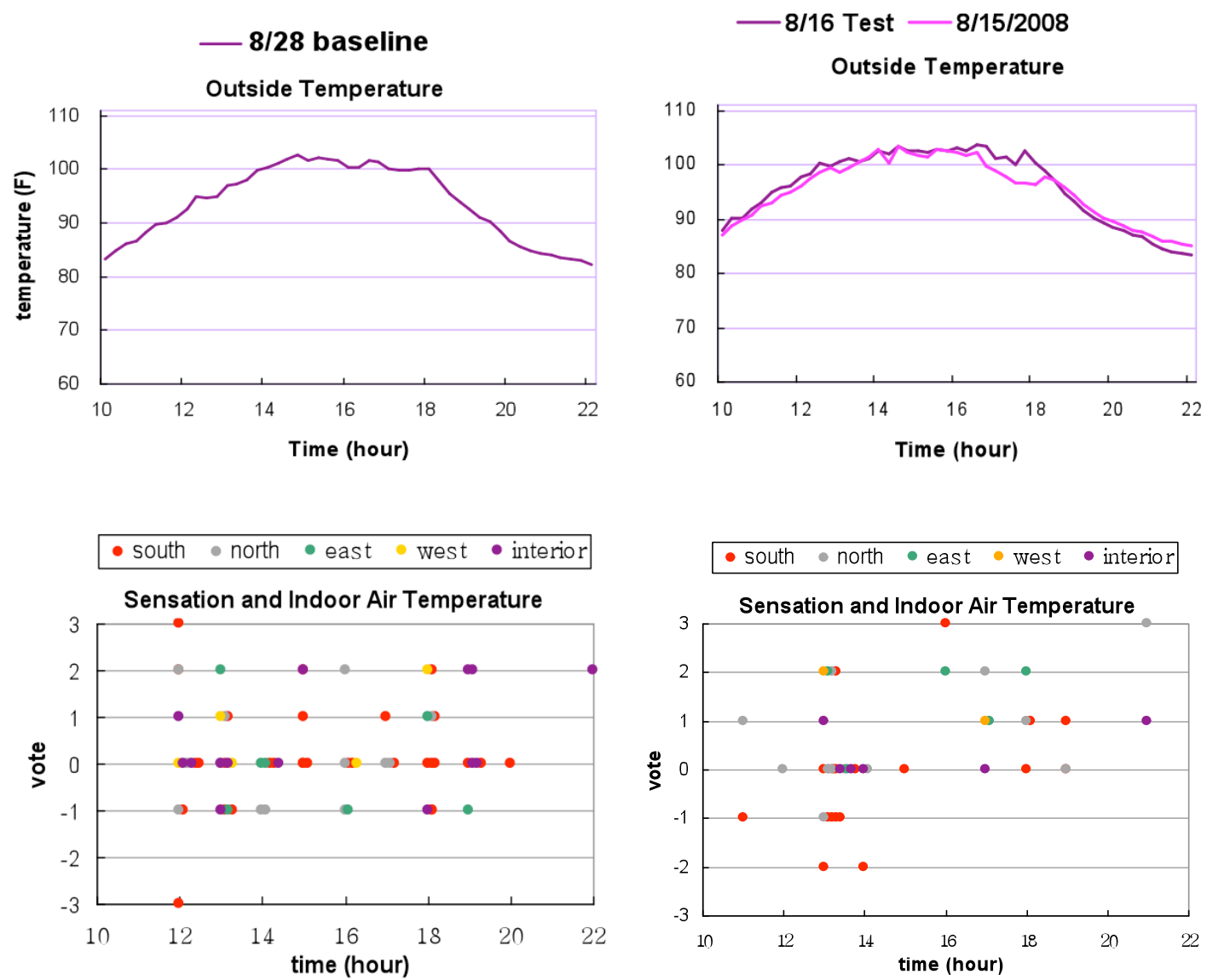

Figure 63. Daily outdoor temperature and sensation votes for the $8 / 28 / 2007$ baseline and combined votes from the $8 / 15 / 2007$ and $8 / 16 / 2007$ test days 
Figure 64 shows the overall indoor temperatures of the test day are slightly higher than the temperatures of the baseline day, and there is only a very small increase during the course of the day.

$8 / 28$ baseline

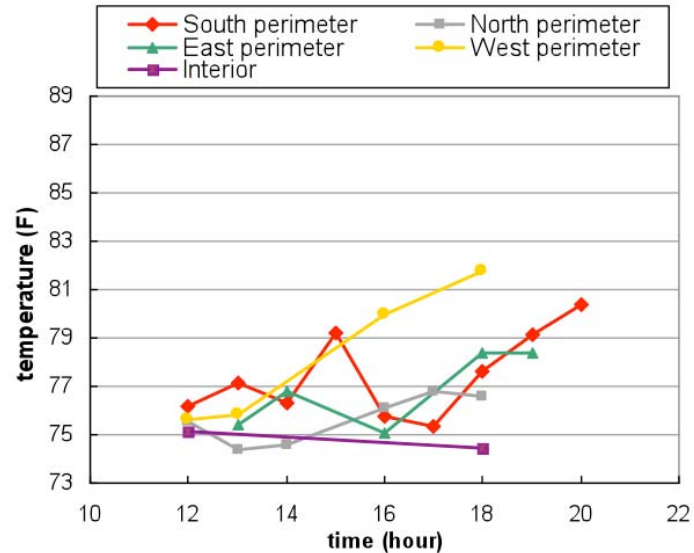

$8 / 15,8 / 16$ test

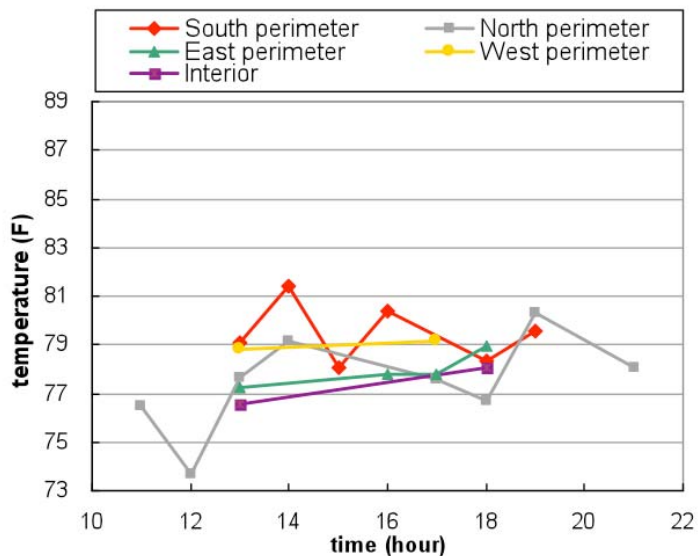

Figure 64. Average indoor air temperatures in the five zones for the $8 / 28 / 2007$ baseline day and combined temperatures from the $8 / 15 / 2007$ and $8 / 16 / 2007$ test days

Both graphs in Figure 65 show a slight increase in extreme votes (both "too warm" and "too cool") in comparison to the baseline day. The result is that approximately $74 \%$ of respondents remain in the "just right" category.
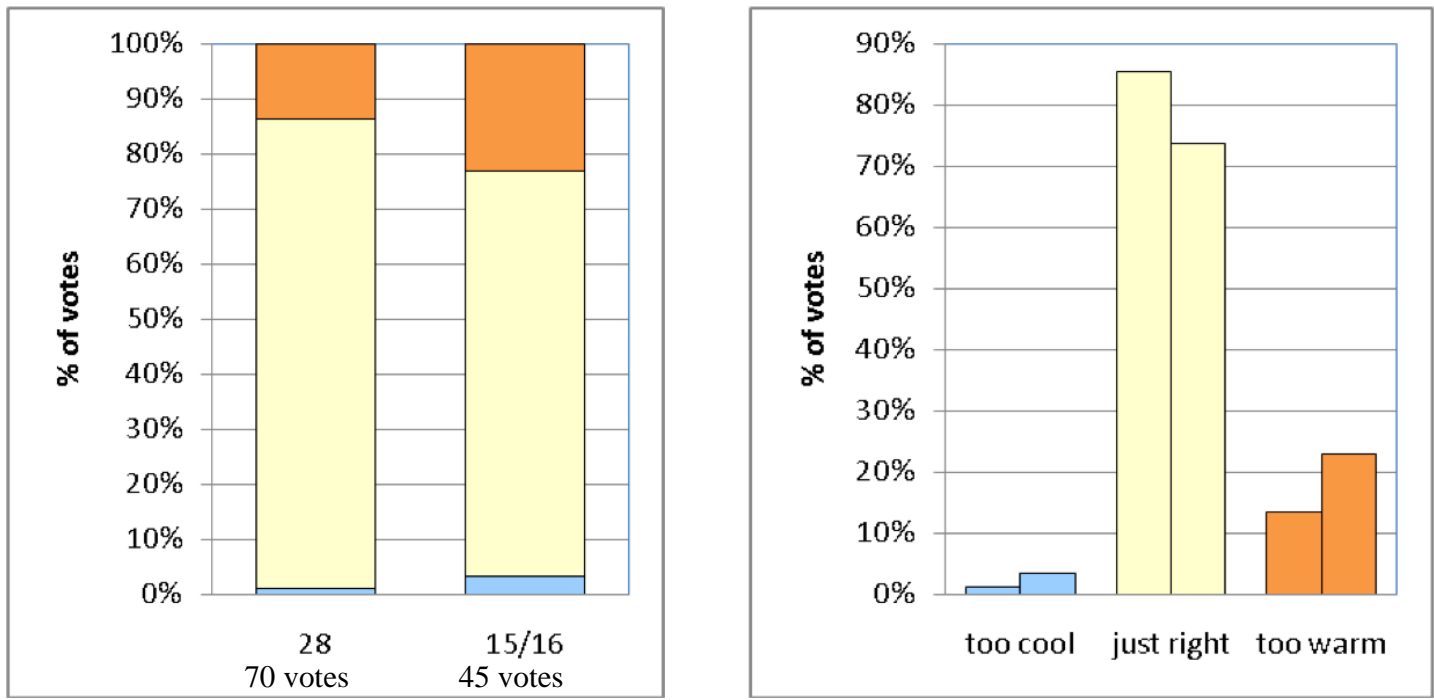

Figure 65. Breakdown of sensation votes for the $8 / 28 / 2007$ baseline day and combined votes from the $8 / 15 / 2007$ and $8 / 16 / 2007$ test days 
Figure 66 shows that the percentage of neutral responses remains about the same on both the test and baseline days. The number of "enhance" votes however, decreases on the test day, while the number of "interfere" votes increase slightly. In both cases, the difference is about $9 \%$.
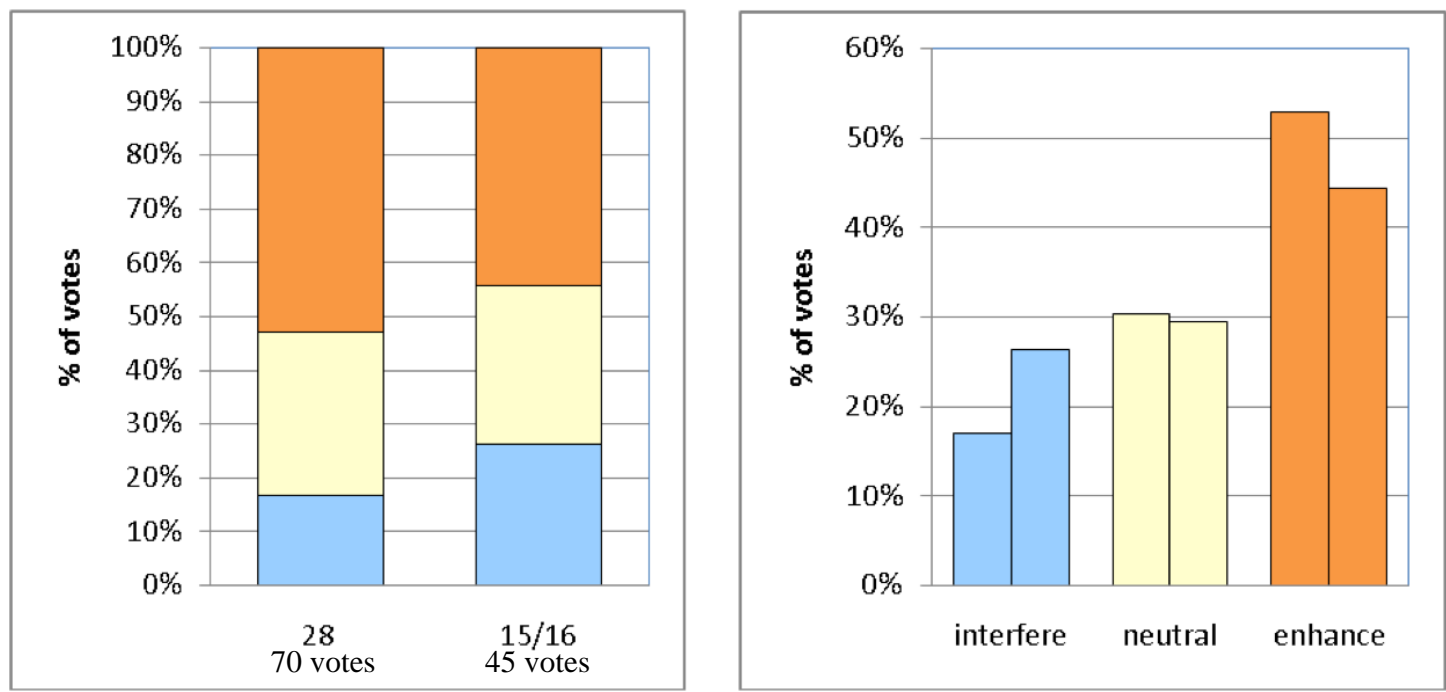

Figure 66. Breakdown of productivity votes for the $8 / 28 / 2007$ baseline and combined votes from the $8 / 15 / 2007$ and $8 / 16 / 2007$ test days 


\section{Extreme Hot Day - Weather Test}

Figure 67 indicates that the survey responses shifted to "too warm" during the course of the August 28 baseline and August 29 test days, and that the tendency is much more significant on the test day.
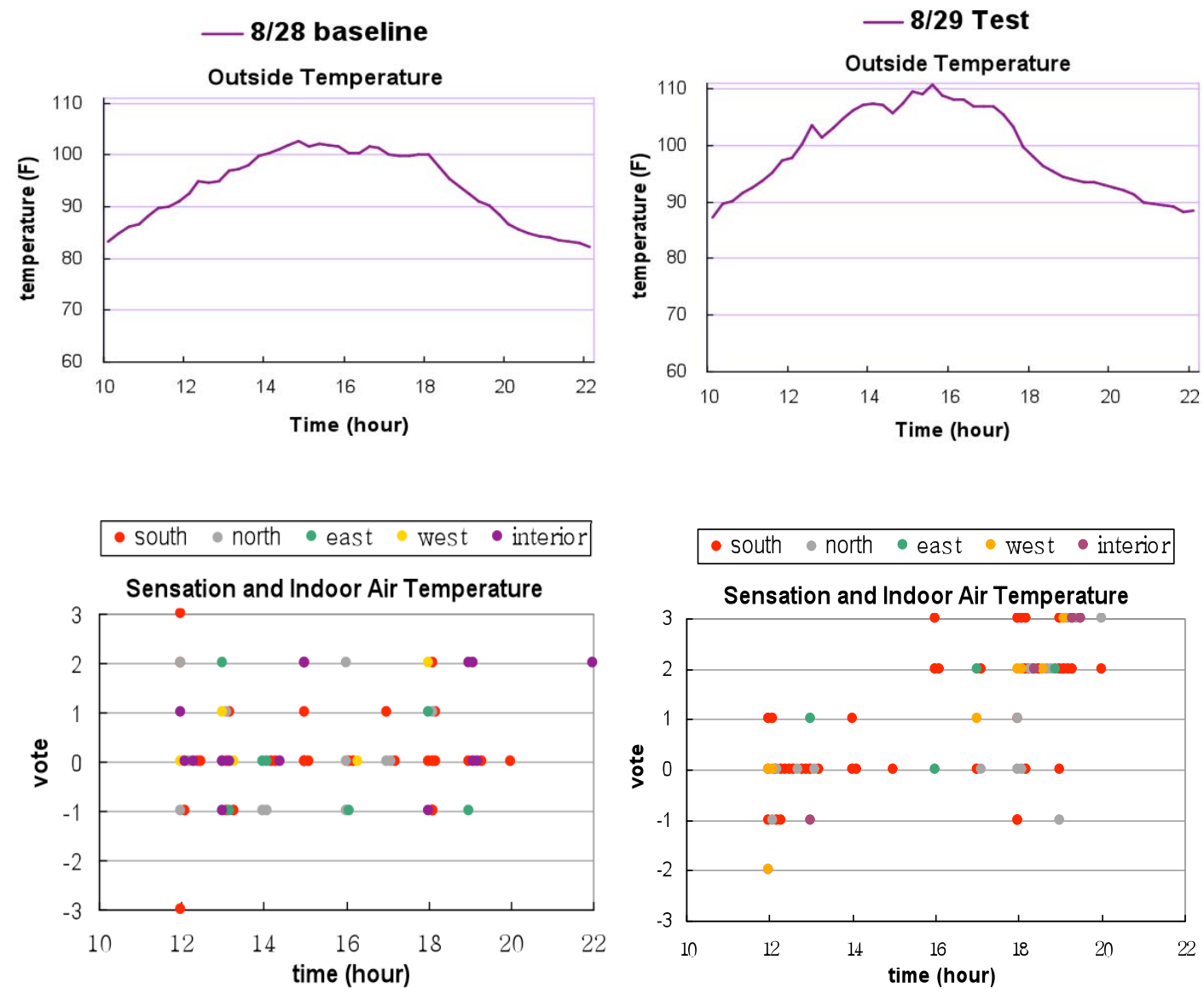

Figure 67. Daily outdoor temperature and sensation votes for the $8 / 28 / 2007$ baseline and the $8 / 29 / 2007$ test day 
In Figure 68, indoor temperature of both the August 28 baseline and August 29 test days was around $75^{\circ} \mathrm{F}$ at 12 p.m.; however, temperatures of the five zones (including the interior zone) increased significantly on the test day. It is possible that the outside hot weather influenced indoor temperature in the perimeter zones through strong solar radiation.

The significant increase in warmer votes (shown in Figure 67) and indoor temperature (shown in Figure 68) most likely resulted from a problem with an AHU that occurred around 4 p.m. The AHU was responsible for the air-conditioning on the third floor, and it tripped off around 4 p.m. causing the substantial increase in indoor temperature after that. In the Figure 67, the peak temperature $\left(89^{\circ} \mathrm{F}\right)$ in the west perimeter at 5 p.m. was collected from the data logger located on the third floor.
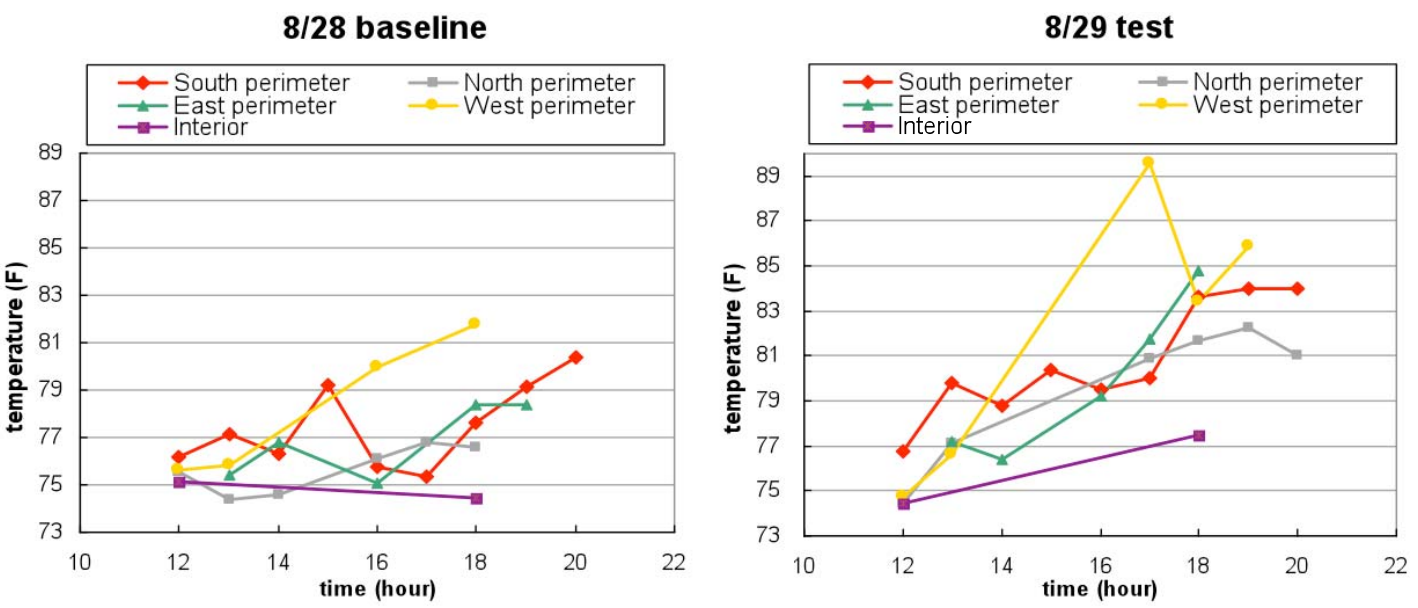

Figure 68. Average indoor air temperatures in the five zones for the $8 / 28 / 2007$ baseline and the $8 / 29 / 2007$ test day 
Figure 69 shows the number of "too warm" responses increased on the test day, albeit to a much greater degree than hot weather condition test days. Some of this increase can be attributed to the high temperatures both indoors and outdoors on August 29.
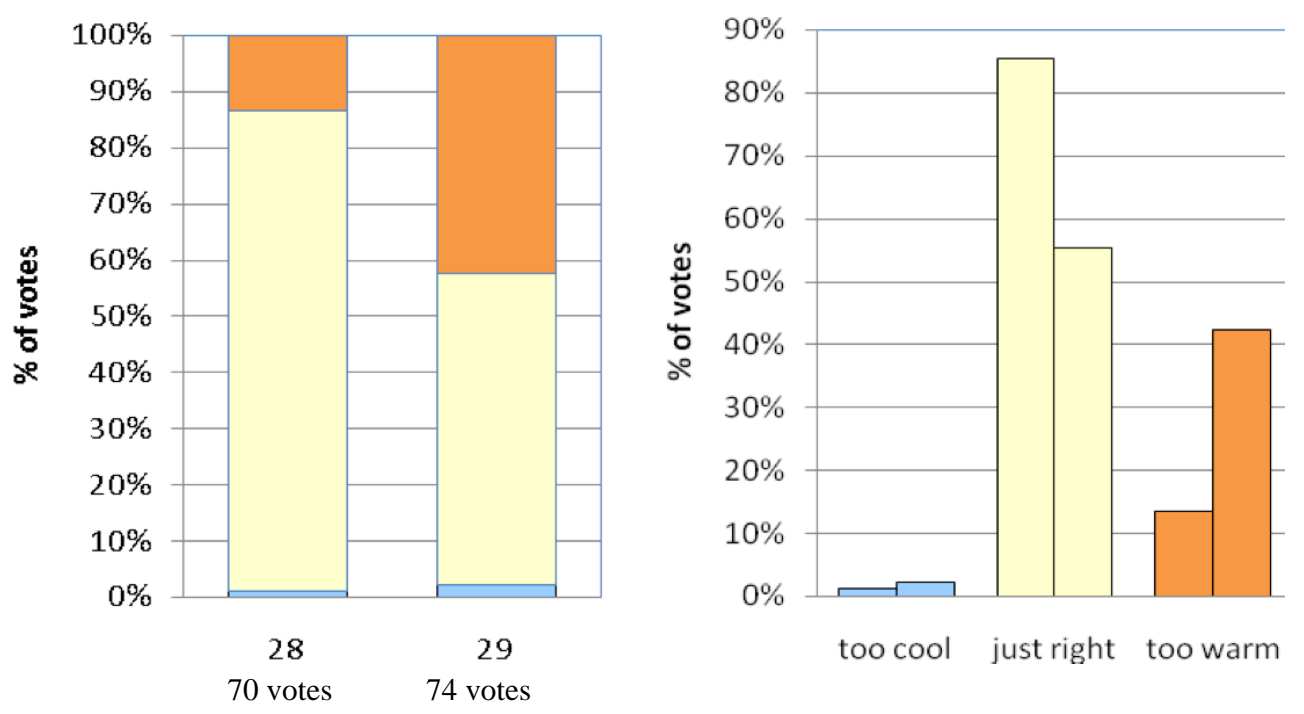

Figure 69. Breakdown of sensation votes for the $8 / 28 / 2007$ baseline and the 8/29/2007 test day

When looking at productivity in Figure 70, the number of "enhance" votes again decreases on the test day while the number of "interfere" votes again increases. The differences on this day are dramatic -15 and 24 percentage points respectively. This may be attributable to the warm sensation from the extreme temperatures on 8/29. Another reason for that is the AHU problem. On the test day, the AHU serving the third floor was tripped off at around 4 p.m., and the third floor was too hot after that. 

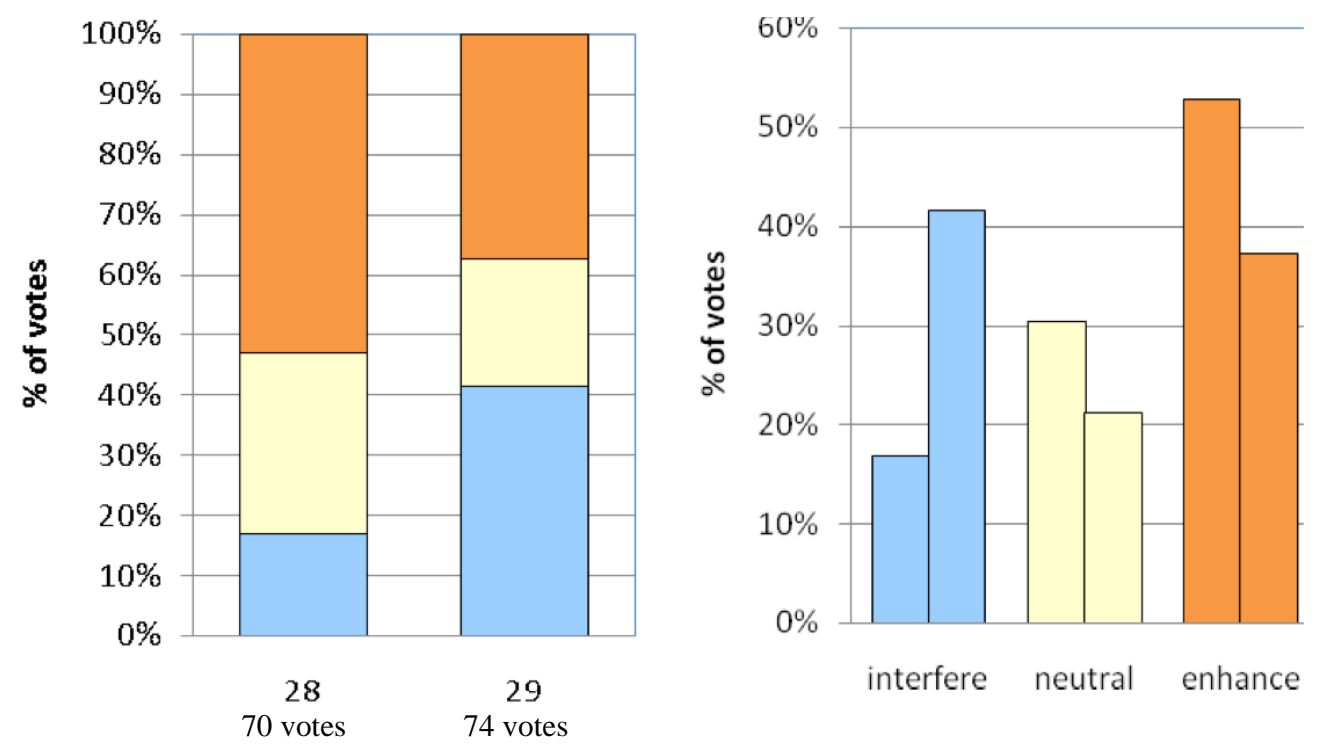

Figure 70. Breakdown of productivity votes for the $8 / 28 / 2007$ baseline and the $8 / 29 / 2007$ test

\section{Cool Day - Weather Test}

The baseline day for the cool weather condition test is also August 28 in spite of the difference in outdoor temperature, because the number of survey responses from a cooler baseline day was too small for a valid comparison. Figure 71 shows that the survey responses are slightly trending toward the warmer side during the course of September 18 test day. According to Figure 72, the five indoor air zone temperatures show similar ranges from 2 p.m. to 6 p.m. on the two days, suggesting that the indoor thermal condition for the August 28 baseline and the September 18 test day was similar. 

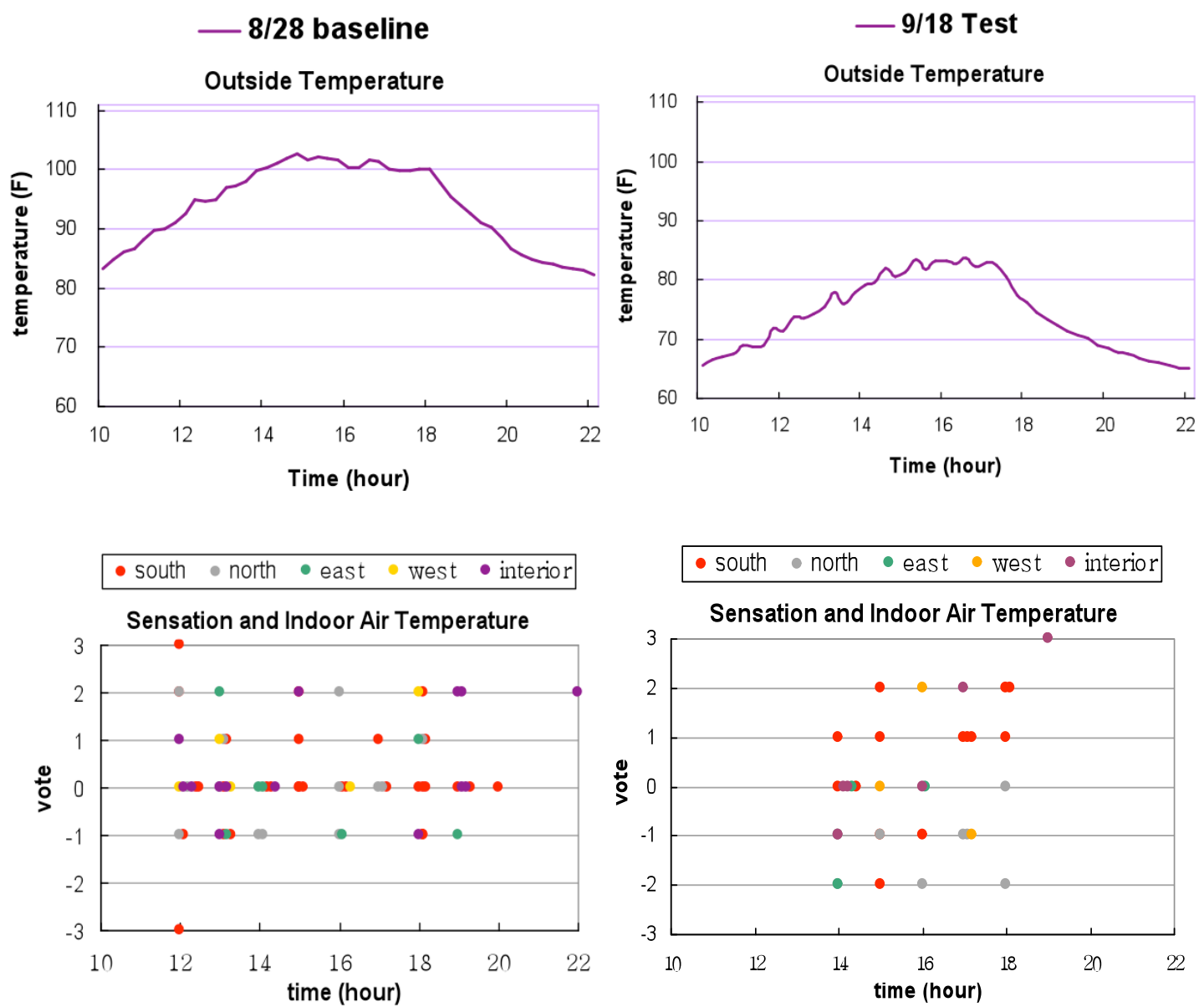

Figure 71. Daily outdoor temperature and sensation votes for the $8 / 28 / 2007$ baseline and the $9 / 18 / 2007$ test days 
Figure 72 shows that the indoor temperatures of five zones are relatively stable during the 9/18 test day.
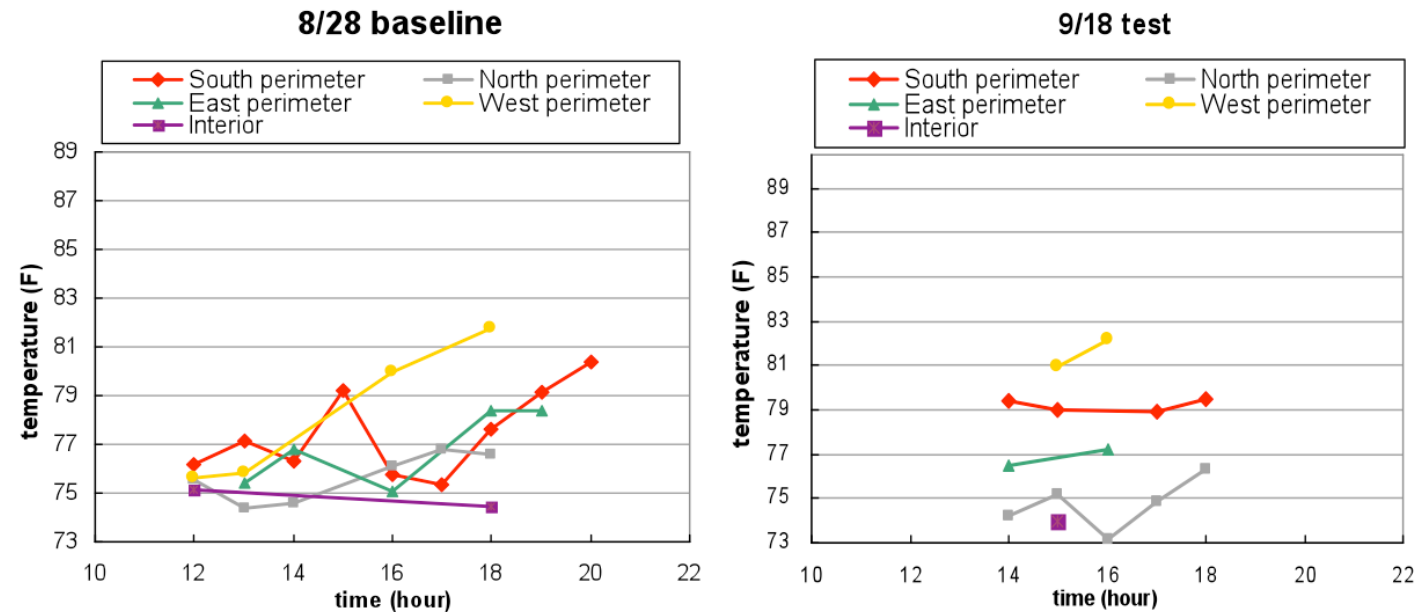

Figure 72. Average indoor air temperatures in the five zones for the $8 / 28 / 2007$ baseline and the $9 / 18 / 2007$ test days

In Figure 73, sensation votes show an increase in "too warm" and "too cool" votes in comparison with the baseline day; whereas the percentage of responses in the "just right" category decreases. The productivity votes in Figure 74 show an increase in "interfere" votes and a decrease in "enhance" votes. As a result, the percentage of "neutral" votes decreases. However, the percentage of "enhance" votes is greater than the sum of "interfere" and "neutral" vote percentages.
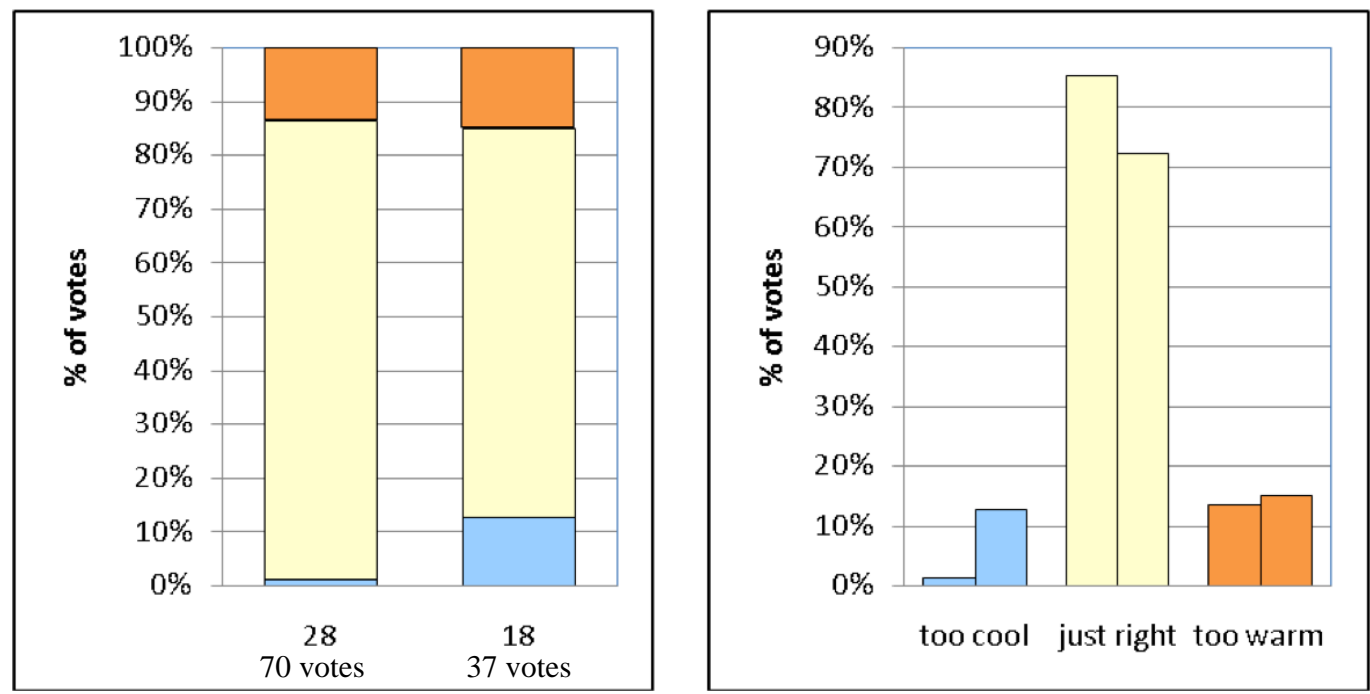

Figure 73. Breakdown of sensation votes for the $8 / 28 / 2007$ baseline and the $9 / 18$ 12007 tests 

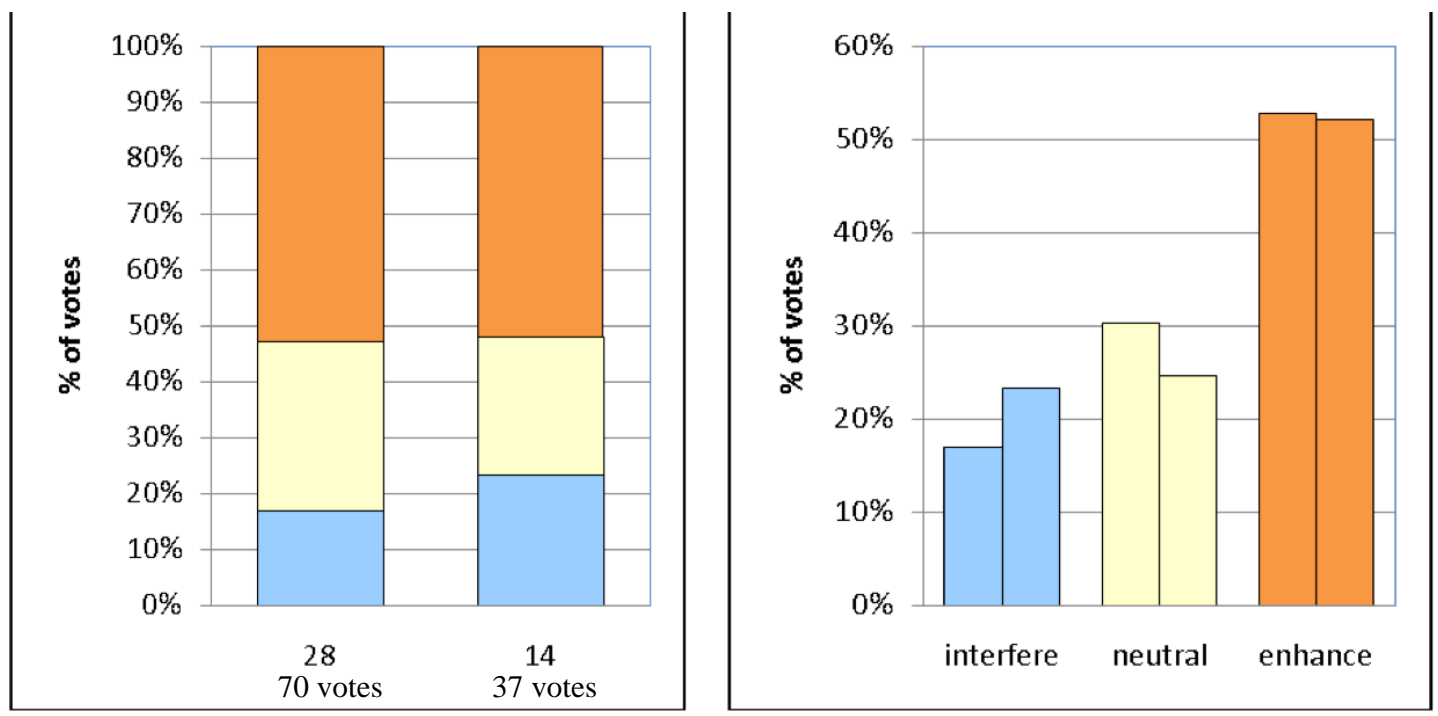

Figure 74. Breakdown of productivity votes for the $8 / 28 / 2007$ baseline and the 9/18/2007 test

\section{Thermal Comfort Summary}

\section{Productivity}

Compared to the baseline days, the test days show a decrease in the percentages of persons who rated their productivity as "enhanced." This decrease may be due to the increase in "too-warm" votes on the test days. There were two main reasons for this. First, the setpoint of normal operation was $74^{\circ} \mathrm{F}-76^{\circ} \mathrm{F}$, much higher than that of the other office building tested, which was $70^{\circ} \mathrm{F}-72^{\circ} \mathrm{F}$. Second, the 2007 surveys were almost entirely performed during the afternoon, when the temperatures were high on both test days (during temperature setup) and baseline days.

It continues to be true as in previous years that most respondents chose the neutral point for the thermal sensation question. In 2007, however, the productivity responses were more often in the extremes, with "enhance" votes outnumbering "interfere" votes. This is a change from last year's findings, where the neutral point was most often selected. Across both test days and baseline days thermal sensation votes show a standard inverted " $U$ " distribution.

\section{Thermal Sensation}

The neutral zone for thermal comfort includes "comfortably warm," "comfortable" (neither warm nor cool), and "comfortably cool." In this category, about the same number of users indicated that they were comfortably cool or comfortably warm. The users' comments suggest an awareness of the pre-cooling with temperature setup test strategy. Comments in the morning hours mostly indicate that occupants are comfortable. As the day progresses, some comments change to "too warm." The number of too warm comments increased until the early evening hours. Some comments even suggest that after-hours workers are the warmest, due to the AHU system shutting off.

The plot in Figure 75 shows all of the thermal comfort votes for all test and baseline days. The non-parametric line (solid black) indicates the general trend as the temperature increases from a 
high probability of "too cool" votes (7 on this scale) to a high probability of "too warm votes" (1 on this scale). The dotted line, as well as the significant overlapping of votes from each sensation category, illustrates the high variability of survey respondents at any given temperature.

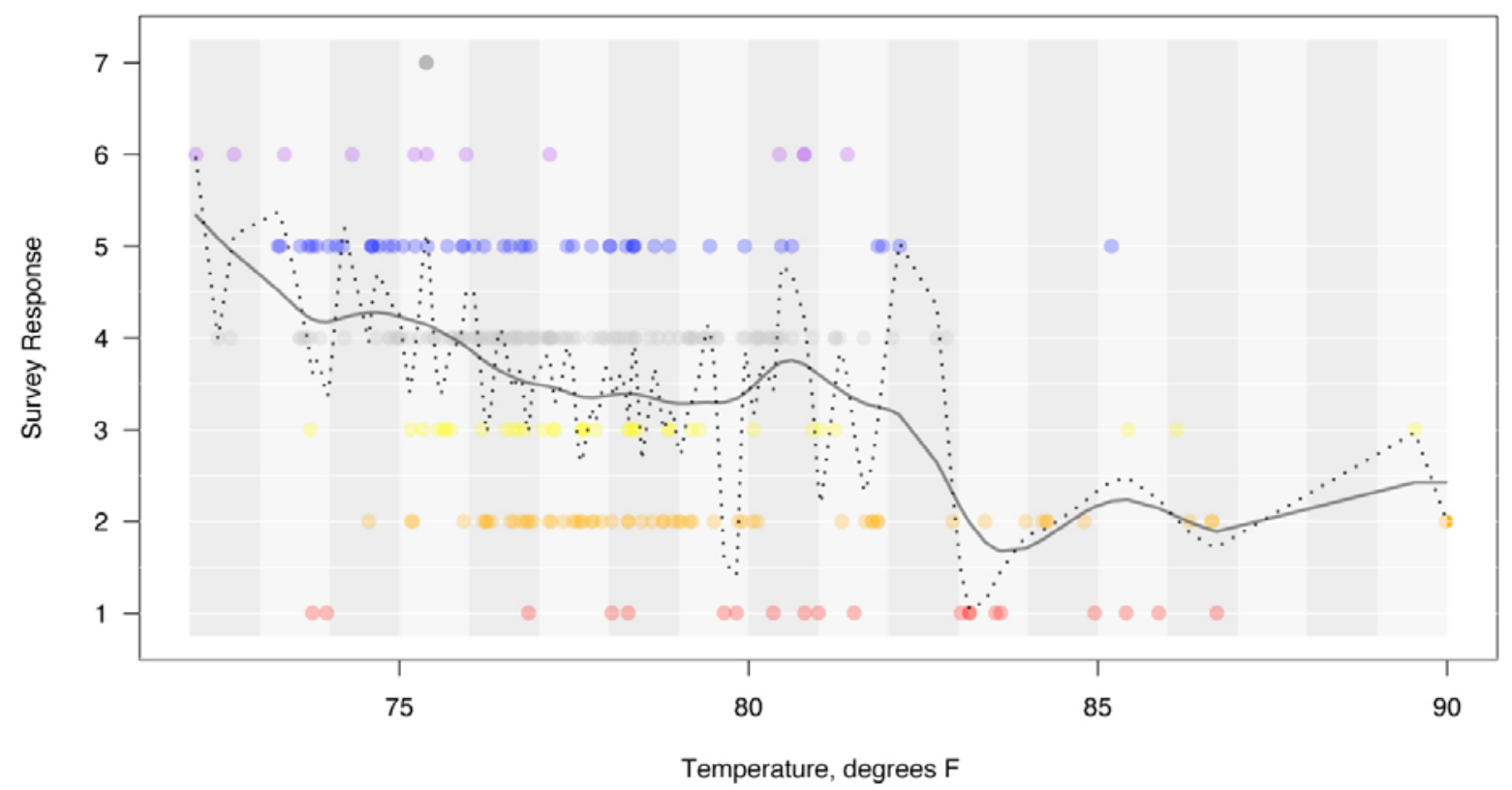

Figure 75. Plot of survey responses to thermal comfort using data from all days. 7 = "Too Cool" and 1 = "Too Warm." $N=287$.

The CDF plot in Figure 76 indicates the indoor air temperature level where $20 \%$ of the building occupants will become dissatisfied with the temperature. Votes of 1 and 2 were used to determine the "too warm" bin and votes of 6 and 7 were used to determine the "too cool" bin. The "too cool" $(\mathrm{n}=17)$ data are represented by the blue dotted line, and the "too warm" $(\mathrm{n}=78)$ data are represented by the red line. The solid red line on the plot indicates that any temperature above $77^{\circ} \mathrm{F}$ will produce greater than $20 \%$ dissatisfaction with the thermal environment in the "too warm" dimension. Although it is tempting to interpret the dotted blue line to determine a threshold for "too cool" (working from the right to the left), the relatively low number of survey responses in this bin $(n=17)$ prohibits any reasonable assumptions from being made. Therefore, these data should only be used to estimate the threshold for the occupants' tolerance of warm temperatures. 


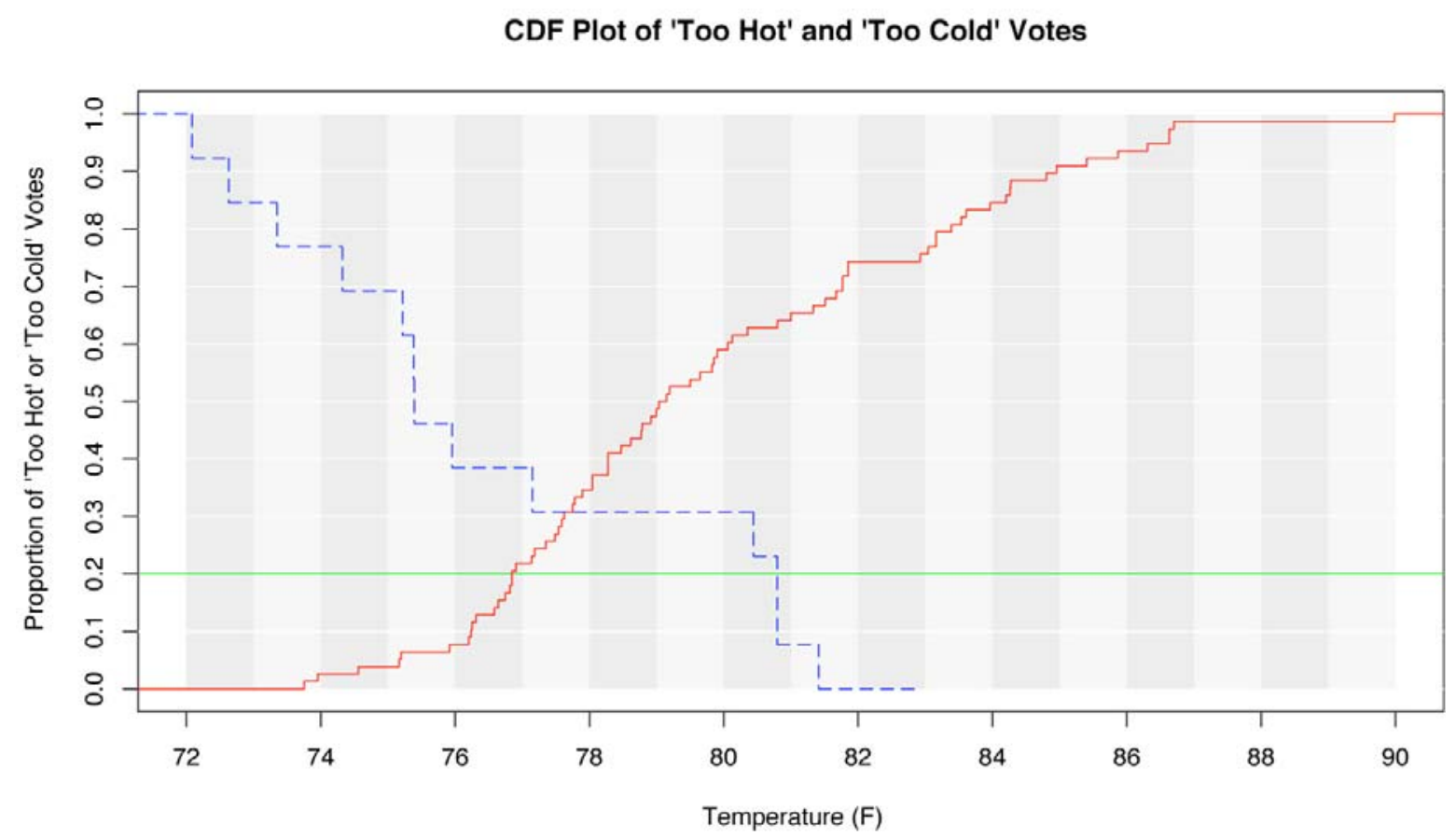

Figure 76. Cumulative Distribution Function (CDF) plot of binned "too hot" and "too cold" votes

The logit curves in Figure 77 can be used to predict the probability of an event-in this case "too warm" or "too cool" thermal dissatisfaction, given the indoor temperature. The Y-axis indicates the probability that a randomly selected individual will be dissatisfied at a given set-point temperature. The green line represents the $20 \%$ dissatisfaction threshold cited in the ASHRAE and ISO indoor environmental standards. The above plot indicates that greater than $80 \%$ of occupants will be satisfied with the indoor air temperature as long as it remains below $77^{\circ} \mathrm{F}$.

Over the range of indoor temperatures recorded, this plot shows that there is a much greater probability of an occupant being "too warm" rather than "too cool." 


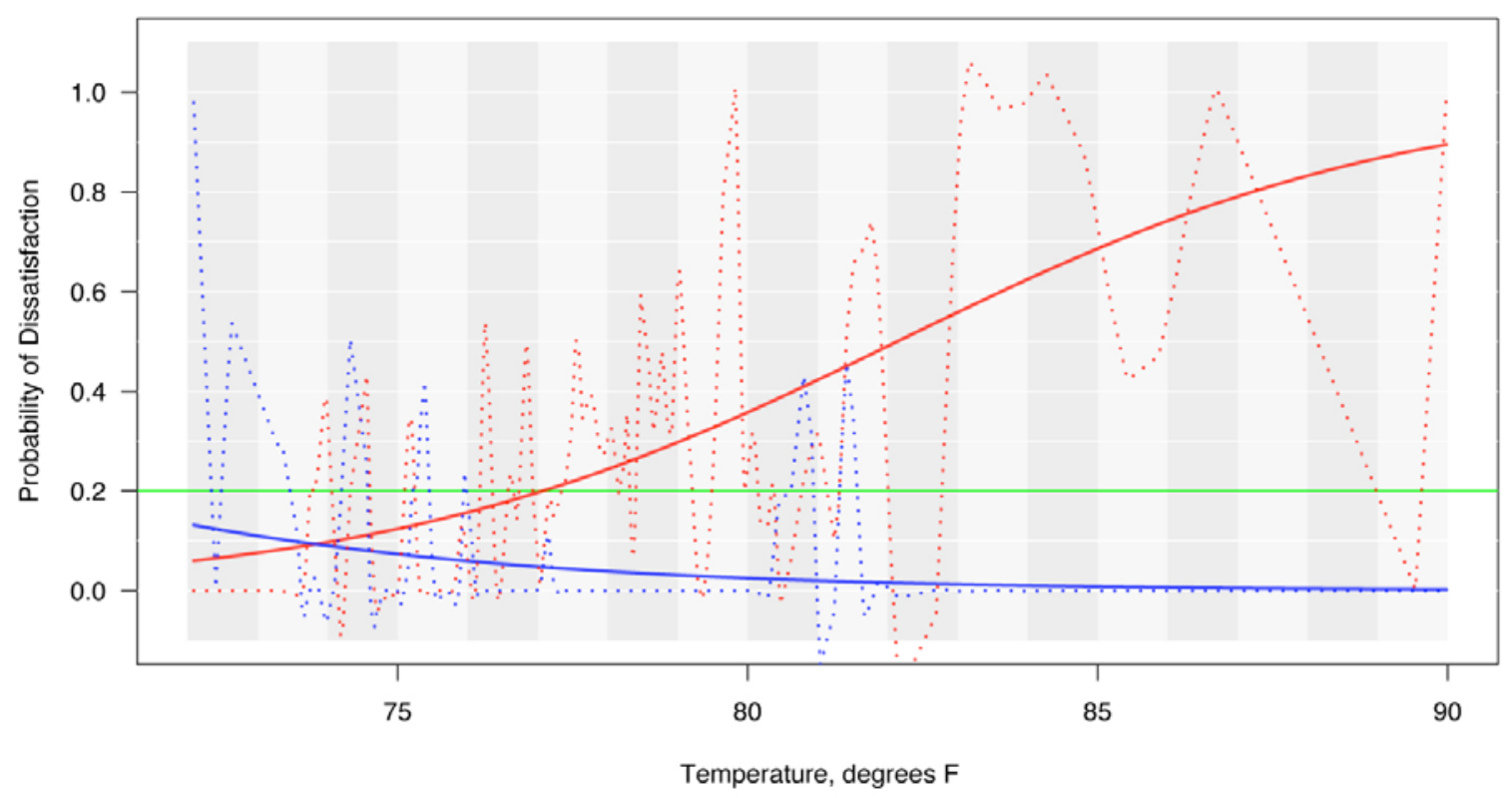

Figure 77. Plot of binned "too warm" and "too cool" votes with logit curves fitted to the binned sensation responses. "Too cool" = votes 6 and $7, N=17$ (descending curve), and "Too Warm" = votes 1 and 2, $N=78$ (ascending curve). The dotted lines provide a visual approximation of the variability of the data 


\subsection{Conclusions and Recommendations}

\subsection{Conclusions}

On the thermal side, the following conclusions can be drawn from the field tests of pre-cooling strategies in the commercial buildings:

- Pre-cooling and demand shift strategies worked well in the office buildings tested under extreme hot weather and were able to reduce cool load significantly $(20 \%-30 \%$ on hot days).

- There is a slight increase in the number of cold complaints in the morning on extreme hot days.

- Properly controlled exponential temperature setup in the shed period can maximize the load reduction.

- Night pre-cooling has no noticeable effects on second-day cooling load reduction.

The following conclusions are drawn from the comfort surveys:

- In general, the survey results did not show a significant difference between test days and baseline days with respect to overall thermal comfort and productivity. However, there was a difference in the daily trends on test days with pre-cooling and those without. While the overall numbers were comparable, on test days with pre-cooling, users tended to be warmer in the afternoon.

- The majority of the votes were in the neutral category for both thermal comfort and productivity. However, the neutral zone for thermal comfort includes comfortably warm, comfortable (neither warm nor cool), and comfortably cool. In this category, more users indicated that they were comfortably warm than comfortably cool. In addition, almost all of the written complaints were about warm conditions in the afternoon. This indicates that the building may be too warm in the afternoon in general during the extreme hot day.

\subsection{Recommendations}

This study has established the potential for pre-cooling and demand shift strategies, and it has also identified several uncertainties that should be resolved before pre-cooling can be reliably implemented in large commercial buildings. The following work is proposed:

- Develop guidelines for appropriate control strategies according to building characteristics. Different buildings with different mechanical systems and different levels of control may require different pre-cooling strategies. For example, the zone temperature setpoint strategies studied in the work reported here are only practical if the zone temperatures are controlled by networked digital controllers. A detailed guide to selecting, implementing and testing demand-shifting control strategies by building mechanical system and control type is needed to support their routine use.

- Assess the market potential. Assessment tools for small and large commercial buildings could be used to estimate the statewide potential in California for demand reduction in commercial buildings. This work would require an estimate of the building stock in different climate zones within California. The building stock statistics could be used 
along with estimates of demand reduction potential according to building type and location determined using the screening tool and guidelines described above.

Information from such a study would be extremely useful in identifying appropriate utility incentives for demand reduction according to building type and location.

- Further test the method to determine building thermal mass metrics. The research team developed and tested a method to calculate the temperature trajectory in the afternoon in the two buildings in this study. There are two key parameters affecting precooling performance: the effective building thermal mass and the thermal conductance between the thermal mass and the zone air. The first parameter determines how much cooling (Btu) can be stored in the mass for a given temperature change, while the second parameter determines the heat transfer rate (Btu/hour) for charging and discharging the thermal mass. Another metric of interest is the building time constant $(1 / \mathrm{s})$, calculated by dividing the thermal capacity by the thermal conductance, which determines the timescale of the building response to increases in zone temperature setpoint. The research team wants to further test the temperature trajectory method with different time constants in other buildings under a wider range of weather conditions.

\subsection{Benefits to California}

Reducing electrical peak demand has a huge economic and environmental benefit to California. Most existing buildings do not have space to install active thermal mass storage system and the capital investment is not cost effective with the current tariff. This study demonstrated that passive demand shedding can be as useful as active system and the load shed in this study is consistent with the results from the previous tests. In average, with this approach, commercial office buildings in California can reduce the peak load by $15 \%-30 \%$, with minimal effort on occupants' thermal comfort. 


\subsection{References}

Andresen, I., and M. J. Brandemuehl. 1992. "Heat Storage in Building Thermal Mass: A Parametric Study." ASHRAE Transactions 98(1).

Becker, R., and M. Paciuk. 2002. “Inter-related Effects of Cooling Strategies and Building Features on Energy Performance of Office Buildings." Energy and Buildings 34(2002): $25-31$.

Braun, J. E. 1990. “Reducing Energy Costs and Peak Electrical Demand Through Optimal Control of Building Thermal Storage." ASHRAE Transactions 96(2):876-888.

Coniff, J. P. 1991. “Strategies for Reducing Peak Air Conditioning Loads by Using Heat Storage in the Building Structure." ASHRAE Transactions 97:704-709.

Keeney, K. R., and J. E. Braun. 1997. “Application of Building Pre-cooling to Reduce Peak Cooling Requirements." ASHRAE Transactions 103(1):463-469.

Lee, K. H., and Braun, J. E. 2008a. “Development of Methods for Determining Demand-Limiting Setpoint Trajectories in Buildings Using Short-Term measurements." Building and Environment 43(10): 1755-1768.

Lee, K. H., and Braun, J. E. 2008b. “Evaluation of methods for determining demand-limiting setpoint trajectories in buildings using short-term measurements." Building and Environment 43(10): 1769-1783.

Mahajan, S., C. Newcomb, S. Bluck, and R. Ehteshamzadeh. 1993. Optimizing the Use of Energy Management and Control Systems to Reduce Peak Load and Energy Consumption in Nonresidential Buildings. Report to California Institute for Energy Efficiency and Sacramento Municipal Utilities District. Berkeley, California and Sacramento, California.

Morris, F. B., J. E. Braun, and S. J. Treado. 1994. "Experimental and Simulated Performance of Optimal Control of Building Thermal Storage." ASHRAE Transactions 100(1):402-414.

Ruud, M. D., J. W. Mitchell, and S. A. Klein. 1990. "Use of Building Thermal Mass to Offset Cooling Loads." ASHRAE Transactions 96(2):820-829.

Xu P. 2006. “Evaluation of Demand Shifting Strategies With Thermal Mass in Two Large Commercial Buildings." Proceedings of SimBuild 2006. IBPSA-USA. LBNL-60977. Cambridge, Massachusetts.

Xu, P. (Lawrence Berkeley National Laboratory) and Zagreus, L. (University of California at Berkeley). 2005. Demand Shifting with Thermal Mass in Large Commercial Buildings: Field Tests, Simulations and Audits. LBNL-58815. September. 


\subsection{Glossary}

\begin{tabular}{|c|c|}
\hline AHU & Air Handling Unit \\
\hline ASHRAE & American Society of Heating, Refrigerating and Air-Conditioning Engineers \\
\hline AVHOAT & average variance of hourly outside air temperature \\
\hline $\mathrm{CBE}$ & Center for the Built Environment \\
\hline $\mathrm{CDF}$ & cumulative distribution function \\
\hline CEC & California Energy Commission \\
\hline CPP & Critical peak pricing \\
\hline DDC & Digital direct control \\
\hline DLAT & Demand-Limiting Assessment Tool \\
\hline$\overline{\mathrm{DR}}$ & Demand response \\
\hline DRRC & Demand Response Research Center \\
\hline DRQAT & Demand Response Quick Assessment Tool \\
\hline EMCS & Energy management and control system \\
\hline EPA & Environmental Protection Agency \\
\hline GSA & General Services Administration \\
\hline HVAC & Heating, ventilating, and air conditioning \\
\hline ICM & Indoor climate monitor \\
\hline $\mathrm{ISO}$ & International Organization for Standardization \\
\hline LBNL & Lawrence Berkeley National Laboratory \\
\hline PG\&E & Pacific Gas and Electric \\
\hline PMV & Predicted mean vote \\
\hline SCE & Southern California Edison \\
\hline SMUD & Sacramento Municipal Utility District \\
\hline VAV & Variable air volume \\
\hline VFD & Variable frequency drive \\
\hline WBP & Whole Building Power (kW) \\
\hline
\end{tabular}




\subsection{Other Resources}

ASHRAE. 2005. Handbook of Fundamentals. Atlanta, Georgia: American Society of Heating, Refrigerating, and Air Conditioning Engineers, Inc.

Balaras, C. A. 1996. "The Role of Thermal Mass on the Cooling Load of Buildings. An overview of computational methods." Energy and Buildings 24 (1996):1-10.

Braun, J. E. 2003. “Load Control Using Building Thermal Mass.” ASHRAE Transactions 125(1):292-301.

Chaturvedi, N. 2000. Analytical Tools for Dynamic Building Control. Herrick Laboratories, Purdue University. Report No. HL2000-15. West Lafayette, Indiana.

Chaturvedi, N., and J. E. Braun. 2002 “An Inverse Gray-Box Model for Transient Building Load Prediction." International Journal of Heating, Ventilating, Air-Conditioning and Refrigerating Research 8(1).

Kyoung-ho, L., and J. E. Braun. 2006. Simple Demand-limiting Strategies for Using Building Thermal Mass in Commercial Buildings. Report to California Energy Commission. Sacramento, California.

Piette, M. A., D. Watson, N. Motegi, S. Kiliccote, and P. Xu. 2006. Automated Critical Peak Pricing Field Tests: Program Description and Results. Lawrence Berkeley National Laboratory. Report to Pacific Gas and Electric Company and California Institute for Energy and the Environment. LBNL-59351. Berkeley, California.

Rabl, A., and L. K. Norford. 1991. "Peak Load Reduction by Preconditioning Buildings at Night." InternationalJournal of Energy Research 15:781-798.

Xu, P., P. Haves, M. A. Piette, and J. E. Braun. 2004. "Peak demand reduction from pre-cooling with zone temperature reset of HVAC in an office." Proceedings of 2004 ACEEE Summer Study on Energy Efficiency in Buildings. Asilomar, Pacific Grove, California. Lawrence Berkeley National Laboratory and Purdue University. LBNL-55800. Berkeley, California and West Lafayette, Indiana.

Zagreus, L., C. Huizenga, E. Arens, and D. Lehrer. 2004. “Listening to the Occupants: A Webbased Indoor Environmental Quality Survey." Indoor Air 2004; 14 (Suppl 8): 65-74. 


\section{Appendix A.}

Request for Participation: Summer 2006 Demand Shifting with Thermal Mass 
APA-2 


\section{Appendix A. Request for Participation}
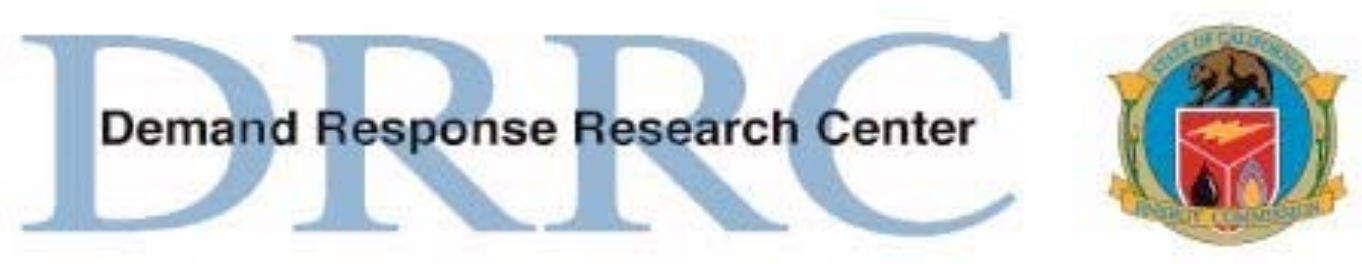

\section{Summer 2006 Demand Shifting with Thermal Mass}

California is embarking on a new era of dynamic pricing with the introduction of Critical Peak Pricing and Demand Bidding. This new tariff was designed to produce incentives to change building operations and manage peak-time energy use on days when the utility grid is constrained. Building owners and facility managers need to evaluate various demand shedding strategies on their sites to reduce peak-period electricity use.

Is your facility ready for using pre-cooling to shed peak demand?

The idea of pre-cooling and demand limiting is to pre-cool buildings at night or in the morning during off-peak hours, storing cooling in the building thermal mass and thereby reducing cooling loads during the peak periods. Savings are achieved by reducing on-peak energy and demand charges. The potential for utilizing building thermal mass for load shifting and peak demand reduction has been demonstrated in a number of simulation, laboratory, and field studies.

To know whether your facility is suitable for passive demand shifting using building thermal mass, the 2006 summer pre-cooling program is a low risk way to get prepared. 


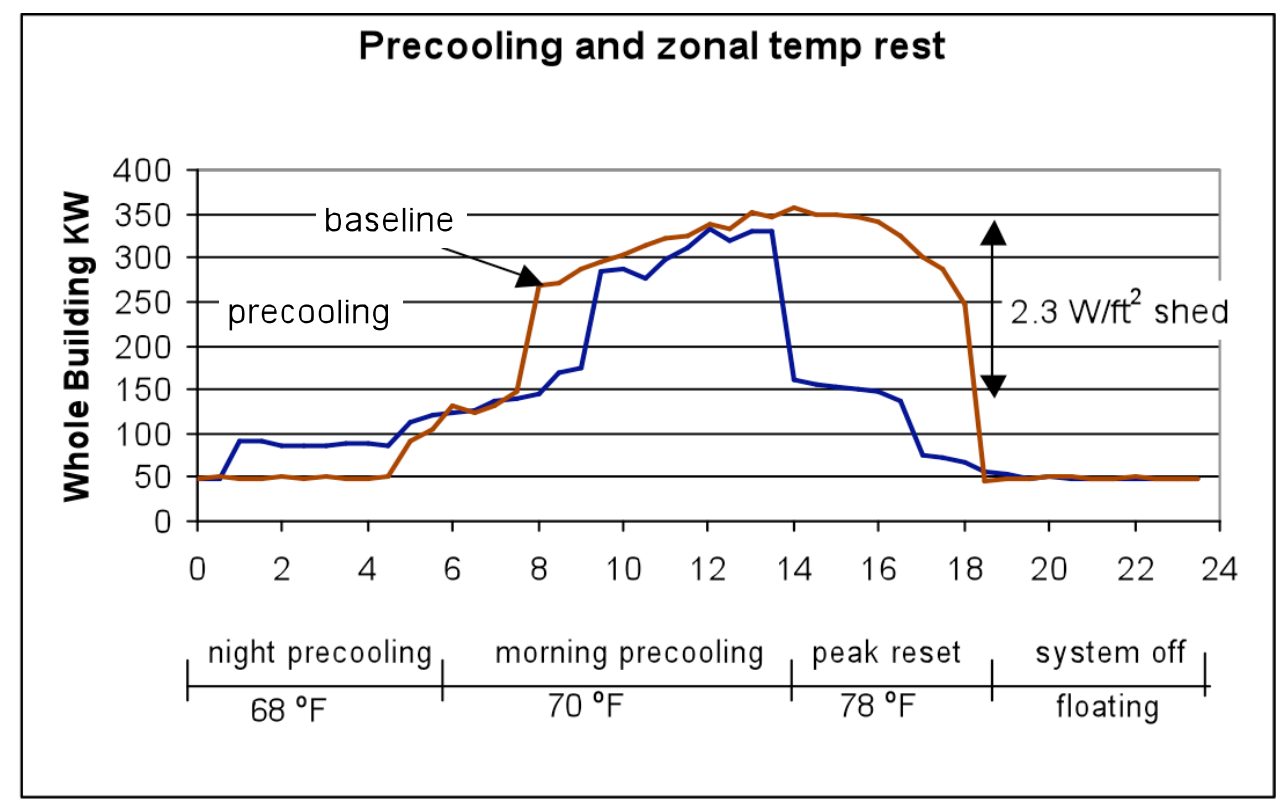

Figure B-1. Sample results of the previous pre-cooling tests

\section{Technical assistance available}

LBNL will conduct two case studies of preliminary assessment of the savings from pre-cooling in two commercial buildings during the summer, 2006. Researchers at the Lawrence Berkeley National Lab (LBNL) will provide guidance to your staff in:

- Develop the pre-cooling and demand limiting strategy and assessing its impacts

- Reset the monitoring plan, install additional sensors and conduct the tests with you.

- Evaluate economic savings under CPP and Demand Bidding programs.

\section{Site requirements}

The buildings to be selected will have of a medium to lightweight mass structure in a southern California. The ideal building to conduct case study should be:

- Located in hot climate zone

- With innovative owners and motivated operators

- With properly functioning HVAC system, ideally commissioned recently.

- With medium to heavy mass structure, buildings with a small window to wall ratios and high accessible building mass be preferable

- With conventional VAV system equipped with central EMCS system

- With direct DDC control of zone temperature

\section{Implementation and Customer requirements}


The case study will be conducted in the following steps

- Collect general building information and determine the feasibility of the pre-cooling.

- Working with building owners, develop pre-cooling, demand limiting strategies and data trending requirements.

- Install sensors and data loggers in the building and collect baseline performance data

- Implement pre-cooling and demand limiting strategy and collect performance data

- Analyze the data and determine economic savings

\section{Schedule}

- $\quad$ Site recruitment and selection before June $1^{\text {st }} 2006$

- System development in June 2005

- Conduct tests through August 2005

To sign-up and/or request more information, please contact

Peng Xu (510) 486-4549 pxu@lbl.gov

This project will be conducted through the PIER Demand Response Research Center (see drrc.lbl.gov) with joint funding from CEC and SCE. 
APA-6 


\section{Appendix B.}

\section{Demand Shedding with Building Thermal Mass for Large Commercial Facilities}


APB-2 


\section{Appendix B. Demand Shedding with Building Thermal Mass for Large Commercial Facilities}
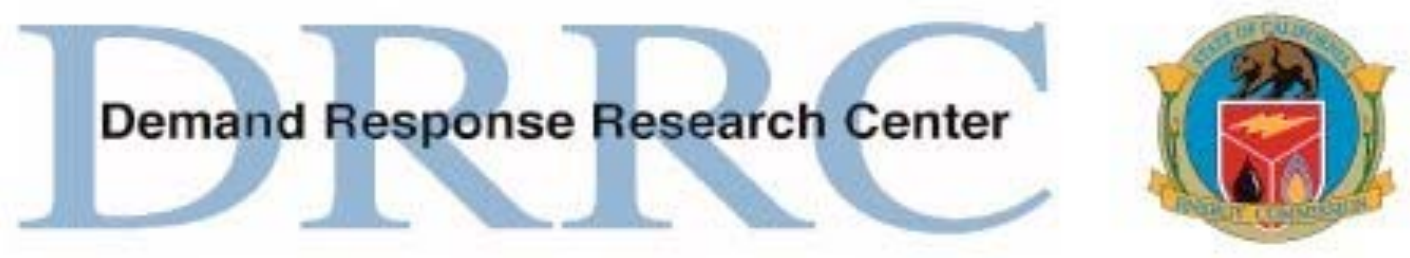

\section{Test Plan}

\section{Background}

California utilities have been exploring the use of critical peak prices (CPP) to help reduce needle peaks in customer end-use loads. CPP is a form of price-responsive demand response. Recent experience has shown that customers have limited knowledge of how to operate their facilities to reduce their electricity costs under CPP. At the same time LBNL has been conducting research to demonstrate how to use building thermal mass for passive electrical demand control. The idea of pre-cooling and demand limiting is to pre-cool buildings at night or in the morning during off-peak hours, storing cooling in the building thermal mass and thereby reducing cooling loads during the peak periods. Savings are achieved by reducing onpeak energy and demand charges. The potential for utilizing building thermal mass for load shifting and peak demand reduction has been demonstrated in a number of simulation, laboratory, and field studies.

\section{Project Goals}

The primary goal associated with the research in the report is to develop information and tools necessary to assess the viability of and, where appropriate, implement demand-response programs involving building thermal mass in buildings throughout California. The project involves evaluating the technology readiness, overall demand reduction potential, and customer acceptance for different classes of buildings. This information can be used along with estimates of the impact of the strategies on energy use to design appropriate incentives for customers.

\section{Objectives}

The objective of this part of the work was to evaluate and demonstrate DR technologies in real buildings. Field-testing of DR control strategies will be performed in two commercial sites in PG\&E territory.

The potential for utilizing building thermal mass for load shifting and peak demand reduction has been demonstrated by LBNL and the Center for the Built Environment (CBE) at the 
University of California, Berkeley in 2003 and 2004. Although the studies were quite successful and the large peak shed was achieved while maintaining the occupant comfort, some key questions remaining unanswered include:

- What will be the comfort reaction if the occupants are informed in advance of the test?

- What will be the comfort reaction when the pre-cooling strategies are performed in truly hot weather?

- What will be the occupant reaction if the pre-cooling persists for a longer period and they have opportunities to adjust to the new thermal environment?

- What are the metrics of the building thermal mass and how are they determined?

- How can thermal mass be discharged more efficiently and more smoothly with no rebound?

- How can a building's pre-cooling potential and determine economic saving quickly? [repeats]

- All our previous tests were conducted manually. On the tests days, the building operators changed the temperature setpoints manually, following our pre-cooling strategies. The automation of the demand-shed has been demonstrated successfully in the previous auto-DR projects. It is worth investigating the possibility of implementing the pre-cooling strategies automatically or semi-automatically, with notice given one day in advance.

\section{Before Tests}

In preparation of tests, the participating sites must work with LBNL on the following tasks:

- Provide General Site Data - LBNL will request general information about your site including: facility size, use, HVAC equipment type, etc.

- Define Electric Data Collection Methods - Most commercial sites have Web access to whole building electric data provided by their utility. If this is the case, please provide a username and password for use by LBNL staff for downloading electric data from your site. Alternately, if your site has local databases that archive data from electric meters, Energy Management Control Systems (EMCS) or Energy Information Systems (EIS) please allow for access by LBNL project staff.

- Define shed strategies using building thermal mass. LBNL will provide guidance based on the previous experience of demand shedding in commercial buildings. Building owners need to choose the pre-cooling temperature and operation schedule.

- Program the EMCS - Each site needs to program the shed strategies into their control system. The strategies can be run either manually with modest efforts or automatically.

- Develop comfort survey plan. LBNL and CBE will provide the web based online survey tool to the owners. Owners need to define a way to communicate with building occupants in a timely fashioned way, such as mail or daily paper notice.

\section{Conduct Tests}

Manual test before CPP days - LBNL will work with each participating site run preliminary tests before CPP days and determine whether the temperature setpoints and pre-cooling 
schedules are appropriate. LBNL will analyze the test results and adjust the pre-cooling parameters accordingly if necessary.

Test in CPP days. LBNL and each participating site will receive a CPP notification one day ahead. LBNL will work with each participant to initiate pre-cooling events. The pre-cooling and demand limiting actions at your site will be based on the strategy created ahead of time jointly. In the mean time, LBNL will send out the comfort survey requests.

Documenting Your Shed - LBNL will collect whole-building electricity consumption data for each site in the pilot. When available, the research team will also collect detailed data from an EMCS or other end-use meters to help us understand the dynamics of the shed strategies.

Documenting Your Comfort and Thermal Condition - LBNL will work with CBE to collect the thermal condition and comfort survey data. The data will be later used to evaluate the changes of the thermal comfort conditions in the buildings before and during the tests.

\section{Project Report}

After the test, LBNL will provide a detailed project report that evaluates the pre-cooling and demand shed strategies; and develop metrics to measure building thermal mass. The report will include the electric consumption data from your facility, a statistical analysis of the shed data (using a weather-corrected baseline), and the comfort survey or related data. These results will be presented publicly in academic and trade publications and conferences.

\section{Project Timeline for Auto-CPP Pilot}

\begin{tabular}{|c|c|}
\hline Activity & Date \\
\hline Site selections & Now - July 30th \\
\hline Plan pre-cooling strategies and preprogram & July - August \\
\hline Conduct preliminary tests & August \\
\hline CPP days & May - October \\
\hline Data Analysis and Reporting & September - December \\
\hline
\end{tabular}

VIII. Staff

LBNL Staff: $\quad$ Peng Xu, pxu@lbl.gov, (510)486 4549

Dave Watson, watson@lbl.gov, (510) 486-5562

Naoya Motegi, namotegi@lbl.gov, (510) 486-4082

Sila Kiliccote, skiliccote@lbl.gov (510) 495-2615

Nance Matson, namatson@lbl.gov, (510) 486-7328

CBE Staff: Leah Zagreus, lzagreus@berkeley.edu, (510) 642-6574

Carrie Brown, carrieb@berkeley.edu, (510) 642-9205

Purdue University: James Braun, jbraun@ecn.purdue.edu, (765)494-9157 
APB-6 


\section{Appendix C.}

Web-based Survey Instrument for Employees

APC-1 
APC-2 


\section{Appendix C. Web-based Survey Instrument for Employees}

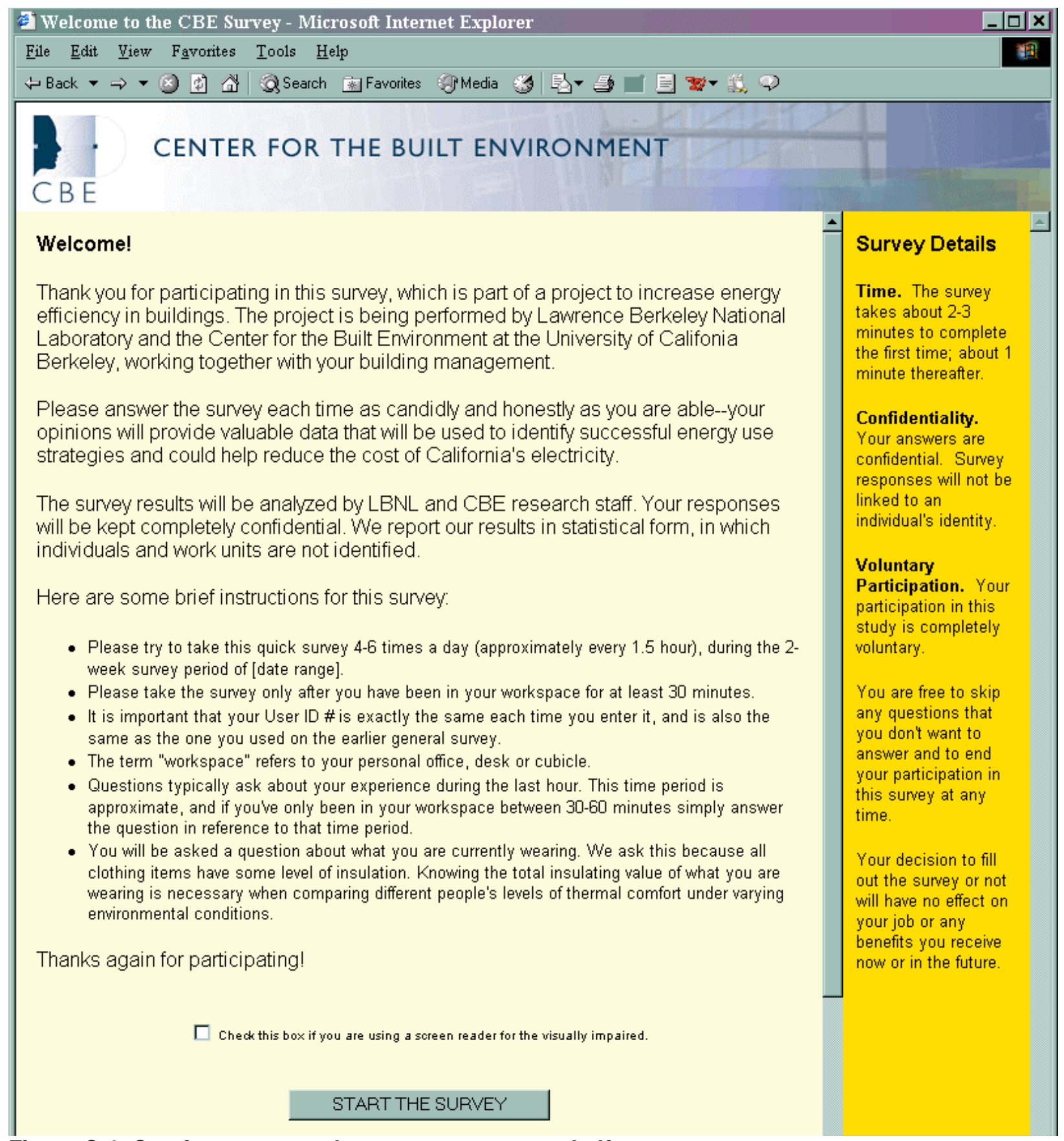

\section{Figure C-1. Comfort survey welcome screen - upper half}




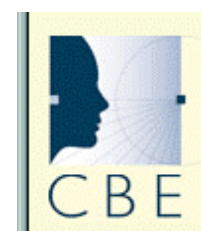

System Requirements. You will need to use a version 4.0 or later edition of Netscape Navigator or Microsoft Internet Explorer. If you have an older version, click to download the current version of Navigator or Internet Explorer.

Questions/Feedback. If you have questions about the study, or for help using the survey or this website, please email the Center for the Built Environment at the University of California, Berkeley. A research specialist will respond to your question promptly.

Your Rights. If you have questions about your rights as a participant in this research project, please email the University of California at Berkeley's Committee for Protection of Human Subjects (CPHS). Please do not contact CPHS regarding technical support issues.

All contents copyright $@ 2000-2006$ The Regents of the University of California. All rights reserved. Terms of Use

\section{E) Done}

Figure C-2. Comfort survey welcome screen - lower half 


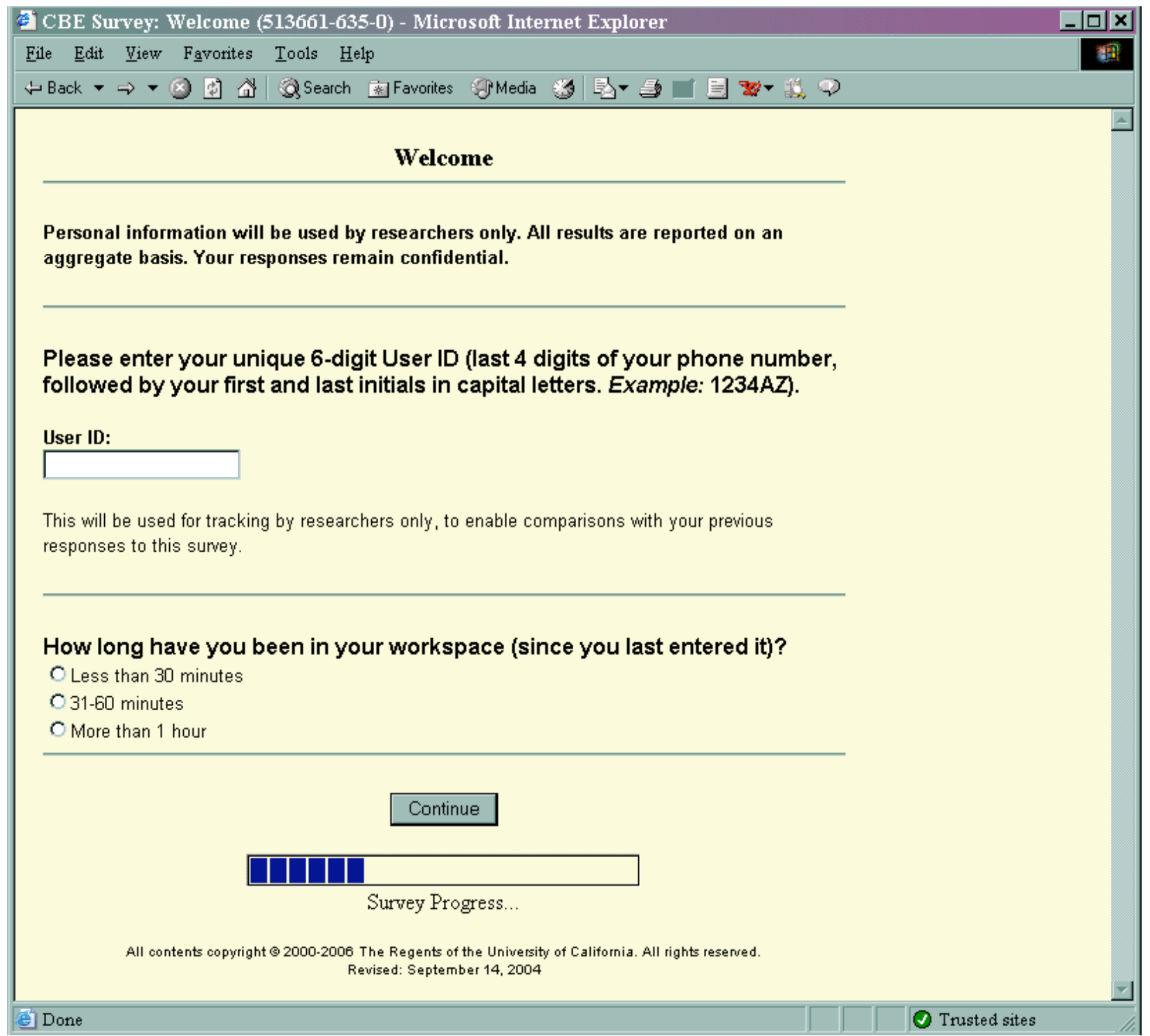

Figure C-3. Comfort survey page 1

Page 1 collects an identifier that allows responses for each individual to be confidentially tracked together, and determines that respondent has been in the space long enough (at least half an hour) to acclimate to the thermal conditions. 


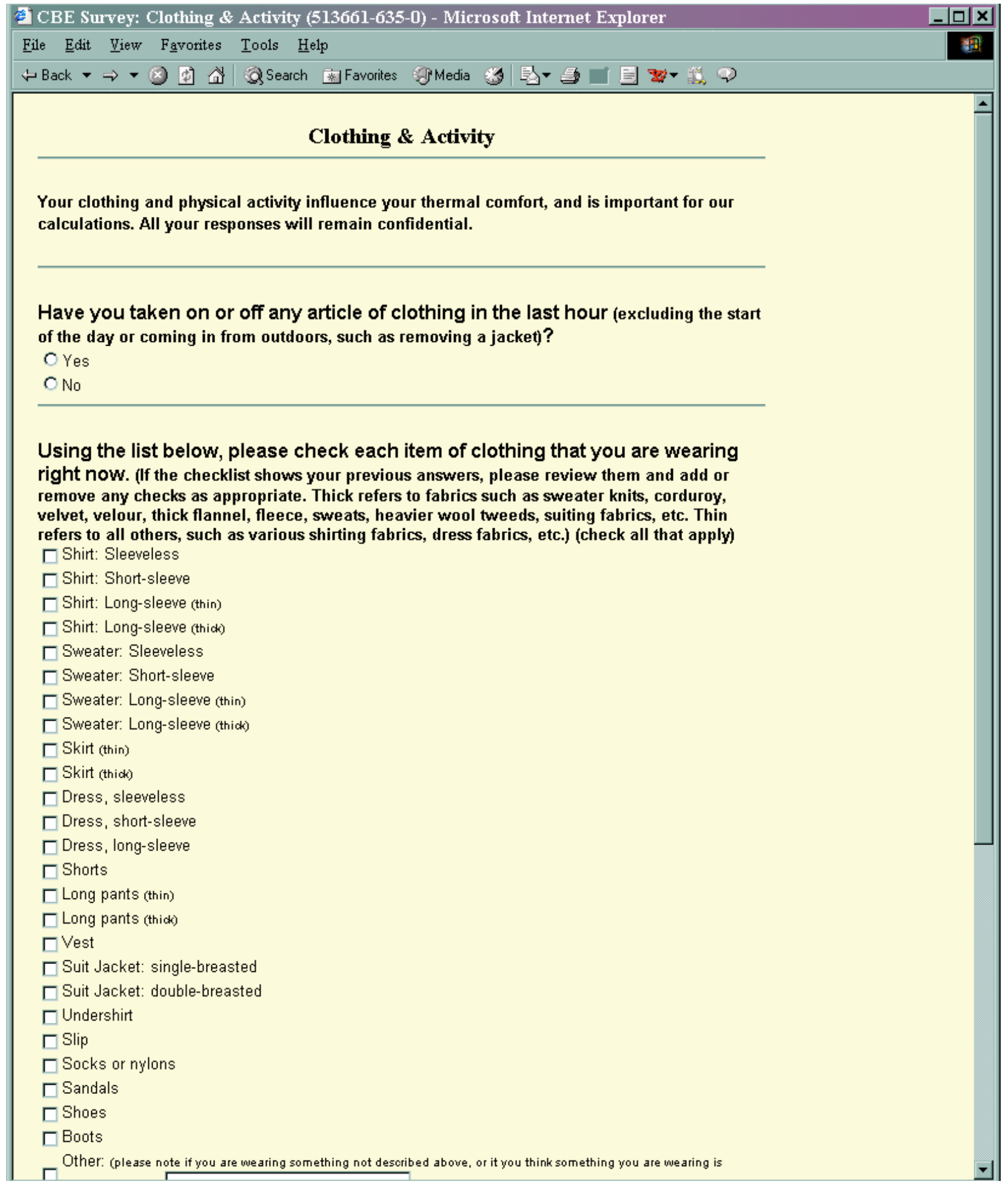

Figure C-4. Comfort survey page 2 - upper half

The upper half of page 2 collects data to calculate the participant's clo (the insulation value of clothes; 1 clo $\sim$ a person wearing a typical business suit). 


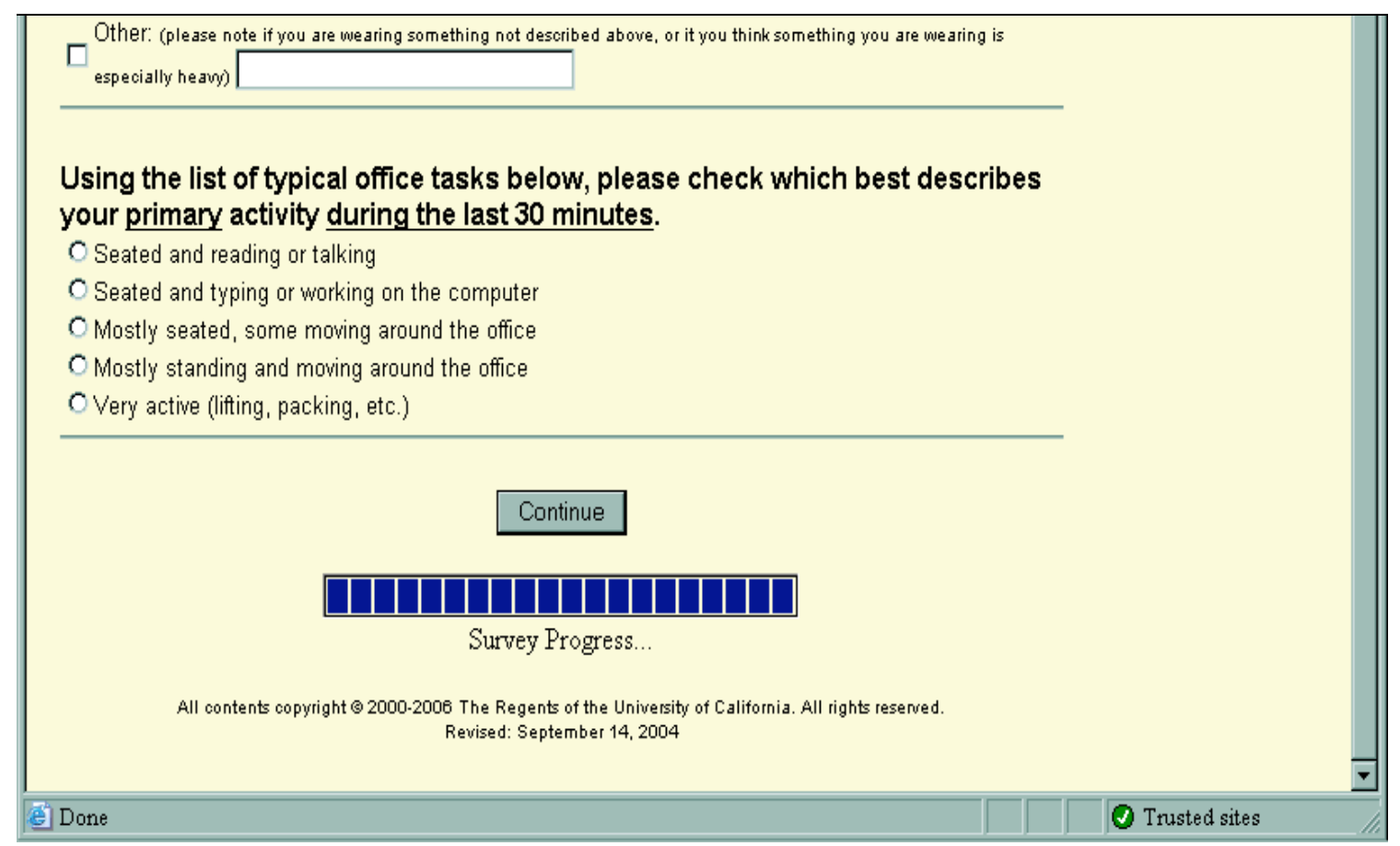

Figure C-5. Comfort survey page 2 - lower half

The lower half of page 2 collects data to calculate the participant's metabolic rate. 


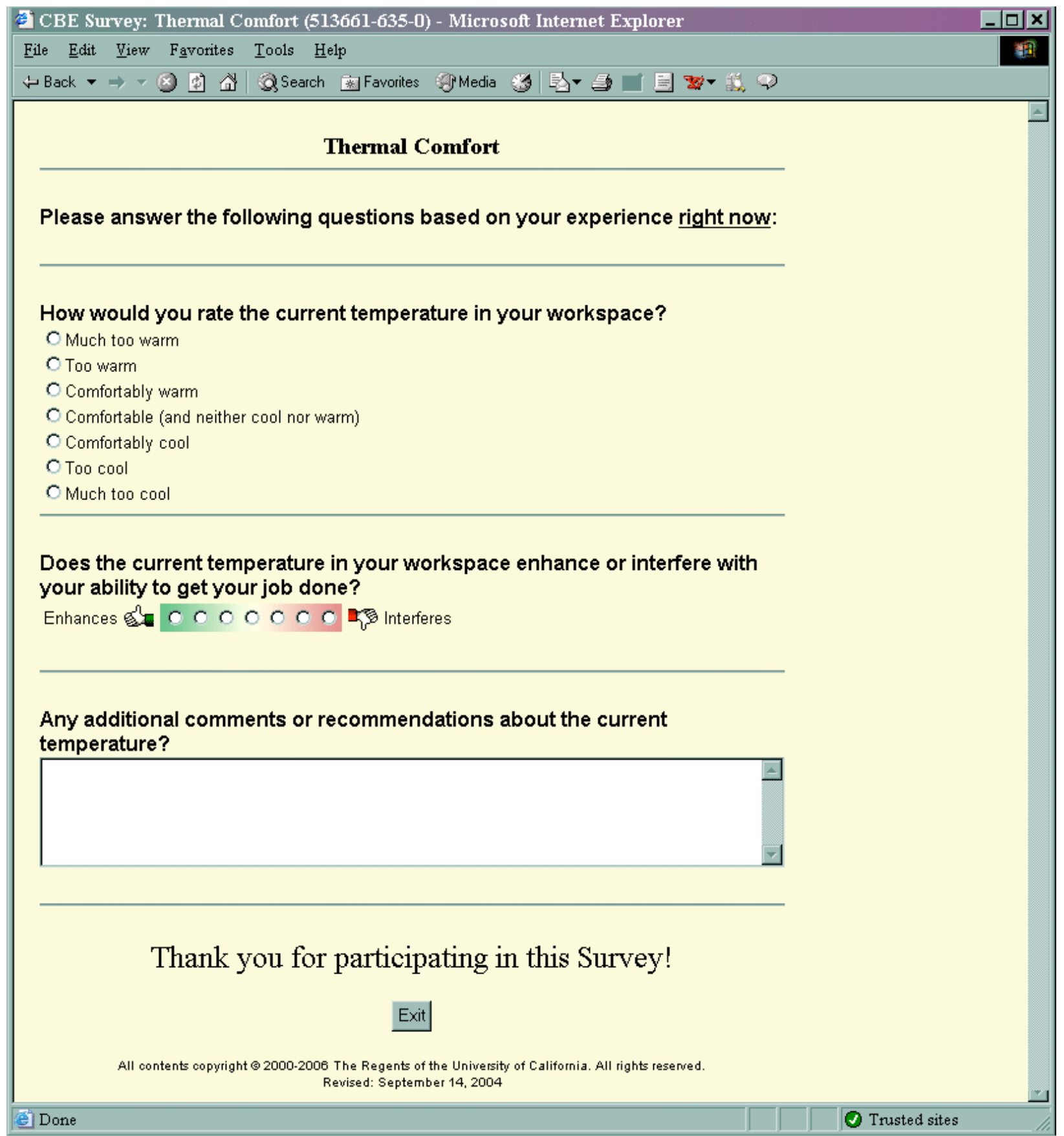

\section{Figure C-6. Comfort survey page 3}

Page 3 includes the Bedford scale to collect the participant's comfort/sensation vote, selfreported productivity affected by temperature, and an open-ended comment field. 


\section{Appendix D.}

\section{Employee Web-Based Survey Invitations}

APD-1 
APD-2 


\section{Appendix D. Employee Web-based Survey Invitations}

Introduction e-mail:

Dear Cigna employees:

Lawrence Berkeley National Lab and UC Berkeley are conducting a study of energy-efficient strategies in this building. Your facility managers are working with PG\&E to use energy more efficiently on certain days when energy is more expensive. These days are called "Critical Peak Pricing" days, and are akin to "Spare the Air" days.

As we employ strategies to reduce energy use during the afternoons on CPP days, we are concerned with the effect on your comfort. We will use an online survey to collect your impressions of temperature sensation and comfort, and its impact on productivity.

Since you will not have access to this survey at your desk, we have designated four computers for voting located in cubicles 1162, 2072, 2400, and next to cubicle 2684 . When taking the survey, please base your answers on your recent experience at your cubicle (not where you are taking the survey).

This survey will take 1-2 minutes to complete and your responses will be kept completely confidential. We will ask that you take the survey at least twice a day on CPP days, and also a few days when the building systems run as usual. Your participation is very important to our understanding of the effectiveness of these strategies.

As an incentive, when you enter your cubicle number, you will be placed in a drawing to win 1 of 3 iPods!

In addition, researchers from LBNL and UCB have placed small, unobtrusive temperature sensors at various places throughout the building. The purpose is to monitor the thermal conditions in close proximity to the survey takers.

We appreciate your cooperation during the next few weeks as your facility takes part in this study. The results could help California conserve substantial amounts of energy.

If you have questions or concerns about the study, please contact your facility management, or me at the contact information below. Thank you in advance for your participation.

Carrie Brown

Graduate Student Researcher

Center for the Built Environment

University of California, Berkeley

www.cbesurvey.org

carrieb@berkeley.edu 
Day before tests day e-mail:

Dear Cigna employees:

Many thanks for your continued participation in the LBNL and UCB study of thermal conditions in your building. The next two days (Thursday and Friday) will be "mock" Critical Peak Pricing days. On a real CPP day, energy would be more expensive during the afternoon, and we would be encouraged to reduce energy use towards the end of the day. (Similarly, we would be encouraged to take public transit on a "Spare the Air" day.) To do this, we will cool the building a bit more than usual during the morning, and then allow the temperature to rise slightly higher than usual during the afternoon.

We believe that this will not significantly impact your comfort, and wish to verify this with your feedback. Please take our brief online survey at least twice each day.

Since you do not have access to this survey at your desk, we have designated four computers for voting located in cubicles 1162, 2072, 2400, and next to cubicle 2684. When taking the survey, please base your answers on your recent experience at your cubicle (not where you are taking the survey).

We ask that you take the survey approximately one hour after you arrive at the office at the beginning of your workday, and again at about 4 p.m. (or earlier, if you leave the office for the day before 4). We encourage you also to take the survey at other times throughout the day, as often as once per hour.

You are, as always, welcome to take the survey on other days too (the more data the better for us), but please especially take care to do so this Thursday and Friday.

As an incentive, when you enter your cubicle number, you will be placed in a drawing to win 1 of 3 iPods!

Feel free to contact me with any questions or concerns about the study.

Thank you!

Carrie Brown

Graduate Student Researcher

Center for the Built Environment

University of California, Berkeley

www.cbesurvey.org

carrieb@berkeley.edu 